\title{
Thermal Spray High-Entropy Alloy Coatings: A Review
}

\author{
Ashok Meghwal $^{1}$ - Ameey Anupam ${ }^{1,2}$ • B. S. Murty ${ }^{2,3} \cdot$ Christopher C. Berndt $^{1}$. \\ Ravi Sankar Kottada ${ }^{2}$. Andrew Siao Ming Ang1 ${ }^{1}$
}

Submitted: 20 February 2020/in revised form: 20 April 2020/Published online: 25 May 2020

(C) The Author(s) 2020

\begin{abstract}
High-entropy alloys (HEAs) are a new generation of materials that exhibit unique characteristics and properties, and are demonstrating potential in the form of thermal spray coatings for demanding environments. The use of HEAs as feedstock for coating processes has advanced due to reports of their exceptional properties in both bulk and coating forms. Emerging reports of thermal sprayed HEA coatings outperforming conventional materials have accelerated further exploration of this field. This early-stage review discusses the outcomes of combining thermal spray and HEAs. Various synthesis routes adopted for HEA feedstock preparation and their properties are discussed, with reference to the requirements of thermal spray processing. The HEA feedstock is then compared and correlated with coating microstructure and phase composition as a function of the thermal spray processing route. Subsequently, the mechanical behavior of thermal spray HEA coatings is summarized in terms of porosity, hardness, and tribological properties, along with their oxidation
\end{abstract}

Ashok Meghwal and Ameey Anupam share the first authorship of this paper.

\footnotetext{
Andrew Siao Ming Ang

aang@swin.edu.au
}

1 Department of Mechanical Engineering and Product Design Engineering, Faculty of Science, Engineering and Technology, "Surface Engineering for Advanced Materials" - SEAM, Swinburne University of Technology, H38, P.O. Box 218, Hawthorn, VIC 3122, Australia

2 Department of Metallurgical and Materials Engineering, Indian Institute of Technology Madras, Chennai 600036, India

3 Indian Institute of Technology Hyderabad, Hyderabad, Telangana 502285, India and electrochemical properties, followed by their potential applications. The thermal spray methods are contrasted against laser cladding and surface alloying techniques for synthesizing thick HEA coatings. Furthermore, HEAs that have displayed excellent properties via alternative processing routes, but have not been explored within the framework of thermal spray, are recommended.

Keywords coatings · high-entropy alloys (HEAs) . mechanical properties $\cdot$ microstructure $\cdot$ review $\cdot$ thermal spray

\section{Introduction}

The performance of a material in industrial applications is associated with its surface characteristics. The wide availability of surface modification technologies permits an economic substitution of a poor base material with a coating that exhibits more desirable surface characteristics and performance. Surface modification is highly valuable in conditions involving corrosive environments, wear protection, thermal insulation, or severe stress applications. For instance, in thermal barrier coatings (TBCs), yttriastabilized zirconia (YSZ) is used as an overlay protective coating to shield the nickel or cobalt based superalloys from extreme high temperature conditions. Thermal spray coating (TSC) is a versatile and rapidly growing surface modification technology.

Thermal spraying is a line-of-sight process, wherein feedstock material, in the form of powder, wire, rod, or suspension, is fed into a spray torch and heated up to a molten or near-molten state and propelled toward a base material (Ref 1-3). Thermal spray (TS) processes are classified into three prime categories: (1) use of 
combustion heat sources, for example detonation gun or high-velocity oxygen fuel spray (HVOF); (2) plasma or arc formation using electrical energy, for example atmospheric plasma spray (APS); and (3) low-temperature processes that use energy evolving from gas expansion, for example cold spray (CS). Figure 1 (Ref 4) illustrates the flexibility offered by TS in terms of the wide spectrum of flame temperature-particle velocities available. Plasma spray (atmospheric and vacuum), high-velocity arc spray, HVOF, warm spray, and cold spray have been employed to synthesize thermal sprayed HEA coatings.

Atmospheric plasma spray (APS) is the most versatile thermal spray technique that holds few limitations concerning the materials that can be sprayed. Therefore, APS is well established at the industrial level (Ref 5). A feedstock (powder or wire) is introduced into the plasma stream where complete or partial melting may occur, eventually depositing as lamellar splats onto the substrate. Numerous process parameters, of which the prime ones are gas flow rate, power input, carrier gas flow rate, stand-off distance, and powder feed-rate, are crucial in determining the coating density, quality, and uniformity. APS is economically attractive since this manufacturing process is performed under ambient conditions, with the primary drawback being in-flight oxidation (IFO) of feedstock particles. APS is best suited for forming ceramic coatings with porosity of less than several percent but can be optimized to reduce oxidation of metal powders. The alternative is to spray with an inert gas shroud, or in a soft vacuum/reducing atmosphere, but the cost of employing a vacuum system, e.g., by low-pressure vacuum spraying, increases by an order of magnitude.

HVOF falls under the ambit of combustion spray processes. A hydrocarbon fuel $\left(\mathrm{C}_{x} \mathrm{H}_{y}\right.$; typically, kerosene, methane, propane, propylene, acetylene or natural gas) is ignited with an oxidizer (air or oxygen). The temperature and pressure so generated then heat and accelerate feedstock particles towards the substrate. Laval nozzles are used to further accelerate the particles up to speeds of $2000 \mathrm{~m} / \mathrm{s}$. Although particle temperatures are lower than those achieved in plasma spray (Fig. 1), higher particle speeds result in lower IFO and better coating densities, with porosity that may be less than 1 percent.

Cold spray (also termed as 'kinetic spray') accelerates feedstock particles by means of a high-pressure gas that passes through a de Laval nozzle (Ref 6, 7). One advantage of CS is that the feedstock is not heated significantly, thus avoiding melting and any temperature-dependent phase transformations or IFO.

Figure 1 (Ref 4) illustrates the spread of particle size, temperature, and velocity offered by TS processes. Using this scheme, an appropriate processing window can be identified based on the nature of the feedstock material (metallic/ceramic) and the desired coating microstructure, such as density and phase content. For example, for ceramic coatings with a predetermined porosity requirement, such as hydroxyapatite coatings for orthopedic applications, APS would be preferred. However, for depositing dense metal coatings, such as coating aluminum alloys on
Fig. 1 Spectrum of thermal spray processes across particle velocity and flame temperatures attainable (Ref 4$)$

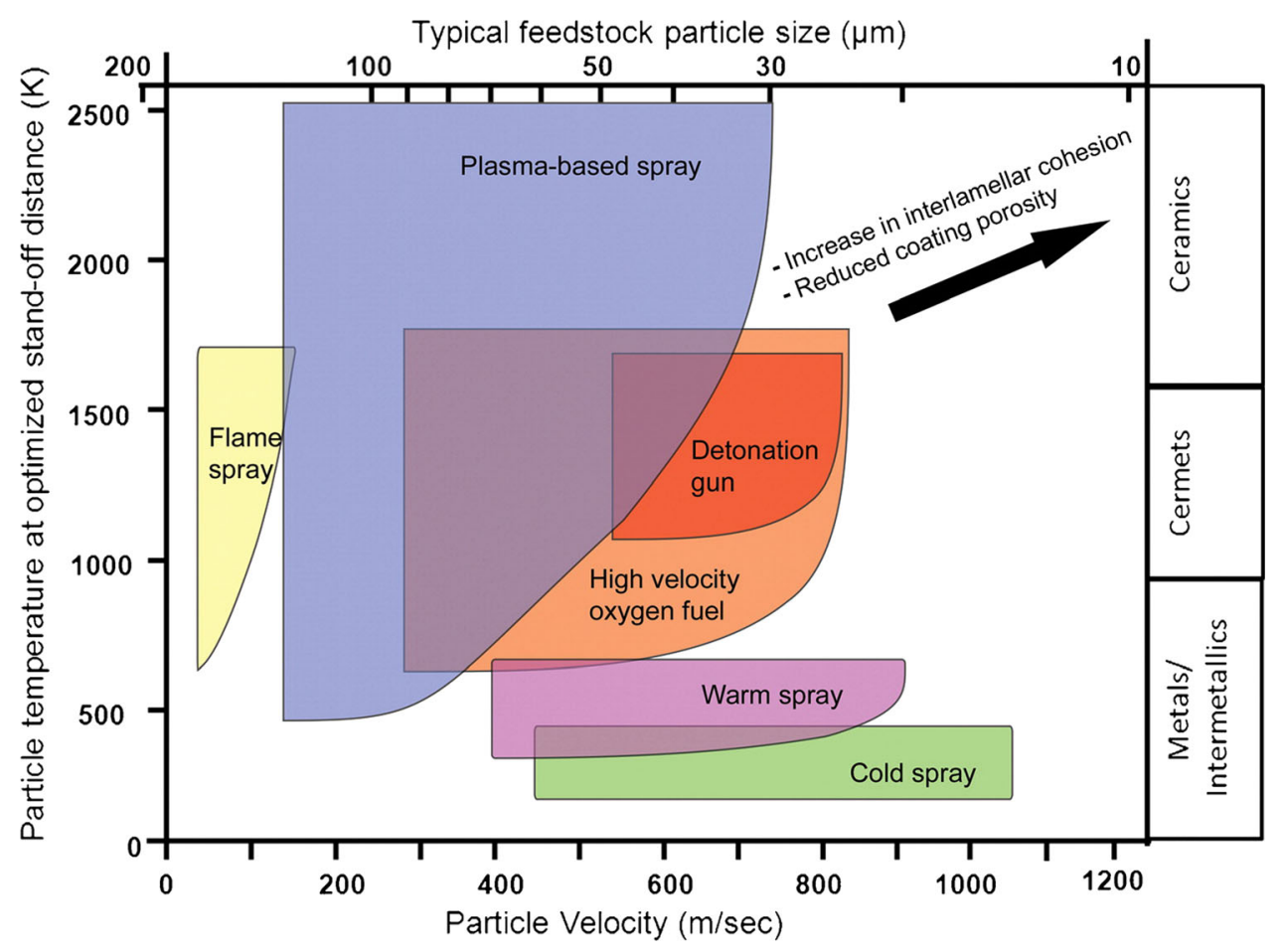


magnesium parts for corrosion protection, cold spray would be the preferred method.

TS technology has seen developments in feedstock materials across metal alloys, composites, intermetallics, ceramics, and cermets, the exact choice depending on the final application. High-quality feedstock, with respect to particle size distribution (referred to as the 'cut') and particle morphology, is vital to produce high-quality coatings (Ref 4, 8). The simultaneous surge in harsh industrial conditions and incremental development in conventional materials has pushed materials research toward the development of new alloys, for instance high-entropy alloys (HEAs). The adoption of these new HEA feedstocks will potentially allow novel surface engineering solutions that are tailored for demanding industrial environments.

HEAs are defined as solid solution alloys of five or more elements in equi- or near-equi-atomic ratios (Ref 9-11). Indeed, research on HEAs has demonstrated that they have outperformed conventional materials, not only at room and high temperature, but also at cryogenic temperatures (Ref $12,13)$

A current major focus of HEA research has been directed to decoding the science governing the fundamental nature of these multicomponent alloys. The stabilization of solid solution phases at elevated temperatures arises due to a combination of mixing enthalpy, higher configurational entropy, and similar atomic characteristics (atomic radius, valency, crystal structure) (Ref 14) that favors the formation of solid solutions such as FCC or BCC over intermetallic compounds (Ref 15, 16). The combined interactions among all the integral elements, termed as 'cocktail effects' (Ref 17), promote these distinctive attributes of HEAs. This is reflected in the development of bulk HEAs with wear resistance (Ref 18, 19), oxidation (Ref 20, 21) and corrosion resistance (Ref 22), and mechanical properties (Ref 23-26) that have outperformed traditional materials. These technical advantages are now being translated to coatings via thermal spray, laser cladding, and sputtering processes.

Laser cladding, also termed as laser surface alloying, involves preparing a powder bed of feedstock slurry (generally, blended unalloyed elemental powders) onto the substrate and scanning it with a focused laser beam. In another variant of the process, termed 'direct laser deposition', feedstock powder is propelled coaxially with the laser beam, instead of preplacement as slurry. In both processes, melting of the substrate surface along with the feedstock slurry occurs, followed by rapid solidification and generation of a coating. While laser clad/surface-alloyed coatings are usually defect free and exhibit good metallurgical bonding with the substrate, the drawbacks include a heat-affected zone, extreme residual stresses, and possible deterioration of the HEA coating and substrate properties due to elemental dilution (Ref 27). When prealloyed HEA powders are used as feedstock for laser cladding, the coating often consists of multiple alloy and intermetallic phases that may require further processing before the desired properties are achieved (Ref 28).

Another prevalent technique for generating HEA coatings is via sputtering or vapor phase deposition in which the HEA is atomically deposited layer-by-layer (Ref 29 ). These processes result in thin films, and are increasingly being used to generate HEA carbide/nitride/boride films that exhibit excellent tribological properties (Ref 30). Reviews discuss these coating categories (Ref 31); however, a comprehensive review of HEA coatings manufactured by thermal spray methods is not available.

Thermal sprayed HEA coatings offer potential applications where novel HEA compositions can be explored. TS technology is well established at the manufacturing scale, for example, in generating reproducible and prime-reliant coatings for aerospace and power generation industries. In addition, several HEA compositions have been demonstrated to be competitive alternatives to conventional materials where there is a strong need for new protective coatings to address extreme engineering environments.

Figure 2 shows the number of research articles published on HEA thermal spray coatings in peer-reviewed journals where the rise in total citations per year is also illustrated. The first report on thermal sprayed HEAs arose in year 2004, when Huang et al. atmospheric-plasmasprayed $\mathrm{AlSiTiCrFeCoNiMo}_{0.5}$ and $\mathrm{AlSiTiCrFeNiMo}{ }_{0.5}$, and analyzed the oxidation and wear resistance of these coatings (Ref 32). A rapid rise in the development of TS HEA coatings can be observed after 2016, with 'The microstructure and strengthening mechanism of thermal spray coating $\mathrm{Ni}_{x} \mathrm{Co}_{0.6} \mathrm{Fe}_{0.2} \mathrm{Cr}_{y} \mathrm{Si}_{z} \mathrm{AlTi}_{0.2}$ high-entropy alloys' by Wang et al. (Ref 33) and 'Plasma-Sprayed High Entropy Alloys: Microstructure and Properties of $\mathrm{AlCoCrFeNi}$ and $\mathrm{MnCoCrFeNi}$ ' by Ang et al. (Ref 34), being the two most cited articles.

This current paper reviews the literature that is specific to thermal sprayed HEA coatings. "Elemental Selection Statistics for High-Entropy Alloys" section elucidates the concepts and statistics employed for designing HEAs toward desired applications. "HEA Feedstock: Synthesis and Properties" section focuses on the various methods of generating HEA feedstock for thermal spray, and examines the effect of synthesis techniques on the coating properties, followed by "Microstructural and Phase Composition Aspects" section, wherein the microstructural and phase analyses of TS processes in conjunction with the feedstock are discussed. A major part of TS HEA research is focused on wear and oxidation resistance of coatings. Thus, "Properties of TS HEA Coatings" section concentrates on those properties of HEA coatings as well as on their 
Fig. 2 Number of reported publications on thermal sprayed high-entropy alloy coatings and rise in number of citations per year (until March 2020)

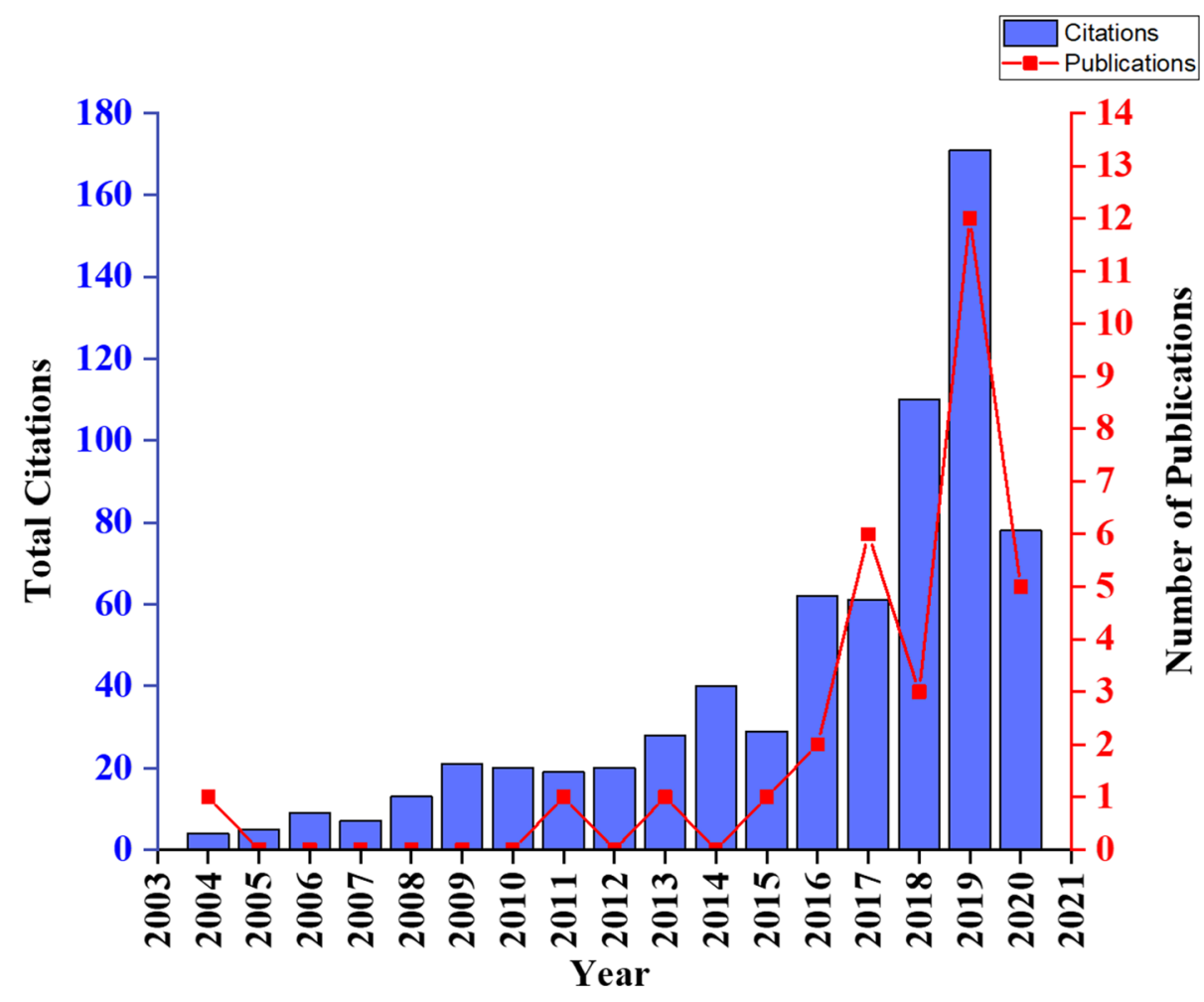

electrochemical performance. "Applications" section addresses the targeted applications as well as suggestions for other potential HEAs not yet processed via thermal spray. "Future Trends: An Optimistic Future for HEAs" section summarizes the state of the art of knowledge on TS HEA coatings and makes recommendations concerning the future scope for this growing technology.

\section{Elemental Selection Statistics of High-Entropy Alloys}

High-entropy alloys tend to demonstrate complex and unique characteristics due to interactions of multiple elements and their diverse processing routes. The additional exposure to high temperature and then rapid solidification during thermal spray generates HEA characteristics that are challenging to understand. The screening of a specific HEA TS feedstock that will engender desirable properties that target a particular application for thermal spray process is a demanding undertaking. Figure 3 analyzes 30 peer-reviewed articles and depicts the relative occurrence of elements that have been employed in HEA feedstocks for TS processing. The majority of HEAs have a base comprising $\mathrm{CrFeCoNi},{ }^{1}$ with the primary addition of $\mathrm{Al}, \mathrm{Si}$, and $\mathrm{Ti}$.

\footnotetext{
${ }^{1}$ To avoid confusion between compositions, the naming convention proposed by Pickering and Jones will be adopted (Ref 35 ); that is, '... major elements have been mentioned in increasing order of their
}

The inclusion of $\mathrm{Mn}, \mathrm{Cu}, \mathrm{Nb}$, and $\mathrm{Mo}$ has also been explored. The selection of these alloys for HEA feedstocks has been influenced by their performance in other processing routes such as casting and other deposition techniques.

The final microstructure and, hence, properties of the coatings not only depend on the thermal spray process but also on the synthesis routes and composition of the HEAs. It is notable that identical alloy chemistries, prepared via different feedstock synthesis techniques and thermal spray process parameters, resulted in different coating characteristics. This need not necessarily be a disadvantage, since knowledge concerning the physical metallurgical behavior guides the selection of the HEA elements for an intended application; for example, $\mathrm{Al}, \mathrm{Cr}, \mathrm{Ti}, \mathrm{Si}$ for oxidation resistance; $\mathrm{Cr}$ for corrosion resistance; $\mathrm{B} 2$-forming $\mathrm{Al}-\mathrm{Ni} /$ $\mathrm{Co} / \mathrm{Fe}$, for wear resistance; and $\mathrm{Co} / \mathrm{Ni}$-based $\mathrm{FCCs}$ for enhanced plasticity are appropriate alloy constituents for HEAs. Multiple compositions can simultaneously be explored for their phase composition and expected properties using high-throughput experiments and computational techniques as demonstrated by Senkov et al. (Ref 36). The diversity of TS processes provides a tool to manipulate the characteristics of HEAs as coatings and tune them for specific applications.

Footnote 1 continued atomic numbers, and the trace alloying elements have been placed at the end in brackets; e.g., $\mathrm{AlCrFeCoNi}(\mathrm{B}, \mathrm{C})$.' 
Fig. 3 Elements selection occurrence in high-entropy alloys used as a feedstock for different thermal spray processes

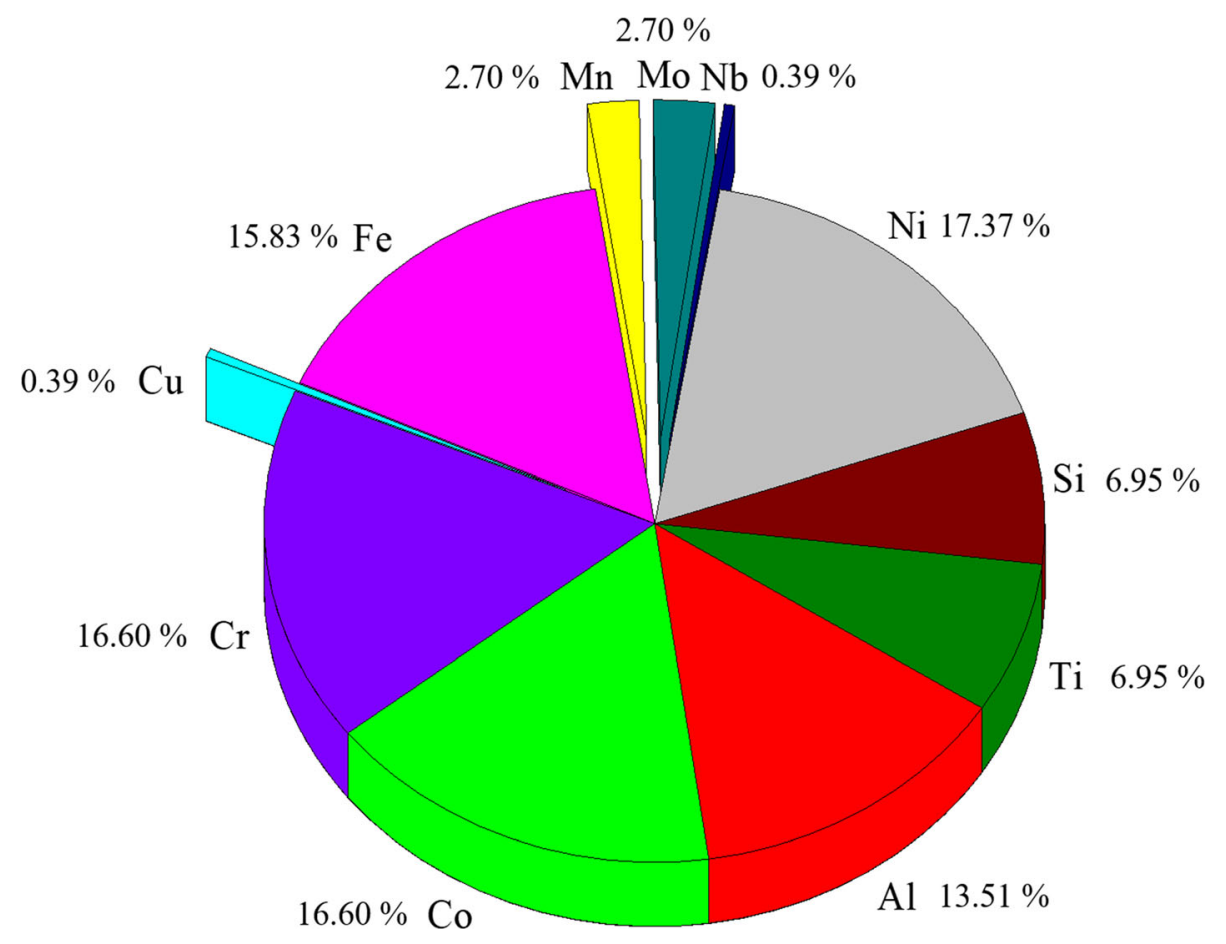

\section{HEA Feedstock: Synthesis and Properties}

Four synthesis routes have been reported to construct HEA feedstocks for TS: (1) blending, (2) arc melting followed by mechanical milling, (3) mechanical alloying, and (4) gas atomization. Each technique imparts unique implications on the powder phase and characteristics and, therefore, on the coating microstructure and properties. The following discussion will focus on the particle size and morphology; extent of alloying and homogeneity; powder yield; and flowability, since these factors influence the TS processing.

Figure 4 outlines the particle size distributions with respect to the synthesis techniques as reported in the TSHEA literature. It is evident that each process has a characteristic output size range, which further depends on the synthesis process parameters. Gas atomization provides the widest cut, that can then be tailored to the thermal spray process by sieving. On the other hand, mechanical alloying results in a much finer cut that exhibits nanocrystallinity.

\section{Blending}

Blending involves mixing the powders without promoting any bonding or alloying. The particle size and shape of the blended mix will retain elemental qualities, leading to individual interactions under APS processing and an inhomogeneous coating microstructure.

Figure 5 (reproduced from Fig. 4a of Lobel et al. (Ref 37)) shows an APS coating cross section with blended elemental powders as feedstock. It reveals imaging contrasts that arise from atomic number differences from the individual elements that are either in elemental or in oxidized states. In another case, AlTiCrFeCoNi HEA powder was first mechanically alloyed and then blended with larger, spherical Ni60 (0.63 C, 2.97 B, 4.50 Si, 5.31 $\mathrm{Fe}, 16.20 \mathrm{Cr}$, Bal. Ni; all in wt.\%) powders (Ref 38) in a 7:3 HEA/Ni60 ratio. The HEA phase was in effect reinforced with the Ni60 alloy in the coating, thereby improving its wear resistance.

Blending is thus an effective method for mixing prealloyed powders to improve their individual properties, but is not a recommended route for the synthesis of primary HEA feedstock.

\section{Arc Melting Followed by Mechanical Milling (AM- MM)}

This method first fuses the desired alloy by arc melting. Then, the alloy button is crushed into smaller pieces, which is followed by ball milling into powder. The need for alloying at an elemental level is achieved by processing in the liquid state, while the requirement for the appropriate particle cut is accomplished by pulverization. Complex non-equiatomic compositions can be created by arc melting without incurring significant contamination from ball milling by this route.

Out of the four reports that employ this method, three reported ball milling to less than $44 \mu \mathrm{m}$ particle size, while one is $<34 \mu \mathrm{m}$, as illustrated in Fig. 4. Information regarding milling parameters adopted, such as rotation 
Fig. 4 Particle size ranges of high-entropy alloys obtained from various powder synthesis techniques

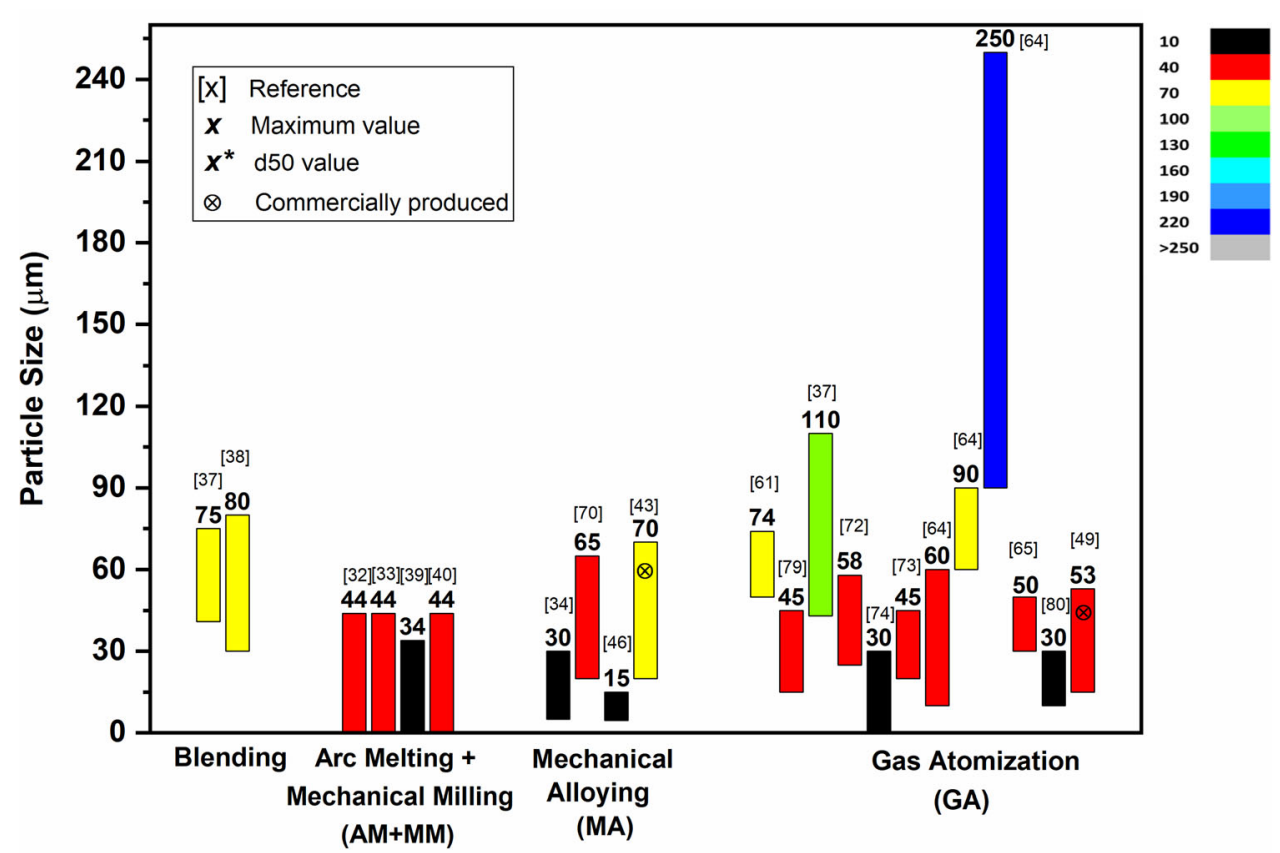

Synthesis Route

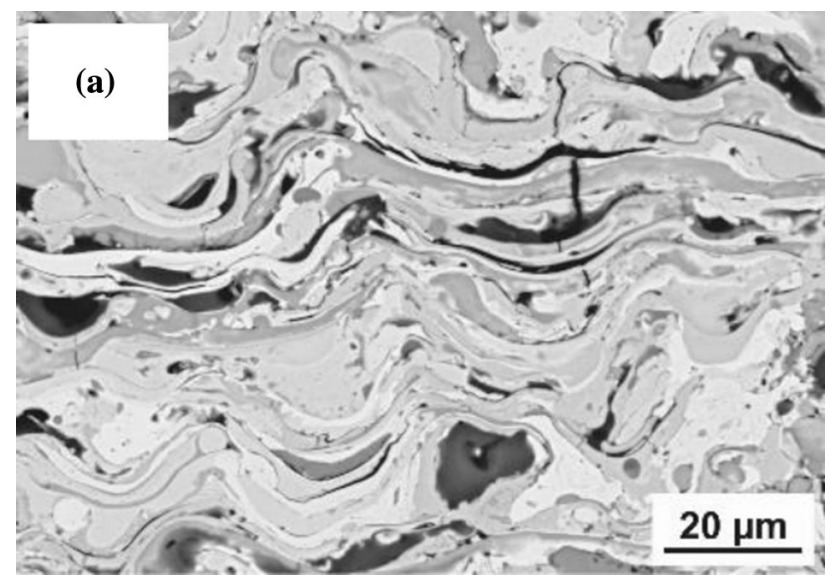

Fig. 5 Atmospheric plasma spray coating generated using blended elemental powders as feedstock, resulting in a heterogeneous microstructure from local interactions during spraying (Ref 37)

speed, duration, milling media, quantity of powder charged, and other essential experimental data, is not available. However, from the authors' experience, it is estimated that up to $90 \%$ of the powder weight charged would be recovered in this process, thereby making it a high yield process. The particle shape is irregular since the particles are fragmented pieces of the cast button. Hence, the powder flowability is likely to be influenced adversely; but the spray parameters can be adjusted to take this into account. The coating microstructure that evolves from these powders is relatively homogeneous in terms of the phases observed since alloy formation has already occurred during the casting procedure.
Huang et al. (Ref 32) were the first to generate thermal sprayed HEA coatings, and AM-MM was their method of choice. These coatings, as well as those documented by Hsu et al. (Ref 39, 40), exhibited excellent oxidation resistance, which depends largely on both, the alloy composition, and the microstructural homogeneity of the feedstock.

\section{Mechanical Alloying (MA)}

Mechanical alloying (MA) is a well-established synthesis technique in HEA literature. Elemental powders are subjected to high-speed rotation and high-energy impacts, causing them to undergo repeated cold welding and fracturing, resulting in 'mixing' at an atomic scale (Ref 41). Over 200 reports, reviewed by Vaidya et al. (Ref 42), indicate that while this route assures alloy formation, the alloy phase formation is subject to multiple process parameters, e.g., the milling medium, milling atmosphere, process control agent (PCA), milling duration, and rotation speed. Each of these prime factors influences the extent of alloying, implying that there is no single distinct recipe for synthesizing an HEA via MA, unlike arc melting.

Another drawback concerns the particle size and morphology. The 'wet' MA route, which uses organic solvents such as toluene as PCAs, results in finer particles of irregular shape, $<30 \mu \mathrm{m}$ after $10 \mathrm{~h}$ of milling (Ref 34). In contrast, the 'dry' MA route, usually performed under argon atmosphere and at much higher rotation speeds, results in larger particles $(20-75 \mu \mathrm{m})(\operatorname{Ref} 43)$ with a wide 
particle size distribution and exhibiting a flake-like nature (Ref 37), as illustrated in Fig. 6.

Dry milling of metals and alloys leads to excessive cold welding and, hence, derives larger particles that are flaky in nature. In contrast, wet milling results in finer, sphericallike particles due to the presence of the liquid surrounding the particles, which prevents excessive agglomeration of particles. However, contamination in wet milling is a concern, and dry milling is preferred when it is necessary to avoid contamination from the milling medium. Higher milling speeds allow for higher impact energy input into the material. It must be noted, however, that ball milling and mechanical alloying is a highly stochastic process with multiple controlling parameters (Ref 41).

The powder characteristics influence powder flowability during its injection in TS, which generally prefers atomized prealloyed powder feedstock (Ref 44). There is also the issue of contamination from organic solvents and/or from the milling medium (e.g., stainless steel, tungsten carbide, zirconia) that may affect feedstock composition. As reported by Praveen et al. (Ref 45), the use of toluene as process control agent in $\mathrm{MA}$ of $\mathrm{AlCrFeCo}$ resulted in the formation of $\mathrm{M}_{23} \mathrm{C}_{6}$-type carbides on subsequent processing. While it was an unsolicited addition of carbon to the alloy, it improved the sintered alloy's thermal stability and mechanical properties, thereby illustrating both the advantages and deficiencies of this method.

Finally, mechanically alloyed particles are nanocrystalline in nature with a grain size $<15 \mathrm{~nm}$, which can be leveraged depending on the thermal spray process and intended application. For example, Anupam et al. (Ref 46) cold-sprayed MA HEA powders on Ni-based superalloy substrate and, after $25 \mathrm{~h}$ of isothermal oxidation, observed the diffusion of molybdenum from the substrate into the coating, which may be attributed partly to nanocrystalline grain boundary diffusion. On the other hand, TSCs generated for MA feedstock are largely homogeneous, with a possibility of greater IFO promoted by the powder nanocrystallinity, especially if the process is associated with a high temperature as experienced in APS.
A variation of the MA/MM process has been used by Srivastava et al. (Ref 47) to develop HEA feedstock for HVOF processing. Starting with milling elemental powders for $2 \mathrm{~h}$ in toluene, followed by drying in Ar, the powders were compacted into green pellets and subjected to pyrolysis in argon at $1100{ }^{\circ} \mathrm{C}$ for $1 \mathrm{~h}$. Alloying is expected to have occurred at this stage. The pellets were then crushed and sieved. Spray drying in a $6 \mathrm{wt} . \%$ polyvinyl alcohol (PVA) suspension was carried out to agglomerate the fine powders. This method, while protracted, avoids the nanocrystallinity and contamination incurred from MA, as well as conferring the desired particle size. However, care must be exercised to confirm alloy formation and homogeneity throughout the process.

\section{Gas Atomization (GA)}

Inert gas atomization is the preferred technique for manufacturing feedstock for TS. It has gained popularity in the HEA coating community and is the most used synthesis method. Gas atomization involves forcing the liquid alloy through a nozzle under high pressure within an inert gas environment. The liquid stream fragments into spherical droplets that rapidly solidify (Ref 48). Faster cooling allows phase separation to occur only at very fine scales, as illustrated in Fig. 7 (Ref 49), and can usually be mitigated during spraying or annealing after coating. Gas atomization is appealing because it results in spherical particles with good flowability and homogeneous alloy formation. The wide size ranges of particles can be sieved to desired size cuts.

In summary: GA is tailor made for synthesizing feedstock for thermal spray processes and is suitable for HEAs. Mechanical alloying presents a strong alternate method, although requiring milling parameter optimization and being time intensive. Arc melting followed by mechanical milling is suitable for laboratory-scale studies, while blending can only be used as a post-alloying technique to further enhance feedstock properties.

It is also imperative to mention that while most of the studies synthesized their own feedstock in a laboratory setup, there are reports of two commercially available
Fig. 6 (a) Typical powder morphologies observed in mechanically alloyed highentropy alloys milled in (a) argon (dry milling): flaky (Ref 37); and (b) toluene (wet milling): irregular (Ref 34)
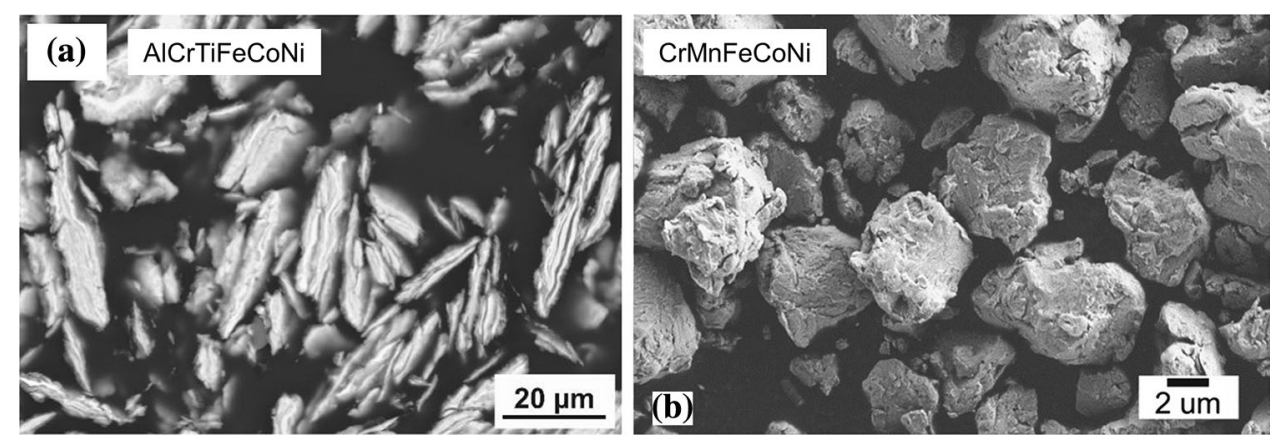


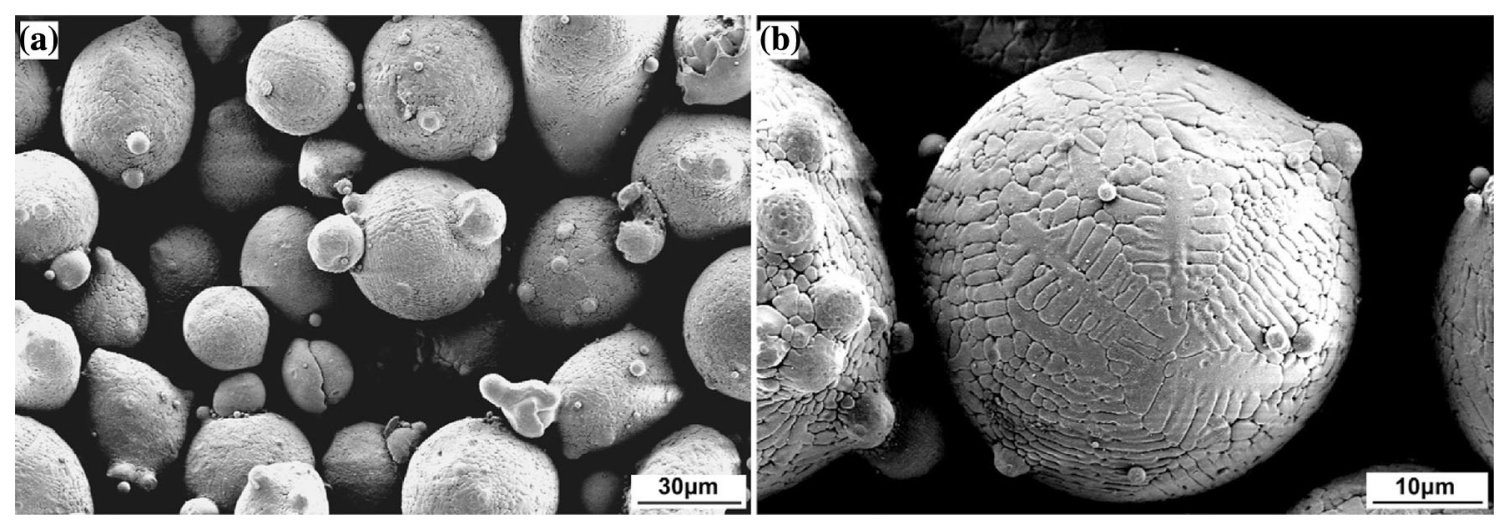

Fig. 7 Typical gas-atomized high-entropy alloy particles with (a) spherical morphology and satellite particles, and (b) dendritic growth discernible at higher magnifications (Ref 49)

sources for HEA powders: (1) F.J. Broadmann \& Co., L.L.C., USA, for mechanically alloyed powders (Ref 43), and (2) Vilory Advanced Materials Technology Ltd., China, for gas-atomized powders (Ref 49). While this points toward a growing future for thermal sprayed HEA coatings, it must be borne in mind that the quality of the feedstock defines the coating quality. Thus, care must be exercised when selecting either laboratory or commercially produced HEAs.

In contrast to usual prealloyed feedstock for thermal spray processes, laser cladding with HEAs is carried out with blended elemental powders mixed into a binder to form a thick slurry, which is preplaced on the substrate and exposed to the laser beam. The slurry melts under the laser beam to form a melt pool that allows mixing and alloying of the blended powders. The melt pool solidifies rapidly at $10^{3}$ $10^{6} \mathrm{~K} / \mathrm{s}$ after passing of the laser beam and supersaturated solid solutions and intermetallic phases are often observed. There are several reports of laser clad HEA coatings using alloy powders synthesized via mechanical alloying (Ref 50) or gas atomization (Ref 51) rather than employing elemental blends. In another variation of laser cladding, termed 'laser surface alloying', the alloy coating is formed by mixing elements of the feedstock and the molten substrate. This transforms the otherwise detrimental problem of elemental dilution from the substrate (Ref 52) into a benefit. Several process parameters, primarily laser power, defocus distance, scanning speed, and track overlap, must be optimized for desirable results. This has been discussed further in the "Post Processing of TS Coatings" section.

\section{Microstructural and Phase Composition Aspects}

The microstructure of a TSC depends strongly on the type of TS method, the specific TS parameters, and the nature of the feedstock. The TS technique includes a multitude of coating parameters that are designated within 'spray tables,' e.g., plasma current and voltage; primary and secondary gas flow rates for plasma spray; carrier gas flow rate; stand-off distance; and design and dimensions of the nozzle for HVOF, D-gun, and cold spray processes. The HEA feedstock characteristics also govern the coating microstructure, which is strongly related to the feedstock synthesis technique (described in the previous section). Therefore, both the feedstock and TS process must be optimized to achieve a repeatable coating that is free from undesirable phases and adverse microstructural artifacts. This section delineates the effects of the TS technique used with respect to the as-sprayed microstructure of HEAs.

It is important to note that depending on the feedstock processing route and TS route chosen, the alloy may be prone to phase transformations. For example, HEA powders synthesized via mechanical alloying result in metastable and often supersaturated solid solution phases. These powders, when sprayed by relatively high-temperature HVOF or APS processes, will undergo melting and rapid solidification, once again resulting in supersaturated solid solution phases. There is also a possibility of in-flight oxidation (IFO) resulting in a composite alloy-oxide splat microstructure. On the other hand, coatings produced via low-temperature techniques such as cold spray or warm spray will tend to retain the feedstock phases. There is further scope to induce phase changes in the coating microstructure by post-processing, by thermal treatments and/or laser remelting of the coating surface, as is elucidated in "Post Processing of TS Coatings" section.

Compositions of HEAs are traditionally based on either the transition element quartet of $\mathrm{Co}, \mathrm{Cr}, \mathrm{Fe}$, and $\mathrm{Ni}$, or refractory elements such as $\mathrm{W}, \mathrm{Mo}, \mathrm{Ta}$, and $\mathrm{Nb}$. Additions of $\mathrm{Al}, \mathrm{Mn}, \mathrm{Ti}, \mathrm{Si}, \mathrm{Cu}, \mathrm{V}, \mathrm{Hf}$, and $\mathrm{Zr}$ have been included in bulk HEAs and their microstructure and properties reported. This section charts the development of certain alloy families that have transitioned from the bulk form to TS 
coatings and that have been optimized for desired applications.

\section{Early Work}

The earliest published work on thermal sprayed HEAs is by Huang et al. (Ref 32) and is among the first reports on highentropy alloys as a concept. Their report on air plasmasprayed $\mathrm{AlSiTiCrFeCoNiMo}_{0.5}$ and $\mathrm{AlSiTiCrFeNiMo}{ }_{0.5}$ initiated the field of TS-HEA coatings, buoyed by initial but promising results on the improved oxidation and wear resistance of the coatings vis-à-vis traditional materials. The effect of synthesis route on the HEA's microstructures is reflected from the phases observed. While the as-cast alloys consisted of $\mathrm{B} 2+\mathrm{FCC} 1+\mathrm{FCC} 2$ phases and a typical dendritic microstructure, only single-phase BCC splats along with several unidentified oxide phases were detected in the coatings. This is attributed to the melting followed by rapid solidification in the APS process, resulting in a supersaturated solid solution. Another aspect introduced by APS processing concerns IFO, which is a major issue when dealing with oxygen-sensitive materials. In this case, $\mathrm{Al}, \mathrm{Cr}, \mathrm{Ti}$, and $\mathrm{Mo}$ are all oxygen active elements and likely constitute the many oxides detected by $\mathrm{x}$-ray diffraction (XRD) and scanning electron microscope (SEM) of the coating. Nevertheless, the coating showed encouraging wear and oxidation resistance in comparison with traditional materials and laid the groundwork for the field of TS-HEA coatings.

It is worthwhile to mention that reducing the extent of IFO of traditional materials during APS by varying process parameters has been researched (Ref 53, 54). A major theme of these articles is that addition of a shrouded environment vastly reduces the IFO of the feedstock. Azarmi et al. (Ref 55) in an experiment designed to delineate the effects of process parameters on the oxide content and porosity of APS Alloy 625 coatings found that the primary gas flow rate, particle size, and stand-off distance most affected the extent of IFO. In the field of APSHEAs, as will be discussed in "AlCrFeCoNi Coatings" section, IFO has been found to depend strongly on the feedstock synthesis route, particle size, distribution, and the primary gas flow rate during spraying.

Liang et al. (Ref 56) reported $\mathrm{CrFeCoNiCu(B)} \mathrm{coatings}$ synthesized by high-velocity arc spraying. The feedstock consisted of blended HEA powders extruded into cored wires and used as consumable electrodes with opposite polarities. An arc is struck between these electrodes, thus melting the wire ends, and compressed air flow is used to atomize and propel the molten droplets toward the substrate where they solidify and form the coating. A dense ( $<5 \%$ porosity) coating, consisting of FCC phase splats and a dark phase that maybe oxide or an unidentified interstitial solid solution, was formed that exhibited a good interface with the substrate. The novelty of this work lies in the addition of boron in the alloy, which they credit to prevent IFO because boron acts as a sacrificial oxygen getter. These coatings exhibited good hardness and bond strengths, lending confidence to this TS method for synthesizing HEA coatings. However, there have been no further reports on high-velocity arc-sprayed HEA coatings.

\section{AlCrFeCoNi Coatings}

The AlCrFeCoNi family of alloys has been researched extensively in the bulk form (Ref 57). The alloy system's chemical (Ref 58,59) and mechanical properties (Ref 60) have illustrated its excellent candidacy for many applications, which has been further targeted for TS-HEA coating developments. Yue et al. (Ref 61) generated $\mathrm{AlCrFeCo}-$ $\mathrm{NiCu}$ coatings, a composition studied widely in bulk form for their fundamental behavior and property correlation, via low-velocity APS. Both $\mathrm{CrFeCoNiCu}(\mathrm{B})$ coatings discussed above and the $\mathrm{AlCrFeCoNiCu}$ coatings were developed for $\mathrm{Mg}$ substrates that are characterized by a low melting point. TS methods are a suitable alternative to laser surface modification, allowing surface property enhancement without deteriorating the substrate. Using gas-atomized alloy powders as feedstock, Yue et al. generated APS coatings with a BCC + FCC + oxide lamellar microstructure, in contrast to the $\mathrm{B} 2+\mathrm{BCC}+\mathrm{FCC}$ phases seen in the bulk form (Ref 62). These cast alloys are further characterized by phase separation and spinodal decomposition occurring at nanolength scales, which are absent in the TS coatings and attributable to rapid solidification.

This was followed by Ang et al. (Ref 34), Bhattacharya et al. (Ref 43), and others who explored compositions in the $\mathrm{AlCrFeCoNi}$ family. Ang et al. (Ref 34) sprayed mechanically alloyed $\mathrm{AlCrFeCoNi}$ via APS and reported significant IFO that transformed the two-phase MA powder into a multi-phase alloy-oxide composite coating. This was attributed to the fine particle size and nanocrystalline nature of the feedstock, which intensified the alloy powder's interaction with the atmosphere during spraying. The coating exhibited a homogeneous lamellar microstructure with good anisotropic mechanical properties.

In 2017, the same composition was sprayed via 'supersonic air plasma spray' by Lin et al. (Ref 63). Blended elemental powders were used as feedstock that formed the coating in addition to attendant oxides. Complete alloying was not possible, and it was not deemed to be an HEA coating in the as-sprayed form, although lamellar splats were observed. Annealing the coatings at 600 and $900{ }^{\circ} \mathrm{C}$ allowed interdiffusion and phase transformations resulting 
in $\mathrm{BCC}, \mathrm{Ni}_{3} \mathrm{Al}$, and $\mathrm{Cr}-\mathrm{O}$ phases. Post-processing treatments will be discussed at the end of this section.

Cheng et al. (Ref 64) systematically studied AlCrFeCoNi APS coatings using gas-atomized powders as feedstock, analyzing the effect of particle size and spray parameters (e.g., plasma current and argon primary gas flow rate) on the coating phases. They demonstrated the phase adjustable nature of TS-HEA coatings by controlling the above-mentioned parameters. First, the phase evolution in the particles as a function of temperature was analyzed. The starting phases in the as-atomized condition were B2 $\mathrm{Ni}$-Al-rich dendritic and $\mathrm{BCC} \mathrm{Fe}-\mathrm{Cr}$ interdendritic microstructures. The BCC phase transformed to FCC at $600{ }^{\circ} \mathrm{C}$ and then to $\sigma$ phase at $800{ }^{\circ} \mathrm{C}$. Further annealing at $1000{ }^{\circ} \mathrm{C}$ revealed dissolution of the $\sigma$ phase and reappearance of FCC.

The powder particles were also observed to melt far below the melting temperature of $1362{ }^{\circ} \mathrm{C}$ of the cast alloys, manifesting as $\mathrm{B} 2+\mathrm{BCC}$ phases after heat treatment at $1200{ }^{\circ} \mathrm{C}$. Subsequently, the GA powders were sieved into two cuts, small $(10-60 \mu \mathrm{m})$ and large (60$90 \mu \mathrm{m})$ and sprayed under several plasma current and argon gas flow conditions. Increasing the plasma current increases the temperature of the plasma, as does raising the primary $\mathrm{Ar}$ gas flow, and thus the particle temperature rises. Smaller particles gave rise to a major BCC with minor FCC + oxide microstructure at lower plasma powers, which transformed to FCC becoming the major phase at higher plasma power.

Three of these coatings are illustrated in Fig. 8 and highlight the differences in coating microstructures as a function of spray parameters. These microstructures are reminiscent of those in Ang et al. (Ref 34)-MA-APS coatings, which also reported major $\mathrm{FCC}+$ minor $\mathrm{BCC}+$ oxides. While Ang et al. attribute the FCC phase formation to the depletion of $\mathrm{Al}$ from the HEA due to IFO ( $\mathrm{Al}$ is a $\mathrm{BCC}$ stabilizer in $\mathrm{Al}_{x} \mathrm{CrFeCoNi}$ at $x \geq 0.8$ ), Cheng et al. attribute the FCC phase stabilization to particles being annealed. A combination of both factors could be in force since significant oxidation occurs in the case of Cheng et al.'s low-energy input coatings. Interestingly, the larger particles, which could retain more heat and remain molten longer than smaller particles, did not transform to FCC. Coatings generated using higher-energy inputs and larger particle sizes exhibited good melting and splat behavior, with negligible IFO, albeit with some interlamellar cracking.

Another point of comparison for $\mathrm{AlCrFeCoNi}$ TS coatings is available in the work of $\mathrm{Mu}$ et al. (Ref 65), where they reported APS coatings of gas-atomized alloy particles. BCC phase observed in the particles is transformed to $\mathrm{BCC}+$ oxide in the APS coating. Table 1 lists the feedstock and APS parameters employed by Ang, Cheng, and
$\mathrm{Mu}$ for generating $\mathrm{AlCrFeCoNi}$ plasma-sprayed coatings and the corresponding phases observed. This summary table may aid in optimization of APS spray and feedstock selection parameters to develop phase-adjustable coatings for these alloy systems. The primary phases observed for each condition are mentioned in bold font.

$\mathrm{Mu}$ et al. (Ref 65) further characterized the coating via x-ray photoelectron spectroscopy (XPS), which detected multiple oxide phases on the coating surface, all attributed to IFO during spraying. Transmission electron microscopy (TEM) studies of the as-sprayed coatings also showed nano-oxide particles dispersed in the alloy matrix, which were attributed to the formation of a by-product from the HEA-plasma-air interaction.

Anupam et al. (Ref 66) investigated the microstructure of the $\mathrm{AlCrFeCoNi}$ APS coatings reported earlier by Ang et al. (Ref 34) and distinguished the multitude of phases resulting from the MA HEA-APS interaction. Aluminumdepleted alloy phases, $\mathrm{Al}_{2} \mathrm{O}_{3}, \mathrm{AB}_{2} \mathrm{O}_{4}$-type spinels, and unoxidized unmelts with equiatomic composition were detected at different length scales. They also provide a model delineating the effects of particle size and temperature during spraying and the consequential result in the coating. An example is illustrated in Fig. 9(a), where a medium-sized $(5-15 \mu \mathrm{m})$ mechanically alloyed $\mathrm{AlCrFe}$ CoNi particle is exposed to the highest temperature zone (particle temperatures of $1200-2300{ }^{\circ} \mathrm{C}$ ) of the plasma plume. It is theorized that such particles would melt completely, spheroidize, and oxidize partially in flight. They would further splat on impact, with the possibility of splashing. Figure 9(b) is a representative image of the HEA feedstock used. Figure 9(c) and (d) shows splats corresponding to medium-sized particles in the high-temperature zone and identified in the coating cross section and top view, respectively. This work (Ref 66) focuses on the experience of mechanically alloyed HEA particles, which are much finer, irregular shaped, and nanocrystalline in nature. These concepts can be applied broadly to any TSHEA process and be used in conjunction with Table 1 to select processing parameters for developing specific coating microstructures.

Figure 10 is based on reference 66 and presents a unified model that mechanistically describes the combined influences of temperature and impact on splat behavior. This model is an extension of the work represented in Fig. 9 and, although formulated for HEA feedstocks, can be applied to thermal spray processes in a generic fashion. Therefore, the focus concerns particle size effects as they experience various temperatures regimes within a thermal spray environment.

Anupam et al. (Ref 46) also developed cold-sprayed HEA coatings using MA AlCrFeCoNi. The phases present in the powder were translated to the coating without any 


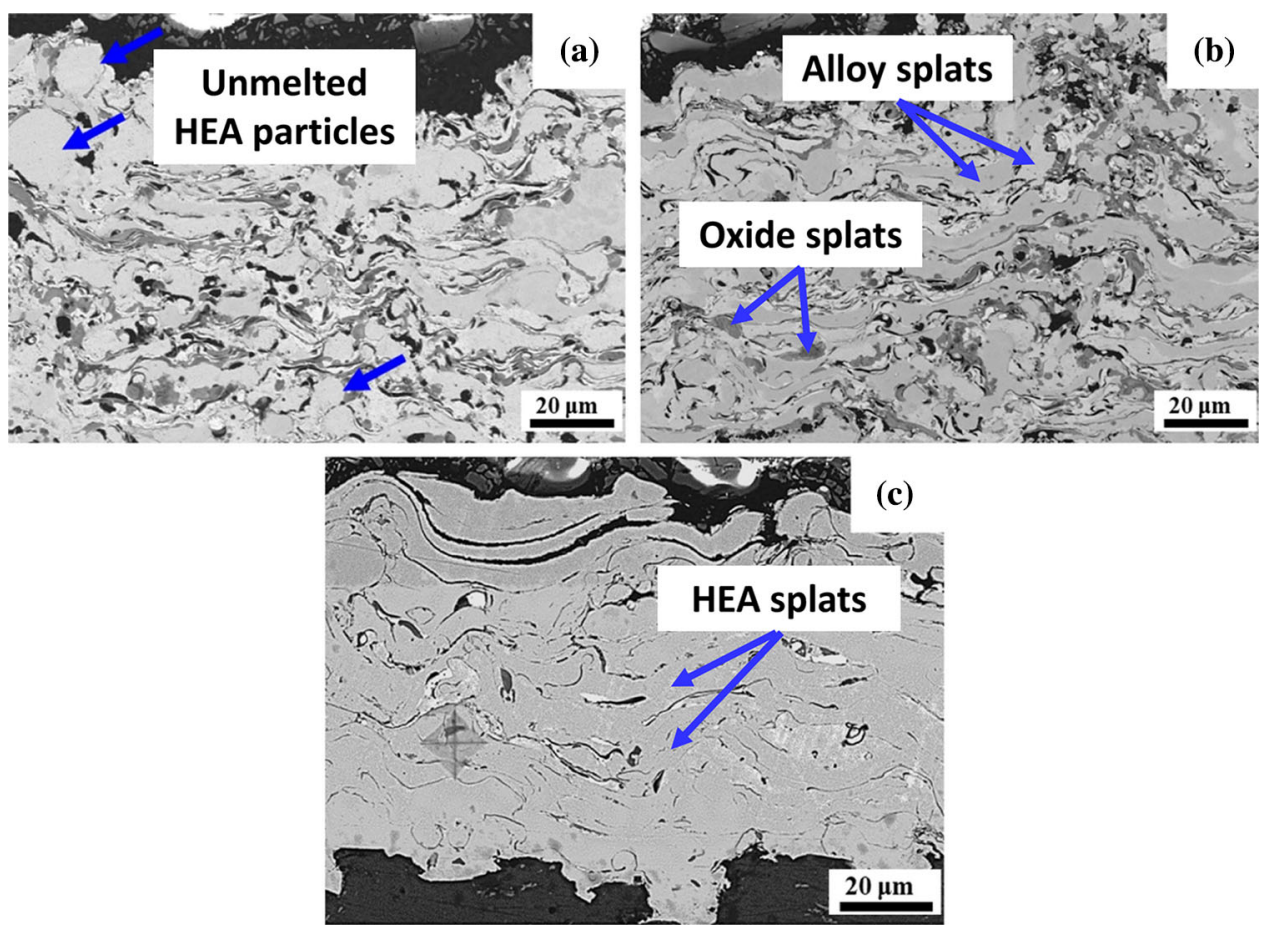

Fig. 8 Coating microstructures achievable by using the same feedstock material and varying the coating parameters: (a) plasma current $I=500 \mathrm{~A}$, Ar flow rate $(f)=35 \mathrm{l} / \mathrm{min}$ result in $\mathrm{BCC}+\mathrm{FCC}+$ oxides + unmelts, (b) $I=600 \mathrm{~A}, f=501 / \mathrm{min}$ results in lower FCC content and fewer unmelts, and (c) $I=750 \mathrm{~A}, f=50 \mathrm{1} / \mathrm{min}$ results in single-phase BCC coating with nearly no IFO (Ref 64)

Table 1 Atmospheric plasma spray parameters used across thermal sprayed high-entropy alloys literature to spray AlCrFeCoNi resulting in different phase constitutions

\begin{tabular}{|c|c|c|c|c|c|c|c|c|c|}
\hline $\begin{array}{l}\text { Feedstock } \\
\text { synthesis } \\
\text { technique } \\
\text { and phase }\end{array}$ & $\begin{array}{l}\text { Particle size } \\
\text { range, } \mu \mathrm{m}\end{array}$ & $\begin{array}{c}\text { Plasma } \\
\text { current, } \\
\text { A }\end{array}$ & $\begin{array}{c}\text { Plasma } \\
\text { voltage, } \\
\text { V }\end{array}$ & $\begin{array}{c}\text { Primary } \\
\text { (Ar) gas } \\
\text { flow rate, } \\
\text { slpm }\end{array}$ & $\begin{array}{l}\text { Secondary gas } \\
\left(\mathrm{He} / \mathrm{H}_{2}\right) \text { gas } \\
\text { flow rate, } \\
\text { slpm }\end{array}$ & $\begin{array}{l}\text { Powder } \\
\text { feed } \\
\text { rate, } \\
\mathrm{g} / \mathrm{min}\end{array}$ & $\begin{array}{l}\text { SOD } \\
\mathrm{mm}\end{array}$ & Phases observed & References \\
\hline $\begin{array}{l}\text { Mechanical } \\
\text { alloying }\end{array}$ & $5-30$ & 300 & 65 & 42 & 2.3 & 18 & 90 & $\mathbf{F C C}+\mathrm{BCC}+\mathrm{AB}_{2} \mathrm{O}_{4}$ & Ref 34 \\
\hline \multicolumn{10}{|l|}{$\mathbf{B C C}+\mathrm{FCC}$} \\
\hline \multirow{2}{*}{$\begin{array}{l}\text { Gas } \\
\text { atomization }\end{array}$} & \multirow[t]{4}{*}{$10-60$} & 500 & \multirow[t]{7}{*}{70.5} & 35 & \multirow[t]{7}{*}{9.3} & \multirow[t]{7}{*}{30} & \multirow[t]{7}{*}{140} & $\mathbf{B C C}+\mathrm{FCC}+$ oxides & \multirow[t]{7}{*}{ Ref 64} \\
\hline & & 500 & & 50 & & & & $\mathbf{B C C}+\mathbf{F C C}+$ oxides & \\
\hline \multirow[t]{5}{*}{$\mathbf{B C C}+\mathrm{B} 2$} & & 600 & & 35 & & & & $\mathbf{B C C}+\mathbf{F C C}+$ oxides & \\
\hline & & 600 & & 50 & & & & $\mathbf{F C C}+\mathrm{BCC}+$ oxides & \\
\hline & $10-60+60-90$ & 650 & & 50 & & & & $\mathbf{B C C}+\mathrm{FCC}+$ oxides & \\
\hline & \multirow[t]{2}{*}{$60-90$} & 550 & & \multirow[t]{2}{*}{50} & & & & $\mathrm{BCC}$ & \\
\hline & & 750 & & & & & & $\mathrm{BCC}$ & \\
\hline $\begin{array}{l}\text { Gas } \\
\text { atomization }\end{array}$ & $30-50$ & 400 & 60 & 45 & 3 & $\cdots$ & 120 & $\mathbf{B C C}+$ oxide & Ref 65 \\
\hline BCC & & & & & & & & & \\
\hline
\end{tabular}

IFO due to the low particle temperatures experienced $\left(<400{ }^{\circ} \mathrm{C}\right)$. Particle deformation into splats was observed, although former particle boundaries were still obvious as the new inter-splat boundaries and attributed to the brittle nature of the BCC alloy particles. This work illustrates that cold spray is also a viable technique for spraying temperature- and oxidation-sensitive HEAs, albeit with further process parameter optimization.

A variation of the traditional $\mathrm{AlCrFeCoNi}$ alloy was developed by Vallimanalan et al. (Ref 67, 68) by replacing 
(a) Feedstock
(AlCoCrFeNi)
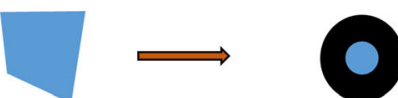

Medium sized (5-15 $\mu \mathrm{m})$ MA HEA particle melts, spheroidizes and is partially oxidized in the highest temperature zone of plasma plume; and splats on impact

In-flight

(APS)
Impact
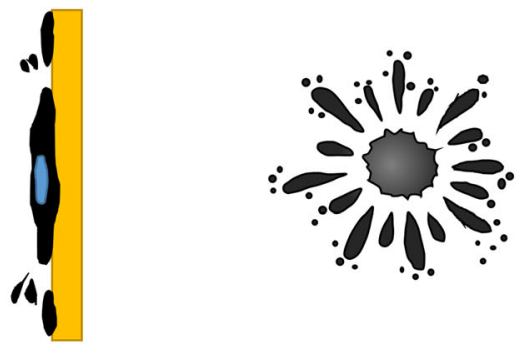

with substrate

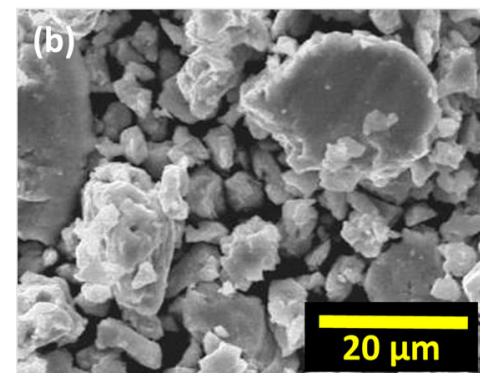

MA HEA powder

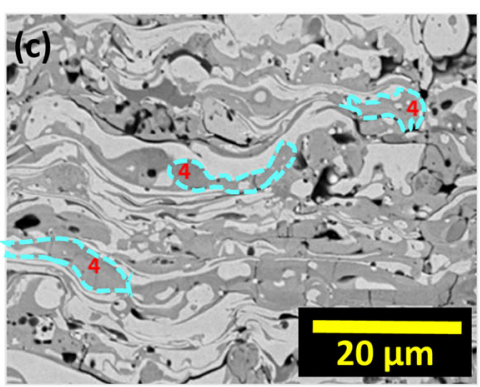

APS coating cross section

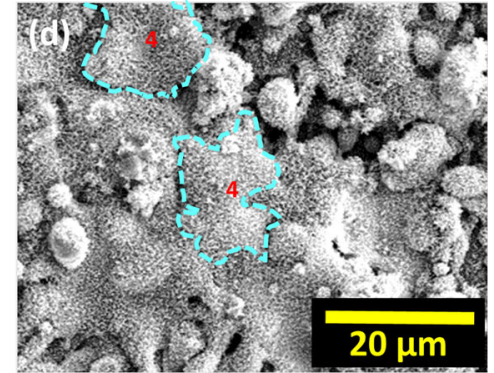

APS coating top view

Fig. 9 (a) Schematic description of the journey of an HEA feedstock particle through the plasma plume and subsequent splatting behavior; (b) typical MA HEA particles used as feedstock; corresponding splats identified in (c) cross-sectional and (d) top view images (Ref 66)

Fig. 10 A unified model for thermal spray processing that illustrates the influences of particle size and the local temperature excursion on splat behavior

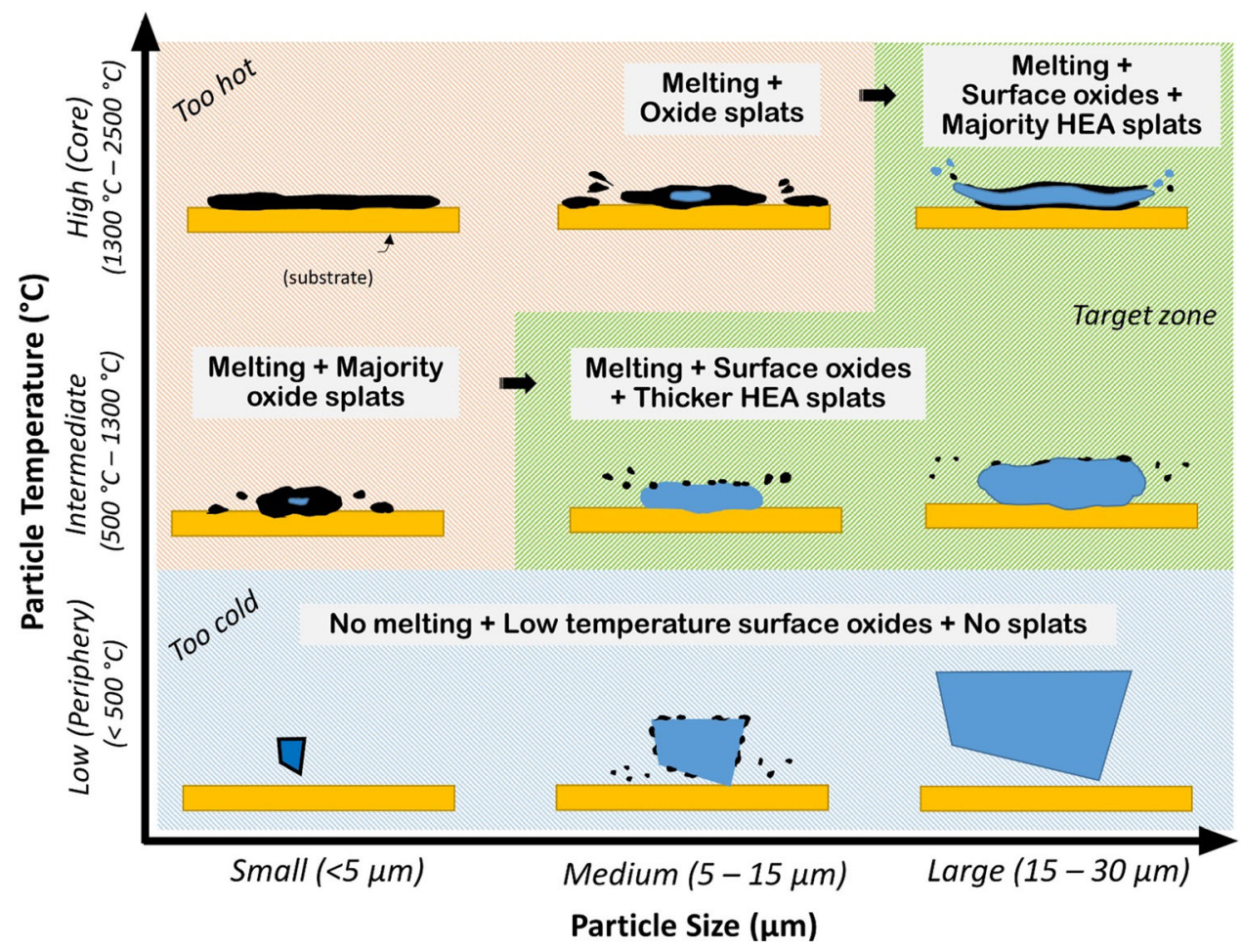


Fe with Mo to confer enhanced corrosion and slurry erosion resistance. MA powders used as feedstock exhibited nanocrystalline nature with BCC phases and WC contamination. These phases were translated into the coating with some IFO products.

\section{AlTiCrFeCoNi Coatings}

The addition of Ti to AlCrFeCoNi has been demonstrated to improve the alloy's mechanical and chemical properties in the bulk form (Ref 69). The first AlTiCrFeCoNi coatings were synthesized by Tian et al. (Ref 70) via APS using MA feedstock. Single-phase BCC in the HEA powder transformed to $\mathrm{B} 2+\mathrm{BCC}+\mathrm{FCC}+$ oxide phases in the coating owing to APS processing conditions that gave rise to a combination of thermally triggered phase transformations and IFO reactions. A dense coating with little or no interlamellar or vertical cracks and with a good bond strength of $50 \pm 8 \mathrm{MPa}$ was realized. This multi-phase nature was also reflected in the coating cross section, by light and dark phase contrasts corresponding to phases lean and rich in $\mathrm{Al}$, respectively. In a continuation of the same work, Tian et al. (Ref 71) postulated the bonding mechanisms operating in these MA-APS coatings. Metallurgical bonding arising from solidification of molten particles on impact, along with some remelting of the previously deposited layers on impact of fresh particles, were credited for the high bond strength exhibited by these coatings.

This composition was further studied by Lobel et al. (Ref 37), where they used different techniques to synthesize the HEA feedstock, as discussed in "Elemental Selection Statistics of High Entropy Alloys" section. The conclusion was that gas-atomized powders resulted in reproducible dense homogeneous coatings with acceptable quantities of oxide inclusion and porosity. In a subsequent work, Lobel et al. (Ref 72) studied HVOF coatings of the same composition, starting again with GA powders. In comparison with the APS coatings, HVOF HEA coatings were observed to be denser with some scattered porosity. The phases transformed from $\mathrm{B} 2+\mathrm{BCC}$ in the feedstock to one FCC + two BCC phases. Some degree of IFO was also observed that is attributed to the higher content of fines in the feedstock.

Chen et al. (Ref 73) also employed HVOF to generate $\mathrm{Al}_{0.6} \mathrm{TiCrFeCoNi}$ coatings using $\mathrm{GA}$ feedstock. Dense ( $<2 \%$ porosity) coatings exhibiting the same phases as the feedstock were produced, ascribed to the lower process temperature and low degree of IFO. Two BCC phases, one $\mathrm{NiAl}$-rich and the other $\mathrm{Fe}-\mathrm{Cr}$-rich, constituted both the powder and the coating, although in slightly different fractions. Peak broadening in XRD was observed for the coating vis-à-vis the powder and is attributed to rapid cooling in HVOF and attendant strains induced during solidification. HVOF is, therefore, demonstrated to be a promising technique for generating low-oxide HEA coatings for oxygen-sensitive compositions.

Tian et al. (Ref 38) extended the scope of TS-HEA coatings by reinforcing the HEA with Ni60 particles to improve their hardness and wear resistance. The blended powders were sprayed via APS and resulted in a non-homogeneous lamellar microstructure with larger splats of Ni60 and finer, more oxidized splats of the HEA. This microstructure may be correlated directly with differences in the feedstock; that is, HEA particles synthesized via mechanical alloying were finer, irregular, and nanocrystalline. Prealloyed Ni60 particles were larger and spherical and thus behaved differently in-flight than the HEA particles. Nevertheless, reinforcement was achieved as evidenced by an improvement in the coating's wear resistance $v s$. the HEA-APS coating. Thus, the potential of improving physical properties by thermal spray processing to form HEA coatings was established.

\section{AlSiCrFeCoNi Coatings}

AlSiCrFeCoNi alloys have also generated some traction primarily due to their high-temperature oxidation resistance. Bhattacharya et al. (Ref 43) generated $\mathrm{Al}_{30} \mathrm{Si}_{2} \mathrm{Cr}_{23}$ $\mathrm{Co}_{22} \mathrm{Ni}_{23}$ coatings using commercially produced GA powder. The coarser cut $(-75+45 \mu \mathrm{m})$ was used as feedstock for APS, and the finer $(-45+20 \mu \mathrm{m})$ cut for HVOF. BCC phase in the feedstock transformed to $\mathrm{BCC}+\mathrm{FCC}+\mathrm{Al}_{2} \mathrm{O}_{3}$ in the APS coating, whereas a $\mathrm{BCC} / \mathrm{B} 2+\mathrm{FCC}+\mathrm{Al}_{2} \mathrm{O}_{3}$ constitution was achieved via HVOF. The APS coating was reportedly inhomogeneous, exhibited larger oxide and porosity content, and was rejected in favor of the denser HVOF coatings for subsequent oxidation studies. Interestingly, two 'layers' were observed in the HVOF coating, the lower layer appearing denser than the top one. This morphological effect may be due to a tempering and shot-peening-like treatment experienced by the bottom layers during deposition of the top layers. This study is novel because the authors used thermodynamically calculated phase diagrams to choose the TS-HEA alloy composition. This method reduces the critical compositional variable of TS-HEA coatings property-parameter optimization.

Tian et al. (Ref 74) studied equiatomic AlSiCrFeCoNi ball-milled for $30 \mathrm{~h}$ and coated via APS. Elemental Si was detected in the $30 \mathrm{~h}$ MA powder, which dissolved during the melting-resolidification routine during spraying, and $\mathrm{B} 2+\mathrm{BCC}+\mathrm{FCC}$ phases were detected in the coating. Jin et al. (Ref 75) explored the effect of varying Si content in $\mathrm{Al}_{0.5} \mathrm{Si}_{x} \mathrm{CrFeCoNi}(x=0.5,1,1.5,2)$ APS coatings. Phase separation into a $\mathrm{Fe}-\mathrm{Co}-\mathrm{Cr}-\mathrm{Al}$-rich $\mathrm{BCC}$, a Fe-Corich $\mathrm{FCC}$, and $\mathrm{Cr}_{3} \mathrm{Si}$ was observed in the coating, attributed 
to the use of blended elemental feedstock. The BCC phase fraction was observed to increase with $\mathrm{Si}$ content, and at $x>1$, no $\mathrm{FCC}$ or $\mathrm{Cr}_{3} \mathrm{Si}$ was observed, due to the formation of a supersaturated solid solution during APS. Oxide splats were also detected in the coating cross section along with porosity and interlamellar cracks. Thus, while some supersaturation may be achieved in-flight during plasma spray, it is not the recommended method for alloying using blended powders. It is noted, on the other hand, that supersaturation may be achieved in laser cladding since the time at temperature is significantly greater.

The effect of Al content on phase formation and wear behavior was examined by Xiao et al. (Ref 76) in MA-APS $\mathrm{Al}_{x} \mathrm{SiCrFeCoNi}(x=0.5,1,1.5$ molar ratios) coatings. $\mathrm{BCC}+\mathrm{FCC}$ phases observed in the MA powder were translated into the coating with some IFO. An increase in the $\mathrm{Al}$ content did not affect the phases significantly. Heat treatment of the coatings led to evolution of the $\mathrm{Cr}_{3} \mathrm{Ni}_{5} \mathrm{Si}_{2}$ phase, which improved the wear resistance of the coatings.

\section{Non-equiatomic Al-Si-Ti-Cr-Fe-Co-Ni coatings}

The non-equiatomic Al-Si-Ti-Cr-Fe-Co-Ni family of alloys are being explored for their oxidation and wear behavior at elevated temperatures. Wang et al. (Ref 33) investigated $\mathrm{AlSiTi}_{0.2} \mathrm{Cr}_{1.5} \mathrm{Fe}_{0.2} \mathrm{Co}_{0.6} \mathrm{Ni}$ in cast and APS-coated forms, along with the effect of heat treatment on the coating microstructure. Powders were synthesized via the AM-MM route, which ensured alloying in the feedstock. While images of the coating cross section have not been reported, XRDs of the cast, as-sprayed, and heat-treated TS-HEAs have been discussed in detail. It is apparent that $\mathrm{Cr}_{3} \mathrm{Si}$ precipitation in a BCC matrix occurs in all cases. Improved mechanical properties observed in the coating can be correlated directly with the size and distribution of precipitates, composition of the HEA, and dislocation density introduced during rapid resolidification.

$\mathrm{Hsu}$ et al. (Ref 39) studied a variant, $\mathrm{AlSi}_{0.2} \mathrm{Ti}_{0.2-}$ $\mathrm{CrFe}_{0.2} \mathrm{Co}_{0.6} \mathrm{Ni}_{0.2}$ AM-MM powder coated via APS and $\mathrm{HVOF}$, followed by heat treatment at 800 and $1100{ }^{\circ} \mathrm{C}$. The $\mathrm{BCC}+\mathrm{Cr}_{3} \mathrm{Si}$ phases in the powder were retained in the coatings with some IFO. The extent of the IFO was more under APS, and both high-temperature processes resulted in the formation of a supersaturated solid solution with lesser degrees of $\mathrm{Cr}_{3} \mathrm{Si}$ precipitation than in the as-cast form. Post-spraying heat treatment was used to optimize coating microstructures and will be discussed separately toward the end of this section.

Learnings from previous studies on these compositions were used by $\mathrm{Hsu}$ et al. (Ref 77) to systematically study AlSiTi ${ }_{0.2} \mathrm{Cr}_{1.5} \mathrm{Fe}_{0.2} \mathrm{Co}_{0.6} \mathrm{Ni}$ deposited by three techniques: APS, HVOF, and warm spray (WS). Warm spray is a modification of the HVOF process, where the gas flow rates are controlled to regulate the combustion rate and therefore the temperatures experienced by the feedstock particles (Ref 78). In terms of particle temperatures experienced, warm spray falls between cold spray and HVOF (Fig. 1), hence the eponym. BCC + FCC $+\mathrm{Cr}_{3} \mathrm{Si}+$ oxide phases were observed in all the coatings. One major difference was that the feedstock was gas-atomized powder, as opposed to the AM + MM powders used earlier, likely due to better flowability and higher yield offered by GA. Typical lamellar microstructures were observed in all three coatings, with salient differences appearing in the phase fractions and degree of IFO (Fig. 11). For instance, precipitation of the $\mathrm{Cr}_{3} \mathrm{Si}$ phase, which was observed in the as-cast and GA states, was subdued in APS and HVOF due to higher process temperatures that promoted the formation of supersaturated solid solutions.

Process temperatures in warm spray were sufficiently low to avoid phase transformations and allow retention of the $\mathrm{BCC}+\mathrm{Cr}_{3} \mathrm{Si}$ phase constitution of the feedstock, but high enough to allow particle deformation and improved inter-splat bonding. The WS microstructures are reminiscent of cold-sprayed AlCrFeCoNi coatings (Ref 46), which also retained feedstock phases, characterized by the deformation of alloy particles into splats with no IFO. The combined advantage of higher process temperatures and no IFO was critical in WS HEA coatings exhibiting better oxidation resistance than their HVOF and APS counterparts. Warm spray, thus, has also demonstrated excellent capability for spraying oxygen- and temperature-sensitive materials, which opens opportunities for the development of TS-HEA coatings.

\section{CrFeCoNi (Mn/Nb/Mo) Coatings}

Other compositions based on $\mathrm{CrFeCoNi}$ have also been explored via the TS route. Addition of Mo to the quartet was studied by Li et al. (Ref 79) as $\mathrm{CrFeCoNiMo}_{0.2}$ and by $\mathrm{Mu}$ et al. (Ref 65) as equiatomic CrCoFeNiMo for APS and HVOF coatings. The $\mathrm{CrFeCoNiMo}_{0.2}$ HVOF coatings showed a markedly lower oxide content of 12 vol.\% compared to $47 \mathrm{vol} \%$ for their APS counterparts, in addition to having $<1 \%$ porosity. The FCC phase of the GA feedstock transformed to FCC + iron oxides and spinels, a result of IFO during both processes. There is also the possibility of losing molybdenum as volatile oxides during APS, which further substantiates the use of optimized HVOF parameters when spraying oxygen-sensitive materials. $\mathrm{Mu}$ et al. (Ref 65) obtained similar results and identified the multiple oxide phases using $\mathrm{x}$-ray photoelectron spectroscopy (XPS) and transmission electron microscopy (TEM). Nano-oxide reinforcement of the APS coating due to IFO was also observed. It has been noted that for the same spray parameters, the deposition 

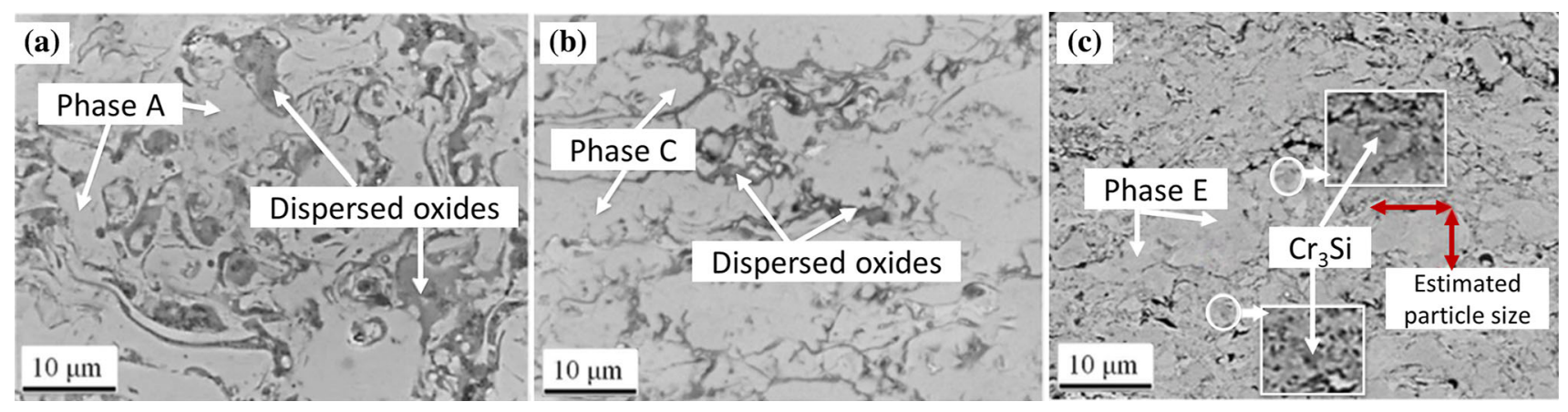

Fig. 11 Microstructures obtained using the same feedstock and several thermal spray processes: (a) atmospheric plasma spray (APS), (b) highvelocity oxy-fuel (HVOF), and (c) warm spray (WS) (Ref 77)

efficiency of $\mathrm{CrFeCoNiMo}$ was lower than that for $\mathrm{AlCr}$ $\mathrm{FeCoNi}$, due to the higher melting point of the former alloy, resulting in fewer instances of melting and splatting.

Wang et al. (Ref 80$)$ developed $(\mathrm{CrFeCoNi})_{95} \mathrm{Nb}_{5}$ coatings via vacuum plasma spray (VPS), employing GA FCC HEA powders. VPS is currently the preferred alternative to APS for spraying oxygen-sensitive materials but is also an expensive process where the object to be coated is constrained by the size of the vacuum chamber. No oxide peaks were detected in the VPS HEA coatings, and a dense, homogeneous microstructure was observed. In comparison with the as-cast form, where an FCC matrix + HCPordered Laves phases were observed, VPS resulted in a supersaturated FCC solid solution with a much lower degree of precipitation. Phase separation into $\mathrm{CrFeCoNi}$ rich, $\mathrm{Cr}-\mathrm{Nb}$-rich, and $\mathrm{CoFeNb}$-rich phases was observed in the coating cross section.

Cantor alloy, $\mathrm{CrMnFeCoNi}$, has also been deposited by Yin et al. (Ref 49) via cold spray using GA feedstock. The FCC particles of dendritic morphology did not undergo any phase transformation, nor was there oxidation of the coating. The coatings were dense, aided by the ductile nature of the alloy, which is advantageous since bonding in CS depends on plastic deformation of feedstock particles. The coating also exhibited significant grain refinement from strains generated from particle deformation on impacting the substrate. Wang et al. (Ref 81) also coated GA CrMnFeCoNi particles via APS and reported FCC phase being conserved in the coating. However, APS coatings exhibited porosity and inter-lamellar cracking. To mitigate this, laser remelting was conducted, as elucidated in the following section. In contrast, Xiao et al. (Ref 82) reported similar microstructures for GA-APS CrMnFe$\mathrm{CoNi}$, but with a fluffy, porous top surface. This is believed to arise from volatilization of manganese during spraying, which has a boiling point $2061{ }^{\circ} \mathrm{C}$. This manganese vapor reacts with oxygen, resulting in the porous manganese oxides detected on the coating surface.
Finally, a Co-free CrMnFeNi coating was developed by Lehtonen et al. (Ref 83) for applications in the nuclear industry. A GA-cold spray route using $\mathrm{N}_{2}$ as the process gas was used. The major FCC phase in the powder was observed in the coating, while a minor BCC phase is believed to have dissolved during processing. As in the work of Yin et al. (Ref 49), grain refinement along the particle boundaries was observed and attributed to the intense plastic deformation typical of the CS process.

\section{Post-processing of TS Coatings}

The microstructure and properties of TS-HEA coatings may be improved further using post-processing treatments. Two popular trends exist: (1) heat treatment and (2) laser remelting of the coating surface.

Annealing and heat treatment of the as-sprayed coating are conducted with two main objectives in mind. The first is to relieve strains incurred during rapid solidification and allow densification to occur. The second is to promote phase transformations such as precipitation from supersaturated alloy phases. Annealing can also be used to promote limited interdiffusion between the coating and substrate to improve bond strength without deteriorating the substrate properties. Annealing can also be used to homogenize coating chemistries that undergo low-temperature TS processes, as in the case of cold-sprayed $\mathrm{AlCrFeCoNi}$ coatings (Ref 46). Wang et al. (Ref 33) and Hsu et al. (Ref 39, 40) used heat treatments to precipitate $\mathrm{Cr}_{3} \mathrm{Si}$ phase from the supersaturated solid solution achieved after APS or HVOF. Heat treatment is an effective tool to control the size and distribution of $\mathrm{Cr}_{3} \mathrm{Si}$ precipitates that are instrumental in improving the wear resistance of these coatings. Chen et al. (Ref 73 ) in studying $\mathrm{Al}_{0.6} \mathrm{TiCrFeCoNi}$ HVOF coatings also subjected their coatings to heat treatment at $800{ }^{\circ} \mathrm{C}$ to form the $\sigma$ phase, which has been chronicled in the bulk HEA literature (Ref 84) and may be used to improve the tribological properties of the softer HEA coating. Xiao et al. (Ref 76) used heat treatment at 
$800{ }^{\circ} \mathrm{C}$ in nitrogen to precipitate $\mathrm{Cr}_{3} \mathrm{Ni}_{5} \mathrm{Si}_{2}$ phase from $\mathrm{Al}_{x} \mathrm{SiCrFeCoNi}$ APS coatings to improve their wear resistance.

Laser remelting of a TS coating surface is the other popular post-processing technique. By controlling the laser parameters such as laser energy and scan rate, melting is limited to the top few tens of micrometers of the TS coating, effectively avoiding element dilution from the substrate. The alloy melt pool so formed is followed by rapid solidification, resulting in a dense and nearly defectfree coating. A columnar and dendritic (Ref 61, 75) microstructure with supersaturated solid solutions, governed by the rapid cooling rates, is often observed, as illustrated in Fig. 12. Laser remelting assists in fluxing out oxide splats that are formed during IFO during the APS/ HVOF process, thereby resulting in an oxide-free top layer of HEA coating (Ref 63). The sequential processes of TS and laser remelting may be combined to tailor HEA coatings with optimum mechanical and microstructural features for desired applications.

It is important to note that laser remelting (LR) of the TS coating is an empirical method. The laser parameters must be optimized, especially if surface alloying is intended to develop the correct stoichiometry in the final TS-LR coating. Attendant issues such as heat-affected zone and solidification cracking in the remelted zone also need to be addressed. As illustrated by Wang et al. (Ref 81), different laser powers can result in different degrees of melting and therefore influence substrate dilution and solidification cracking.

Traditional post-processing treatments for thermal spray coatings include vacuum heating and high-energy beam remelting. Alternative treatments such as microwave processing, in which energy is directly transferred to the material through interaction with electromagnetic waves with molecules resulting in volumetric heating (Ref 85), are available. There is also work using hot isostatic pressing (HIPing) to improve coating density and effect phase changes in the coating microstructure (Ref 86, 87). Besides these, traditional diffusion-based surface treatments such as carburizing/nitriding/aluminizing can also be applied to TS-HEA coatings to engineer their properties for targeted applications. The post-processing parameters must also be optimized with regard to the coating and intended application.
Fig. 12 (a) Cross section of laser-remelted plasma-sprayed high-entropy alloy coating, (b) epitaxial growth observed in a laser-melted layer (Ref 61) (a)
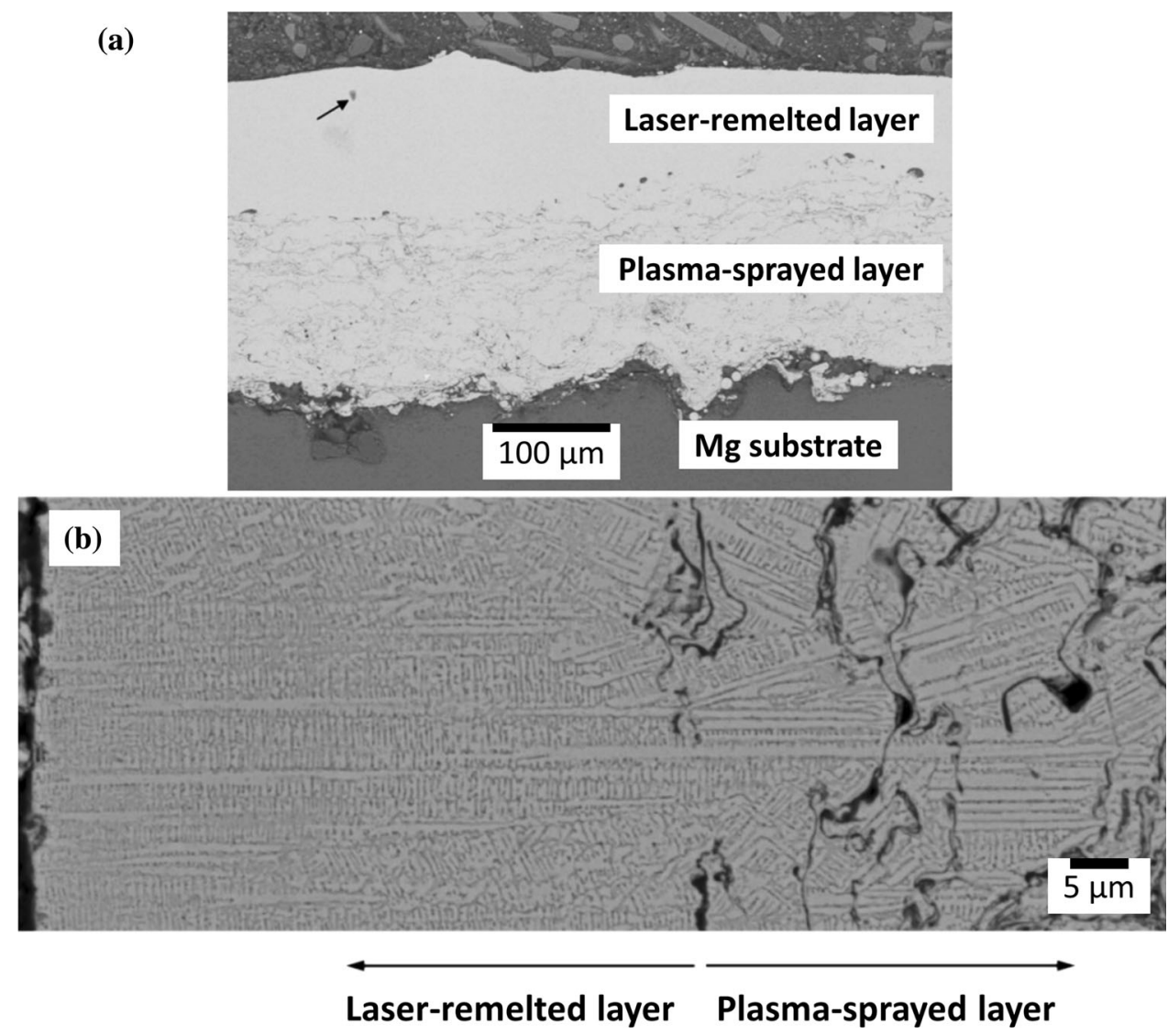


\section{Comparison of TS HEA Coatings with LC HEA Coatings}

In this section, the microstructure observed for thick HEA coatings synthesized via laser cladding (LC) has been compared against their TS counterparts. Laser cladding, laser metal deposition, and laser surface alloying are monikers for the same process. As mentioned previously, LC usually employs blended powders as feedstock, which melt under the laser beam and the alloy rapidly resolidifies into a characteristic dendritic structure.

Although there are more than 60 reports on laser clad HEA coatings, this section will focus on those studying the same HEA composition for corresponding TS HEA coatings, thereby permitting equivalent comparisons.

The AlCrFeCoNi family of alloys has seen significant attention in the laser cladding community. The literature has reported several phase combinations over a range of laser processing parameters for the same HEA composition. Katakam et al. (Ref 88) and Chao et al. (Ref 89) studied the effect of increasing $\mathrm{Al}$ content on the coating microstructure. They reported the presence of multiple solid solution (BCC, B2, FCC) and intermetallic $\left(\mathrm{Al}_{8} \mathrm{Cr}_{5}\right.$, $\mathrm{Al}_{3} \mathrm{Ni}$ ) phases. Two-phase microstructures with a darkappearing matrix and bright-appearing precipitates were observed. The precipitate morphologies were observed to transform from equiaxed for lower $\mathrm{Al}$ content, to dendritic, and finally to Widmanstätten plate morphology for higher $\mathrm{Al}$ contents.
Figure 13 illustrates microstructures observed for laser clad $\mathrm{Al}_{x} \mathrm{CrFeCoNi}(x=0.3,0.5,0.8)$. Shon et al. (Ref 90) also reported similar phase constitution and morphologies with the added novelty of formulating a double-layered coating to control the effect of substrate dilution on the corrosion properties of the HEA coating. Zhang et al. (Ref 91), by controlling the laser parameters, were able to generate a single-phase BCC coating for the equiatomic composition, whereas Li et al. (Ref 92) reported simple BCC + FCC phases in laser clad coatings developed with the addition of $\mathrm{NbC}$ particles. A higher $\mathrm{NbC}$ content favored an increase in $\mathrm{BCC}$ phase by restricting the grain growth of the FCC phase.

Coatings with the addition of $\mathrm{Ti}$ to $\mathrm{AlCrFeCoNi}$ have been developed to improve the alloy's hardness and wear resistance. He et al. (Ref 50) studied the systematic addition of titanium to the equiatomic alloy coating. Eutectic BCC + FCC microstructure was observed in the alloy without titanium, whereas the FCC phase formation was restrained with titanium addition. Two BCC phases were stabilized, one $\mathrm{Fe}$ and $\mathrm{Cr}$ rich, and the other $\mathrm{Ni}$ and $\mathrm{Al}$ rich. Sha et al. (Ref 93) investigated $\mathrm{AlTi}_{0.5} \mathrm{CrFeCoNi}$ and reported the formation of $\mathrm{Al}_{80} \mathrm{Cr}_{13} \mathrm{Co}_{7}, \mathrm{Co}_{3} \mathrm{Ti}$ and $\mathrm{AlFe}$ BCC solid solution phases, which homogenized into a typical spinodal microstructure after annealing. For the same composition, Zhao et al. (Ref 94) studied the variation of aluminum content. On increasing the percentage of aluminum, the reported phases ranged from BCC + FCC, to single-phase $\mathrm{BCC}$, to $\mathrm{BCC}+$ intermetallic phases. Liu et al. (Ref 95) also increased the titanium content in the

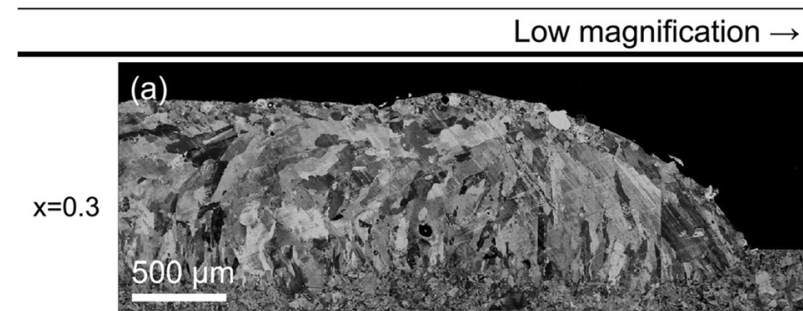

\section{high magnification}
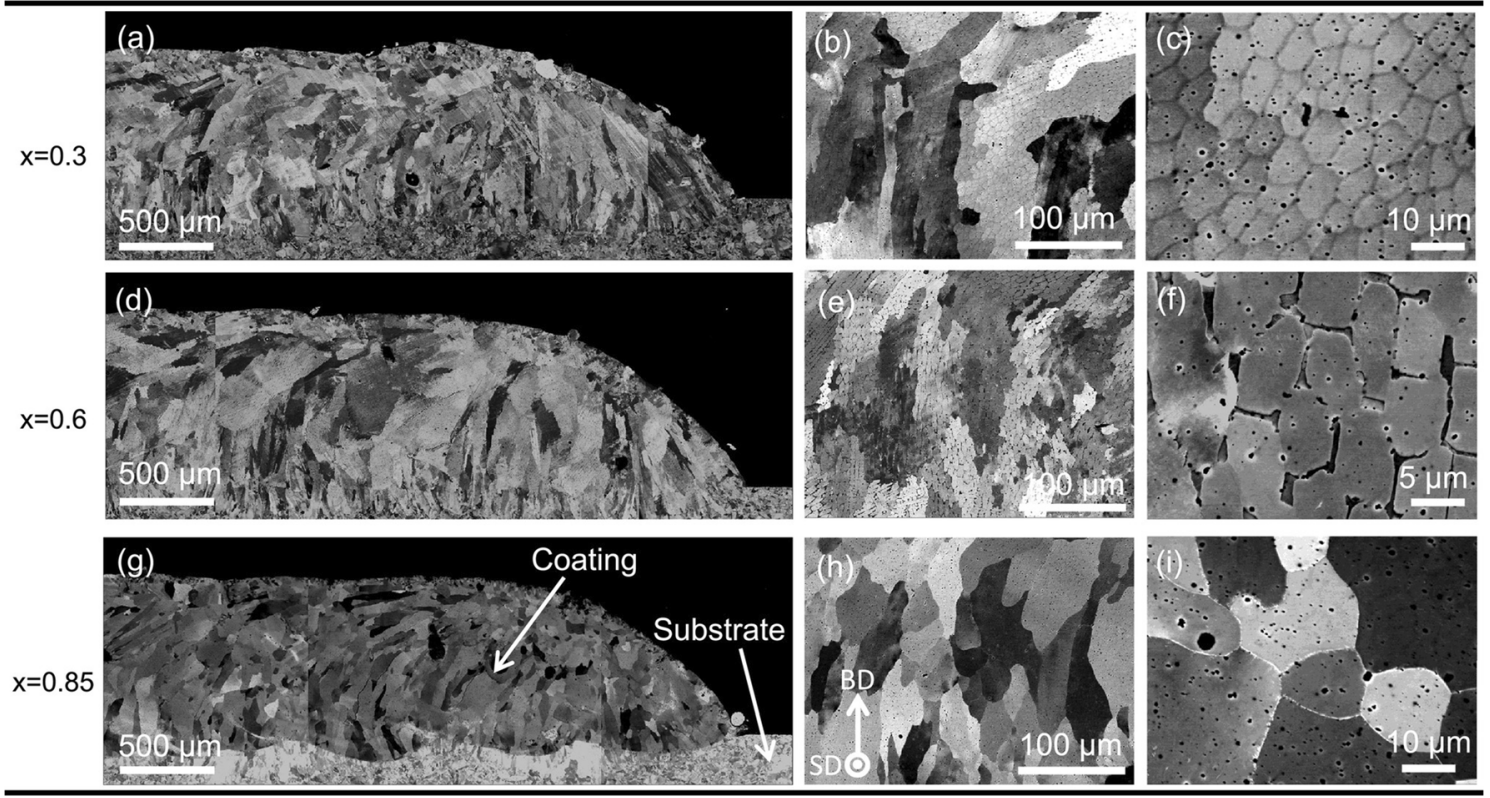

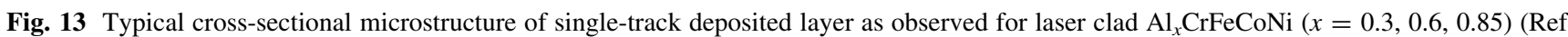
89) 
alloy. The titanium tended to dissolve in the NiAl-based phase and promoted the formation of equiaxed dendritic grains.

While equiatomic AlSiCrFeCoNi has not been studied in the laser cladding HEA literature, compositions such as $\mathrm{Al}_{2} \mathrm{SiCrFeCoNi}$ (Ref 96) and $\mathrm{AlSi}_{0.5} \mathrm{CrFeCoNi}$ (Ref 97) have been investigated. Supersaturated BCC and B2 solid solutions were observed for $\mathrm{Al}_{2} \mathrm{SiCrFeCoNi}$ with elemental segregation becoming more pronounced on annealing after cladding. Solid solution phases of FCC + BCC were observed for $\mathrm{AlSi}_{0.5} \mathrm{CrFeCoNi}$.

Thus, TS HEA coatings exhibit lamellar splats and IFO can be expected along with some inherent cracks and porosity. In contrast, laser clad HEA coatings are characterized by equiaxed or columnar dendritic morphologies and are practically defect free. Argon shielding during laser scanning is a standard practice with laser cladding to avoid oxidation of the melt pool. Both coatings are prone to supersaturated solid solution formation due to higher cooling rates. Additionally, grain refinement is observed for laser clad HEA coatings.

\section{Properties of TS HEA Coatings}

The following section focuses on the properties exhibited by TS HEA coatings, many of which have outperformed traditional materials. Subdivisions have been made based on (1) porosity, (2) hardness and strengthening mechanisms, (3) tribology, (4) oxidation resistance, and (5) electrochemical studies.

\section{Porosity Measurement}

High-entropy alloy coatings developed by thermal spray processes feature composite and lamellar microstructures resulting from splat bonding and rapid solidification. The lamellar microstructure consists of porosity, micro-cracks, oxides (if any), and unmelts. Ang et al. (Ref 34) indicated that the lamellar microstructure of thermal sprayed HEA coatings confers anisotropic mechanical properties. Porosity is the key artifact found within the lamellar microstructure and, other than the thermal spray process, is a major factor that restricts the mechanical properties of these coatings. The overall performance of the HEA coatings can be highly influenced by controlling the size and amount of the pores as well as their location within the 3 -D structure of a coating.

Table 2 presents the porosity data for thermal sprayed HEA coatings. The HEA coatings produced by cold spray exhibit noteworthy low porosity compared to APS and HVOF processes. The ability of imparting high kinetic energies to particles, leading to large impact velocities, led to low porosity in the cold-spray-processed coatings. HVOF coatings, although processed at lower particle velocities than cold spray coatings, also revealed lower porosity, whereas APS HEA coatings, processed at lower velocity and high particle temperatures, resulted in higherporosity coatings that exhibited phase transformations.

\section{Hardness Analysis}

Figure 14 compiles the hardness values reported in the TS HEA literature. As evident from Fig. 14, the highest values are obtained for HVOF coatings vis-à-vis other TS processes. The hardness and strengthening mechanisms of any coating are a function of the composition, TS technique, coating microstructure, and coating quality. The first TS HEA coatings were reported by Huang et al. (Ref 32), where AM-MM AlSiTiCrFeCoNiMo 0.5 and $\mathrm{AlSiTiCrFeNiMo}_{0.5}$ alloy feedstocks were coated via APS. Average values of 486 and $524 \mathrm{HV}$ were reported for compositions with and without $\mathrm{Co}$, respectively. Heat treatment of the coatings at $800{ }^{\circ} \mathrm{C}$ for $100 \mathrm{~h}$ improved the hardness to 962 and $990 \mathrm{HV}$, respectively, owing to precipitation of the $\mathrm{Cr}_{3} \mathrm{Si}$ phase from the supersaturated solid solution.

$\mathrm{AlSi}_{z} \mathrm{Ti}_{0.2} \mathrm{Cr}_{y} \mathrm{Fe}_{0.2} \mathrm{Co}_{0.6} \mathrm{Ni}_{x}$-based HEAs were coated via APS by Wang et al. (Ref 33). The as-sprayed AlSiTi ${ }_{0.2}$ $\mathrm{Cr}_{1.5} \mathrm{Fe}_{0.2} \mathrm{Co}_{0.6} \mathrm{Ni}$ coating achieved a hardness of $450 \mathrm{HV}$, which was half of the as-cast material. Like the observation of Huang et al. (Ref 32) for their alloys, subjecting these coatings to heat treatment at $1100{ }^{\circ} \mathrm{C}$ for $10 \mathrm{~h}$ led to a hardness increase to $964 \mathrm{HV}$, which was attributed to nanoscale $\mathrm{Cr}_{3} \mathrm{Si}$ precipitation. Slight modifications of the above composition, $\mathrm{AlSiTi}_{0.2} \mathrm{CrFe}_{0.2} \mathrm{Co}_{0.6} \mathrm{Ni}$ and $\mathrm{AlSi}_{0.2-}$ $\mathrm{Ti}_{0.2} \mathrm{CrFe}_{0.2} \mathrm{Co}_{0.6} \mathrm{Ni}_{0.2}$, were also sprayed, but reported lower hardness values. This result illustrates the significance of individual element contributions to the alloy properties of HEAs.

Hsu et al. (Ref 39) also studied the thermal sprayed $\mathrm{AlSi}_{0.2} \mathrm{Ti}_{0.2} \mathrm{CrFe}_{0.2} \mathrm{Co}_{0.6} \mathrm{Ni}_{0.2}$ HEA overlay coating as a potential alternative to traditional MCrAlY bond coats. The HEA composition was selected due to its excellent properties achieved with cast samples in earlier research work. The AM-MM AlSi ${ }_{0.2} \mathrm{Ti}_{0.2} \mathrm{CrFe}_{0.2} \mathrm{Co}_{0.6} \mathrm{Ni}_{0.2}$ HEA coatings were generated by APS and HVOF on Incoloy $800 \mathrm{H}$ (a Ni$\mathrm{Cr}$-Fe-based alloy) substrate. Comparable values of 450 and $429 \mathrm{HV}$ were obtained for the as-sprayed HVOF and APS coatings, respectively. A nearly twofold increase was noted in both coatings after annealing at 800 and $1100{ }^{\circ} \mathrm{C}$ for $250 \mathrm{~h}$. These values are much higher than those observed for CoNiCrAlY-based coatings, which imply better wear resistance for the HEA coatings.

Another study (Ref 34) explored HEAs as alternatives to bond coats; MA $\mathrm{AlCrFeCoNi}$ and $\mathrm{CrMnFeCoNi}$ HEAs 


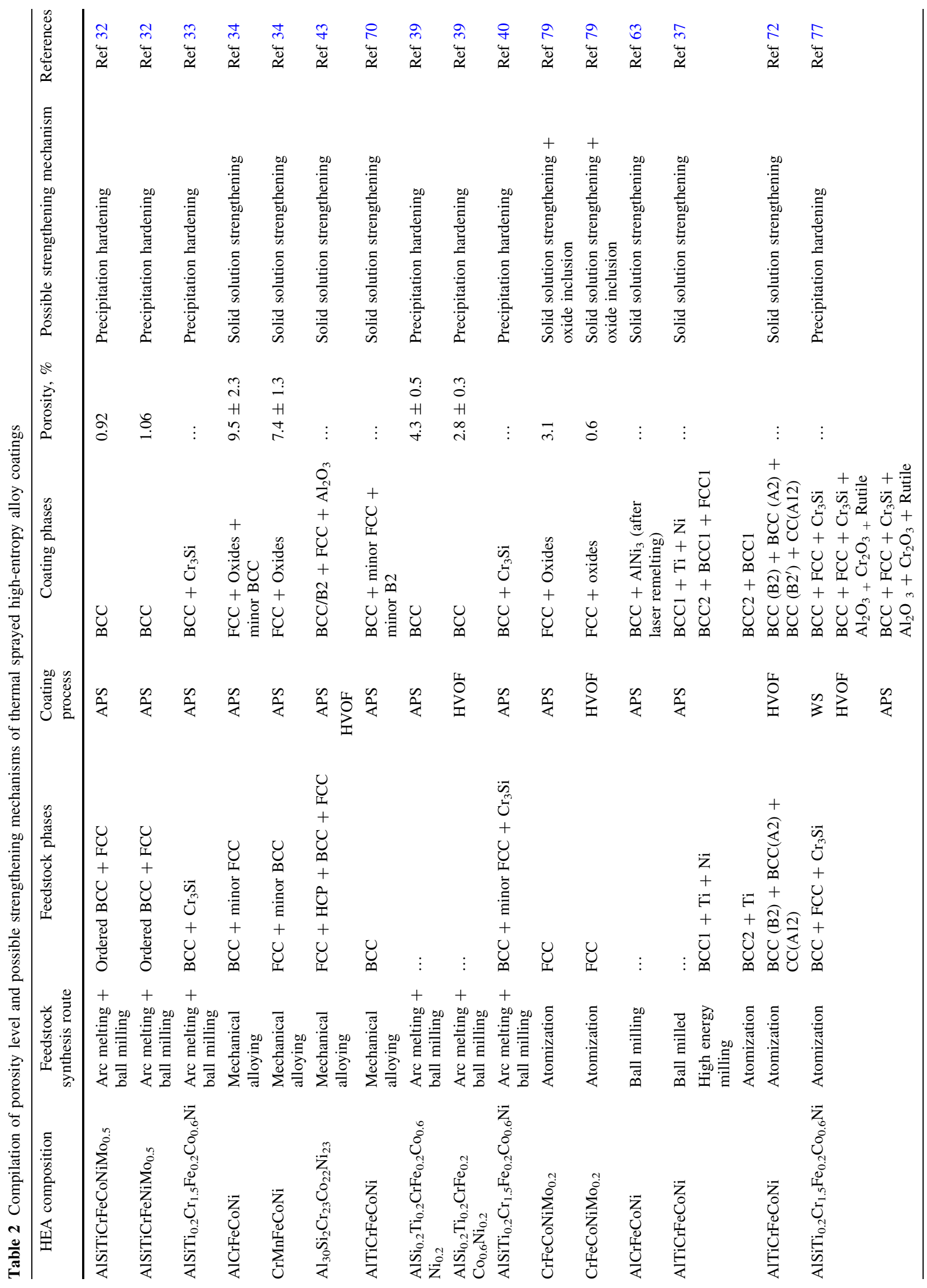




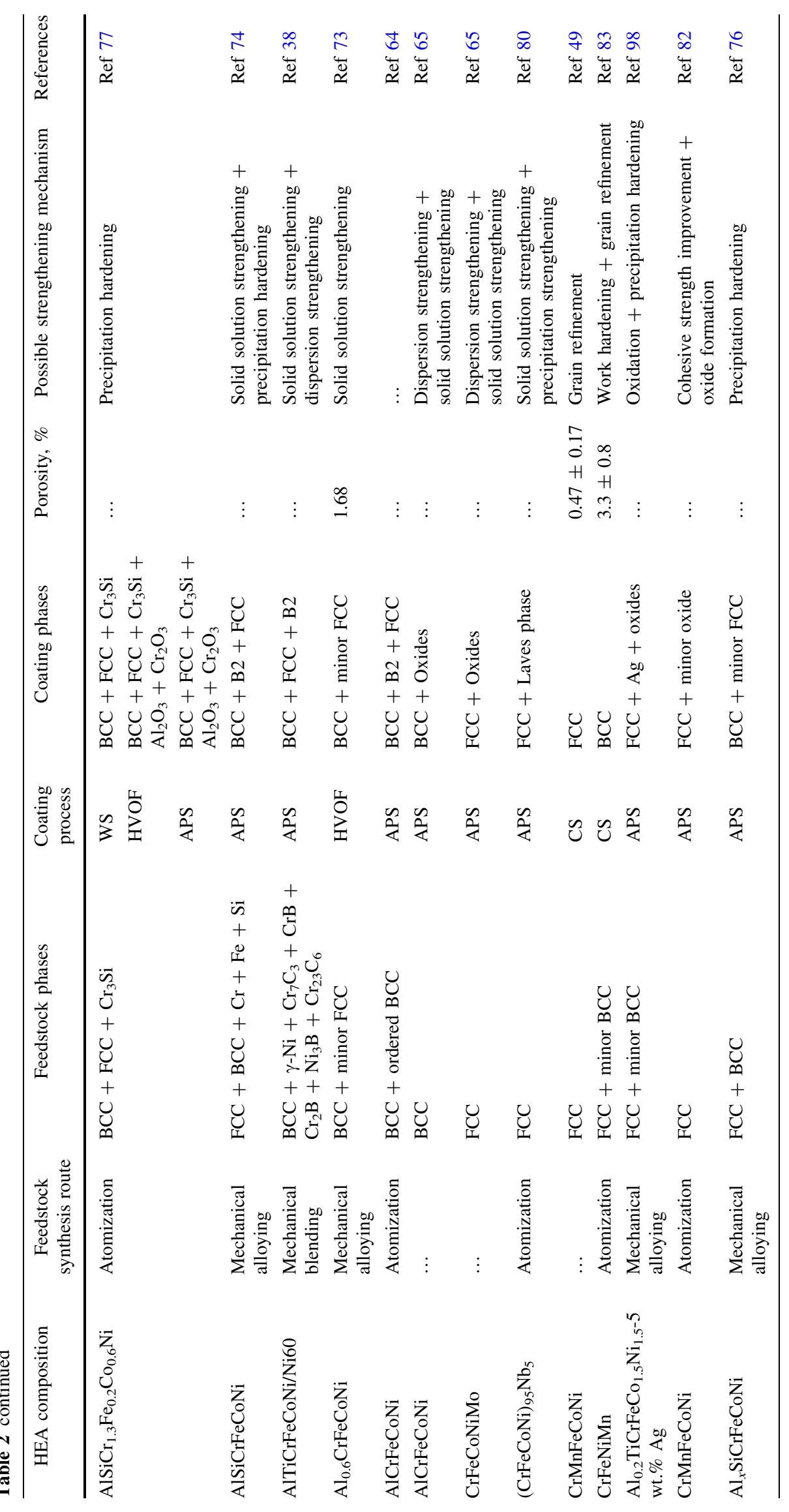


Fig. 14 Hardness comparison of thermal sprayed high-entropy alloy coatings. WS warm spray, $C S$ cold spray, HVOF highvelocity oxygen fuel spray, $A P S$ atmospheric plasma spray

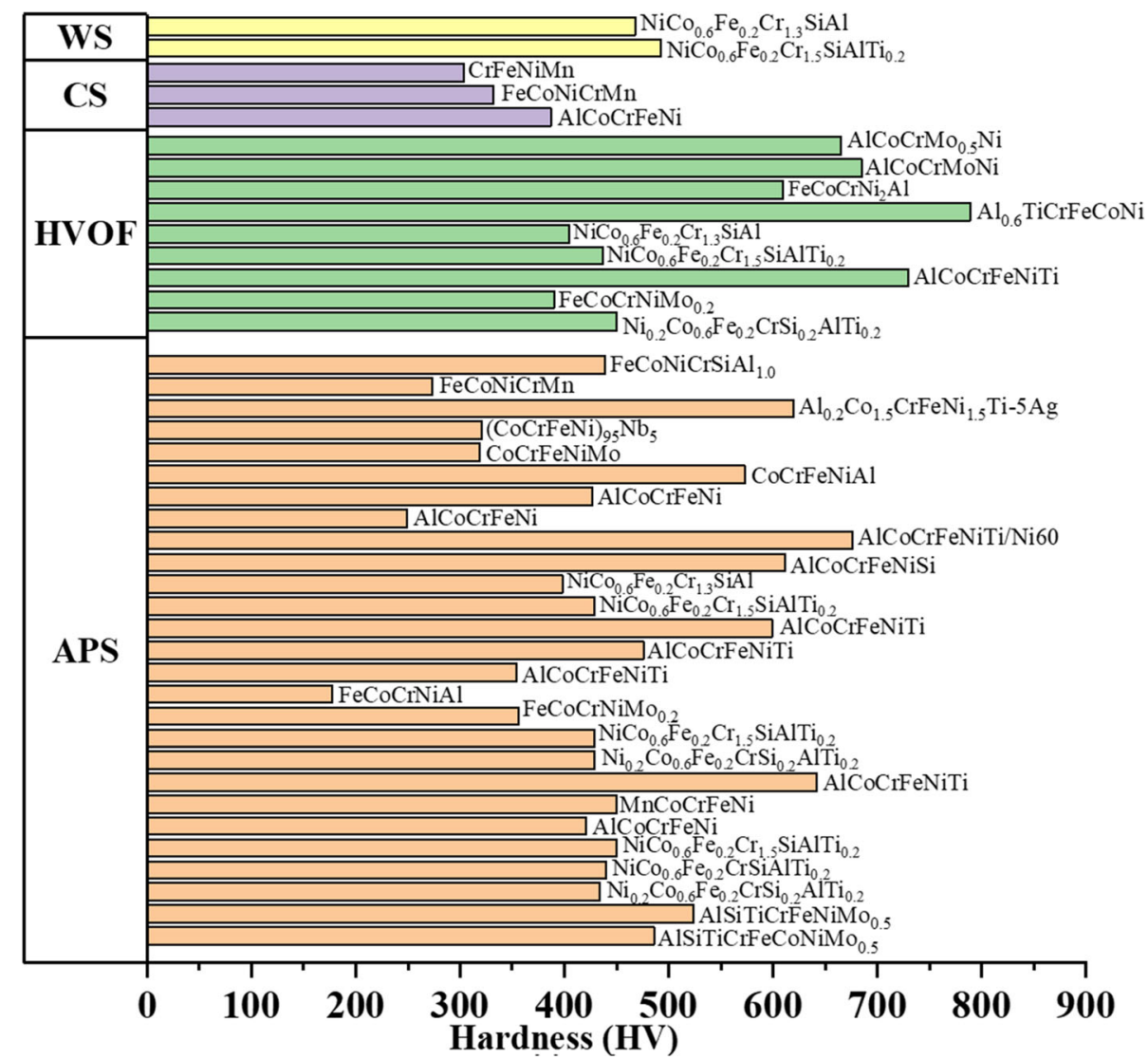

were coated onto a mild steel substrate via APS. Vickers hardness values $\left(\mathrm{HV} 0.3_{\mathrm{kgf}}\right)$ of $4.13 \mathrm{GPa}(421 \mathrm{HV})^{2}$ and $4.42 \mathrm{GPa}(451 \mathrm{HV})$ were reported for $\mathrm{AlCrFeCoNi}$ and $\mathrm{CrMnFeCoNi}$, respectively. On the other hand, the conventional bond coat materials exhibited a hardness of $2.45 \mathrm{GPa}(250 \mathrm{HV})$. The higher hardness of plasma sprayed HEA coatings was attributed to the formation of multicomponent BCC and FCC solid solutions and oxide phases. The lamellar, composite microstructure is responsible for the anisotropic mechanical behavior in these HEA coatings. High values of Weibull modulus $\left(m_{\mathrm{AlCrFeCoNi}}=\right.$ 12.24 and $\left.m_{\mathrm{CrMnFeCoNi}}=10.30\right)$ indicate that microstructural flaws were not concentrated within the coatings.

AlCrFeCoNi APS coatings were also fabricated by Cheng et al. (Ref 64) using atomized feedstock. The average coating hardness was higher when a coarse cut (60-90 $\mu \mathrm{m})$ was used as feedstock in comparison with the fine cut $(10-60 \mu \mathrm{m})$, peaking at $427.9 \mathrm{HV}_{0.3}$. For the same composition coated via cold spray, slight lower hardness values (measured at load of $25 \mathrm{gf}$ ), $3.8 \mathrm{GPa}(388 \mathrm{HV})$, were reported (Ref 46). The hardness variation between APS and CS coatings may be attributed to the additional reinforcement of alloy phases $(\mathrm{FCC}+$ minor $\mathrm{BCC})$ with

\footnotetext{
${ }^{2}$ Note that all GPa-to-HV conversions have been carried out by the authors so that these data are presented with consistency.
}

harder oxide phases in the APS coatings, which is absent in cold spray, i.e., the cold spray coating reveals only BCC phase and no oxides.

Nanoindentation studies of plasma sprayed $\mathrm{AlCrFeCoNi}$ HEA coatings indicated that the presence of oxides and mixed oxides within the coating microstructure significantly enhances the coating's hardness (Ref 66). With a slight modification in the nickel HEA chemistry, Srivastava et al. (Ref 47) sprayed $\mathrm{AlCrFeCoNi}$ through the $\mathrm{HVOF}$ process and attained an average coating microhardness of $610 \pm 30$ VHN measured under loads from $100 \mathrm{gf}$ to $1.0 \mathrm{kgf}$. A crack-free indentation profile was observed with increasing load, thus suggesting a high fracture toughness for this HEA coating.

As mentioned previously, addition of titanium to cast AlCrFeCoNi-based HEA systems increased the hardness and wear resistance of the alloys (Ref 69). This has prompted investigation of AlTiCrFeCoNi-based HEAs employing TS techniques (Ref 37, 38, 70, 72, 73). Tian et al. (Ref 70) fabricated equi-atomic AlTiCrFeCoNi APS coatings using mechanically alloyed feedstock with an average microhardness of $642 \mathrm{HV}_{0.2}$. This value was higher than that for the spark plasma-sintered alloy, which has been attributed to an integrated outcome of lattice distortion of the dominant BCC phase caused by larger 
aluminum and titanium atoms, and the formation of hard oxides within coating. In another study on $\mathrm{AlTiCrFeCoNi}$ by Lobel et al. (Ref 37), feedstock was synthesized separately by powder blending, high-energy milling, and inert gas atomization (GA), and sprayed onto steel substrates by APS. The homogeneous coating using GA feedstock exhibited the highest hardness of $599 \mathrm{HV}_{0.1}$ in comparison with APS coatings of the same composition manufactured using MA $\left(476 \mathrm{HV}_{0.1}\right)$ or blended feedstock $\left(354 \mathrm{HV}_{0.1}\right)$.

Tian et al. (Ref 38) blended MA AlTiCrFeCoNi feedstock with atomized Ni60 alloy, followed by APS, to improve hardness and wear resistance. The Ni60 reinforcement increased the hardness from $642 \mathrm{HV}_{0.2}$ (Ref 70) to $676 \mathrm{HV}_{0.2}$ due to a combined effect of solution hardening and dispersion hardening. Moreover, a much higher microhardness of $730 \pm 82 \mathrm{HV}_{0.1}$ (Ref 72) was achieved for atomized AlTiCrFeCoNi HVOF coatings when compared against their APS coating counterparts (Ref 37). Likewise, the microhardness (measured with a load of $0.982 \mathrm{~N}$ ) of the GA-HVOF $\mathrm{Al}_{0.6} \mathrm{TiCrFeCoNi} \mathrm{HEA}$ with a lower aluminum content was found to be $789 \pm 54 \mathrm{HV}_{0.1}$ (Ref 73).

Li et al. (Ref 98) synthesized the $\mathrm{Al}_{0.2} \mathrm{TiCrFeCo}_{1.5} \mathrm{Ni}_{1.5^{-}}$ 5 wt.\% Ag-based HEA composite coating through an APS process, wherein powders were mechanically blended before spraying. Cross-sectional hardness (measured with a $2 \mathrm{~N}$ load held for $10 \mathrm{~s}$ ) of the composite coating was $620 \mathrm{HV}$, which further augmented to $740 \mathrm{HV}$ post-treatment in air for $1 \mathrm{~h}$ at $750{ }^{\circ} \mathrm{C}$. A combination of oxidation and precipitation hardening was responsible for the hardness enhancement. Overall, HVOF-sprayed AlTiCrFeCoNi-based HEA performed better than APS-sprayed HEAs in terms of coating hardness.

On the other hand, addition of Si to AlCrFeCoNi by MA produced APS coatings with an average hardness of $612 \pm 41 \mathrm{HV}_{0.2}$ (Ref 74). Xiao et al. (Ref 76) studied the $\mathrm{Al}_{x} \mathrm{SiCrFeCoNi} \mathrm{HEA}$ APS coatings with varying aluminum content of $0.5,1.0$, and 1.5 molar ratios. The AlSiCrFeCoNi achieved the highest hardness of $439 \pm 63 \mathrm{HV}_{0.2}$ among the three coatings due to the presence of a major BCC phase with a minor FCC phase. Moreover, the hardness increased to $666 \pm 55 \mathrm{HV}_{0.2}$ after heat treatment at $800{ }^{\circ} \mathrm{C}$ for $2 \mathrm{~h}$ in nitrogen atmosphere. The increase in hardness was attributed to development of additional $\mathrm{Cr}_{3} \mathrm{Ni}_{5} \mathrm{Si}_{2}$ intermetallic phase along with a major BCC phase.

Hsu et al. (Ref 77) systematically compared APS-, HVOF-, and WS-sprayed AlSiTi ${ }_{0.2} \mathrm{Cr}_{1.5} \mathrm{Fe}_{0.2} \mathrm{Co}_{0.6} \mathrm{Ni}$ and AlSiCr ${ }_{1.3} \mathrm{Fe}_{0.2} \mathrm{Co}_{0.6} \mathrm{Ni}$ HEA coatings. The WS coatings of both HEAs achieved higher hardness (470-490 HV) in the as-sprayed state, than both APS and HVOF coatings (400$440 \mathrm{HV})$. The high hardness in WS coatings was attributed to its dense structure and the degree of $\mathrm{Cr}_{3} \mathrm{Si}$ precipitation compared to the supersaturated solid solutions for the other two spray processes. However, heat treatment at $800{ }^{\circ} \mathrm{C}$ for $10 \mathrm{~h}$ allowed $\mathrm{Cr}_{3} \mathrm{Si}$ precipitation to occur in the APS and HVOF coatings, thereby increasing their hardness over that of the warm-sprayed coating.

The HEAs that contain the quaternary metals of $\mathrm{CrFe}$ CoNi in the bulk state exist as an FCC solid solution and possess a superior combination of corrosion resistance, thermal stability, high ductility, and fracture toughness. Thus, it is considered as a high-performance coating material and has been widely investigated as feedstock for different TS processes.

In a report published by Lin et al. (Ref 63), MA AlCrFeCoNi HEA coatings were fabricated by supersonic APS and the influence of post-treatment on the structure and properties was investigated. The post-coating treatment included vacuum heat treatment at 600 and $900{ }^{\circ} \mathrm{C}$ for $10 \mathrm{~h}$ and then laser remelting at a power of $300 \mathrm{~W}$. The average hardness (measured with a $1.96 \mathrm{~N}$ load and $10 \mathrm{~s}$ of dwell time) of the as-spayed coating was $177 \mathrm{HV}_{0.2}$, which increased to 227 and $266 \mathrm{HV}_{0.2}$ post-vacuum heat-treated at 600 and $900{ }^{\circ} \mathrm{C}$, respectively. Laser remelting of the assprayed $\mathrm{AlCrFeCoNi}$ coating enhanced the hardness significantly from 177 to $682 \mathrm{HV}_{0.2}$, owing to the existence of a single-phase solid solution and $\mathrm{AlNi}_{3}$ phase in the coating. In addition, hardness values were relatively stable throughout the coating surface. Mu et al. (Ref 65) examined APS AlCrCoFeNi reinforced with nano-oxides that improved the coating hardness to $573 \pm 19 \mathrm{HV}_{0.1}$, notably higher than the as-sprayed value of $177 \mathrm{HV}_{0.2}$ reported by Lin et al. (Ref 63).

$\mathrm{Li}$ et al. (Ref 79) investigated $\mathrm{CrFeCoNiMo}_{0.2}$-based HEA coatings generated by APS and HVOF. An average microhardness of 356 and $390 \mathrm{HV}_{0.2}$ was observed for the APS and HVOF coatings, respectively. The homogenous microstructure with low oxide and defects content in the HVOF coating was responsible for their higher microhardness, although it should be noted that the statistical error in these measurements is unknown and variations of \pm 15 hardness units are typical. In contrast, APS coatings of CrFeCoNiMo HEA doped with nano-oxides achieved a hardness of $319 \pm 10 \mathrm{HV}_{0.1}$, as reported by Mu et al. (Ref 65). In both the cases, the hardness of these HEA coatings was higher compared to $\mathrm{CrFeCoNiMo}_{0.3}$ bulk alloys (210 HV) as reported by Shun et al. (Ref 99). Vallimanalan et al. (Ref 67, 68) substituted molybdenum for the iron and investigated $\mathrm{AlCrCoNiMo-}$ and $\mathrm{AlCrCoNiMo}_{0.5}$-based HEA coatings. The HVOF coatings exhibited hardness values of 685 and 665 VHN, respectively.

Wang et al. (Ref 80) synthesized GA-APS $(\mathrm{CrFeCoNi})_{95} \mathrm{Nb}_{5}$ coatings on Q235 steel substrate (Chinese specification: $\mathrm{C}=0.22, \mathrm{Si}=0.35, \mathrm{Mn}=1.40$, $\mathrm{P}=0.045, \mathrm{~S}=0.050, \mathrm{Fe}=$ bal.; all in wt.\%). The 
Fig. 15 Hardness comparison of laser-cladded coatings with respect to high-entropy alloy composition

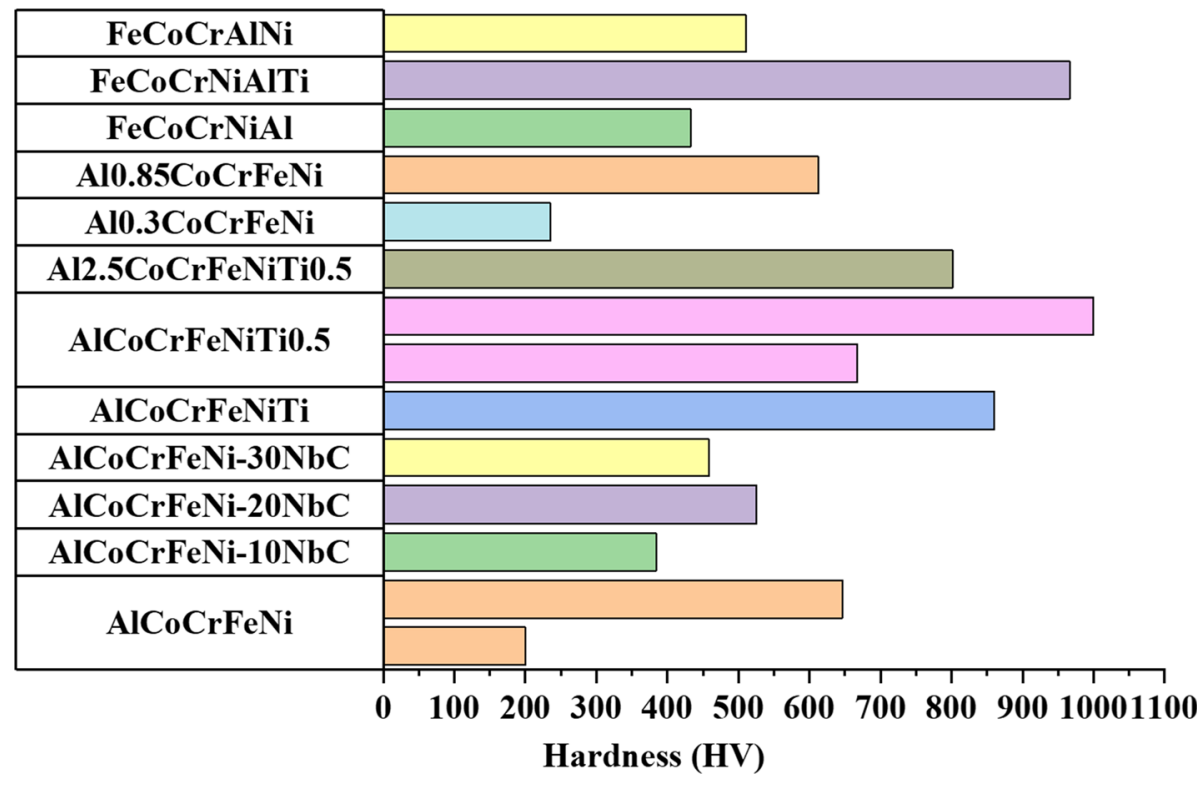

hardness of the HEA coating ranged between 310 and $325 \mathrm{HV}_{0.5}$. The increase in hardness was attributed to lattice strains from size mismatch between $\mathrm{Nb}(145 \mathrm{pm})$ with Co (135 pm), Cr (140 pm), Fe (140 pm), and Ni (135 pm), resulting in solution strengthening, and also to strengthening from ordered Laves phase precipitation in the coating. More importantly, an approximately $500-\mu \mathrm{m}$-thick coating exhibited only slight variation in hardness throughout the coating entire microstructure, thus emphasizing the stability and uniformity of the HEA coating. Cold-sprayed CrMnFeCoNi reported by Yin et al. (Ref 49) credited an increase in dislocation density and number of grain boundaries for the observed microhardness values of $332.91 \pm 34.74 \mathrm{HV}_{0.1}$. However, a similar HEA system sprayed using APS attained microhardness value of $273 \pm 35 \mathrm{HV}_{0.2}$, which increased marginally to $332 \pm 43 \mathrm{HV}_{0.2}$ after annealing at $800{ }^{\circ} \mathrm{C}$ for $2 \mathrm{~h}$ in an argon atmosphere. Note that large and overlapping statistical scatter of these data is typical of coatings formed by APS. Post-annealing, an increase in cohesive strength among splats and the oxides content were stated as the major factors responsible for the microhardness (Ref 82) increase. Cold-sprayed Co-free equiatomic $\mathrm{CrMnFeNi}$ sprayed at different powder feed rates and gas feed pressures exhibited a peak hardness of $304 \pm 10 \mathrm{HV}_{0.3}$ under a low feed rate $(1 \mathrm{rpm})$ and high gas feed pressure (60 bar). The overall increase in hardness was observed due to work hardening from the high particle deformation characteristics of cold spraying (Ref 83).

As stated in earlier sections, laser cladding (LC) has been widely used to develop thick HEA coatings. Figure 15 shows the hardness data of pertinent laser clad HEA coatings. A comparison between the mechanical properties of TS and LC coatings in terms of hardness (see Fig. 14 and 15) revealed both techniques to be complementary. For example, Zhang et al. (Ref 91) synthesized AlCrFeCoNibased HEA coatings using laser surface alloying that achieved a microhardness of around $5 \mathrm{GPa}(510 \mathrm{HV})$, which has been attributed to solid solution strengthening and lattice distortion. Similarly, He et al. (Ref 50), Li et al. (Ref 92), and Liu et al. (Ref 95) reported average hardnessess of $432.73 \mathrm{HV}_{0.2}, 646 \mathrm{HV}_{0.3}$, and $200 \mathrm{HV}_{0.2}$ for $\mathrm{LC}$ $\mathrm{AlCrFeCoNi-based} \mathrm{HEA} \mathrm{coatings.} \mathrm{These} \mathrm{values} \mathrm{are} \mathrm{com-}$ parable to the $\mathrm{TS} \mathrm{AlCrFeCoNi}$ coatings summarized in Fig. 14. The observed increase in LC coating hardness has been achieved either by the addition of another element or by the dispersion of different hard phases. For example, the addition of $\mathrm{Ti}$ to the $\mathrm{AlCrFeCoNi}$ (Ref 50, 93-95), or reinforcement with ceramic $\mathrm{NbC}$ or $\mathrm{TiC}$ particles (Ref 92, 95), improved significantly the hardness of LC coatings. The improvement in hardness for both coatings is attributable to solid solution strengthening and precipitation hardening.

In summary: Among all TS processes used to fabricate HEA coatings, HEAs sprayed with HVOF achieved the highest average hardness: $789 \pm 54 \mathrm{HV}_{0.1}$, in the case of atomized $\mathrm{Al}_{0.6} \mathrm{TiCrFeCoNi}$ HEA feedstock, as depicted in Fig. 14. Numerous reports on the mechanical behavior of bulk HEAs attribute their outstanding properties to strains arising from 'lattice distortion,' one of the four core effects thought to govern the behavior of HEAs. However, recent reports have found that the strains arising from the 'mismatched' lattice are not significantly different from those experienced by traditional solid solution alloys (Ref 35 ). Thus, it is more appropriate to attribute the observed high hardness and strength values to supersaturated solid 
solution strengthening, precipitation hardening, and other mechanisms induced by the processing technique. Table 2 summarizes the hardness and the possible strengthening mechanisms operating in TS-HEA coatings. Both properties are observed to depend strongly on the processing route of the feedstock, HEA composition, and TS route.

High-temperature TS processes invariably result in supersaturated solid solutions, while intermediate cooling rates and/or process temperatures allow fine second-phase precipitation to occur. Low-temperature TS processes on the other hand rely on substantial plastic deformation of particles, resulting in grain refinement, to improve the mechanical properties of coatings. There is further latitude for tuning these properties by post-coating thermal treatments. Combining these process tools with the extensive scope of applying physical metallurgy concepts to the HEA materials hyperspace, such as tuning the microstructure to allow strain hardening to occur due to load-induced phase transformations, e.g., TWIP/TRIP effects, opens technological potential for the future of TS-HEA coatings.

\section{Tribological Assessment}

TS-HEAs have demonstrated microstructural stability and high hardness; thus, they are promising candidates for extreme environment applications. This section discusses the tribological behavior observed across TS-HEA coatings, some of which is summarized in Table 3.

Huang et al. (Ref 32) fabricated APS $\mathrm{AlSiTiCrFeCoNiMo}_{0.5}$ and $\mathrm{AlSiTiCrFeNiMo}_{0.5}$ coatings where the wear resistance was analyzed using pin-on-disk apparatus and the coating was abraded against an $\mathrm{Al}_{2} \mathrm{O}_{3}$ belt at a load of $1 \mathrm{~kg}$ for $20 \mathrm{~m}$. Both coatings exhibited similar wear resistance in the as-sprayed state to SUJ2 bearing steel $(\mathrm{C}=0.95-1.10, \mathrm{Cr}=1.30-1.60, \mathrm{Si}=0.15$ $0.35, \mathrm{Mn}=0.05 \max , \mathrm{P} \leq 0.025, \mathrm{~S} \leq 0.025, \mathrm{Fe}=$ bal.; all in wt.\%). However, after aging the coatings at $800{ }^{\circ} \mathrm{C}$, the volume wear rate of the coatings reached $18 \mathrm{~m} / \mathrm{mm}^{3}$, higher than those for both SUJ2 bearing steel and SKD61 hot-die tool steel $(\mathrm{C}=0.35-0.42, \quad \mathrm{Cr}=4.80-5.50$, $\mathrm{V}=0.80-1.15, \mathrm{Mo}=1.0-1.5, \mathrm{Si}=0.80-1.2, \mathrm{Mn}=0.25-$ $0.50, \mathrm{P} \leq 0.03, \mathrm{~S} \leq 0.020, \mathrm{Fe}=$ bal.; all in wt.\%).

Tribological assessment of APS AlTiCrFeCoNi coating was conducted by Tian et al. (Ref 70) at 25, 500, 700 and $900{ }^{\circ} \mathrm{C}$ against $\mathrm{Si}_{3} \mathrm{~N}_{4}$ balls at a load of $5 \mathrm{~N}$ for a duration of $20 \mathrm{~min}$. Tests at room temperature resulted in a volume wear rate of $0.77 \pm 0.01 \times 10^{-4} \mathrm{~mm}^{3} / \mathrm{N}-\mathrm{m}$, much lower than 316 stainless steel $\left(2.55 \pm 0.31 \times 10^{-4} \mathrm{~mm}^{3} / \mathrm{N}-\mathrm{m}\right)$. On the other hand, at $500{ }^{\circ} \mathrm{C}$, the volume wear rate increased to $0.93 \pm 0.02 \times 10^{-4} \mathrm{~mm}^{3} / \mathrm{N}-\mathrm{m}$ due to a hardness decrease and operation of a more severe adhesive wear mechanism than at room temperature. Major adhesive

Table 3 Room-temperature wear resistance or volume wear rate of thermal sprayed high-entropy alloy coatings

\begin{tabular}{|c|c|c|c|c|c|c|c|}
\hline High-entropy alloys (HEAs) & $\begin{array}{c}\text { Thermal } \\
\text { spray } \\
\text { process }\end{array}$ & $\begin{array}{l}\text { Abrasion } \\
\text { media }\end{array}$ & $\begin{array}{l}\text { Applied } \\
\text { load }\end{array}$ & $\begin{array}{l}\text { Wear } \\
\text { speed }\end{array}$ & $\begin{array}{c}\text { Wear } \\
\text { distance/time }\end{array}$ & $\begin{array}{c}\text { Wear resistance or volume } \\
\text { wear rate }\end{array}$ & References \\
\hline $\mathrm{AlSiTiCrFeCoNiMo}_{0.5}$ & APS & $\mathrm{Al}_{2} \mathrm{O}_{3}$ & $1 \mathrm{~kg}$ & $0.5 \mathrm{~m} / \mathrm{s}$ & $20 \mathrm{~m}$ & $\sim 11 \mathrm{~m} / \mathrm{mm}^{3}$ & Ref 32 \\
\hline $\mathrm{AlSiTiCrFeNiMo}_{0.5}$ & APS & $\mathrm{Al}_{2} \mathrm{O}_{3}$ & $1 \mathrm{~kg}$ & $0.5 \mathrm{~m} / \mathrm{s}$ & $20 \mathrm{~m}$ & $\sim 12 \mathrm{~m} / \mathrm{mm}^{3}$ & Ref 32 \\
\hline $\mathrm{AlCoCrFeNiTi}$ & APS & $\mathrm{Si}_{3} \mathrm{~N}_{4}$ & $5 \mathrm{~N}$ & $573 \mathrm{rpm}$ & $20 \mathrm{~min}$ & $0.77 \pm 0.01 \times 10^{-4} \mathrm{~mm}^{3} / \mathrm{N}-\mathrm{m}$ & Ref 70 \\
\hline $\mathrm{Al}_{0.6} \mathrm{TiCrFeCoNi}$ & HVOF & $\mathrm{Al}_{2} \mathrm{O}_{3}$ & $5 \mathrm{~N}$ & $0.10 \mathrm{~m} / \mathrm{s}$ & $500 \mathrm{~m}$ & $1.044 \times 10^{-4} \mathrm{~mm}^{3} / \mathrm{N}-\mathrm{m}$ & Ref 73 \\
\hline $\mathrm{AlCoCrFeNiSi}$ & APS & $\mathrm{Si}_{3} \mathrm{~N}_{4}$ & $5 \mathrm{~N}$ & $573 \mathrm{rpm}$ & $30 \mathrm{~min}$ & $0.38 \pm 0.08 \times 10^{-4} \mathrm{~mm}^{3} / \mathrm{N}-\mathrm{m}$ & Ref 74 \\
\hline AlTiCrFeCoNi/Ni60 & APS & $\mathrm{Si}_{3} \mathrm{~N}_{4}$ & $5 \mathrm{~N}$ & $573 \mathrm{rpm}$ & $20 \mathrm{~min}$ & $0.55 \pm 0.06 \times 10^{-4} \mathrm{~mm}^{3} / \mathrm{N}-\mathrm{m}$ & Ref 38 \\
\hline $\mathrm{AlSi}_{0.2} \mathrm{Ti}_{0.2} \mathrm{CrFe}_{0.2} \mathrm{Co}_{0.6} \mathrm{Ni}_{0.2}$ & APS & $\mathrm{SiC}$ & $1 \mathrm{~kg}$ & $0.5 \mathrm{~m} / \mathrm{s}$ & $20 \mathrm{~m}$ & $21 \pm 3 \mathrm{~m} / \mathrm{mm}^{3}$ & Ref 39 \\
\hline $\mathrm{AlSi}_{0.2} \mathrm{Ti}_{0.2} \mathrm{CrFe}_{0.2} \mathrm{Co}_{0.6} \mathrm{Ni}_{0.2}$ & HVOF & $\mathrm{SiC}$ & $1 \mathrm{~kg}$ & $0.5 \mathrm{~m} / \mathrm{s}$ & $20 \mathrm{~m}$ & $20 \pm 2 \mathrm{~m} / \mathrm{mm}^{3}$ & Ref 39 \\
\hline $\mathrm{AlSiTi}_{0.2} \mathrm{Cr}_{1.5} \mathrm{Fe}_{0.2} \mathrm{Co}_{0.6} \mathrm{Ni}$ & APS & $\mathrm{SiC}$ & $1 \mathrm{~kg}$ & $0.5 \mathrm{~m} / \mathrm{s}$ & $20 \mathrm{~m}$ & $\sim 8.5 \mathrm{~m} / \mathrm{mm}^{3}$ & Ref 40 \\
\hline $\mathrm{CrFeCoNiMo}_{0.2}$ & APS & GCr15 & $10 \mathrm{~N}$ & $50 \mathrm{~mm} / \mathrm{s}$ & $\ldots$ & $0.39 \times 10^{-4} \mathrm{~mm}^{3} / \mathrm{N}-\mathrm{m}$ & Ref 79 \\
\hline $\mathrm{CrFeCoNiMo}_{0.2}$ & HVOF & GCr15 & $10 \mathrm{~N}$ & $50 \mathrm{~mm} / \mathrm{s}$ & $\ldots$ & $4.8 \times 10^{-4} \mathrm{~mm}^{3} / \mathrm{N}-\mathrm{m}$ & Ref 79 \\
\hline $\mathrm{CrMnFeCoNi}$ & $\mathrm{CS}$ & WC-Co & $5 \mathrm{~N}$ & $100 \mathrm{~mm} / \mathrm{s}$ & $200 \mathrm{~m}$ & $4.76 \pm 0.22 \times 10^{-4} \mathrm{~mm}^{3} / \mathrm{N}-\mathrm{m}$ & $\operatorname{Ref} 49$ \\
\hline $\begin{array}{l}\mathrm{Al}_{0.2} \mathrm{TiCrFeCo}_{1.5} \mathrm{Ni}_{1.5^{-}} \\
5 \text { wt.\% Ag }\end{array}$ & APS & $\mathrm{Si}_{3} \mathrm{~N}_{4}$ & $5 \mathrm{~N}$ & $300 \mathrm{rpm}$ & $60 \mathrm{~min}$ & $0.80 \times 10^{-5} \mathrm{~mm}^{3} / \mathrm{N}-\mathrm{m}$ & Ref 98 \\
\hline $\mathrm{Al}_{0.2} \mathrm{TiCrFeCo}_{1.5} \mathrm{Ni}_{1.5}$ & APS & $\mathrm{Si}_{3} \mathrm{~N}_{4}$ & $5 \mathrm{~N}$ & $300 \mathrm{rpm}$ & $60 \mathrm{~min}$ & $4 \times 10^{-5} \mathrm{~mm}^{3} / \mathrm{N}-\mathrm{m}$ & Ref 98 \\
\hline $\mathrm{Al}_{0.5} \mathrm{SiCrFeCoNi}$ & APS & WC-12Co & $20 \mathrm{~N}$ & $40 \mathrm{~mm} / \mathrm{s}$ & $100 \mathrm{~m}$ & $5.5 \times 10^{-5} \mathrm{~mm}^{3} / \mathrm{N}-\mathrm{m}$ & Ref 76 \\
\hline $\mathrm{Al}_{1.0} \mathrm{SiCrFeCoNi}$ & APS & WC-12Co & $20 \mathrm{~N}$ & $40 \mathrm{~mm} / \mathrm{s}$ & $100 \mathrm{~m}$ & $4.3 \times 10^{-5} \mathrm{~mm}^{3} / \mathrm{N}-\mathrm{m}$ & Ref 76 \\
\hline $\mathrm{Al}_{1.5} \mathrm{SiCrFeCoNi}$ & APS & WC-12Co & $20 \mathrm{~N}$ & $40 \mathrm{~mm} / \mathrm{s}$ & $100 \mathrm{~m}$ & $3 \times 10^{-5} \mathrm{~mm}^{3} / \mathrm{N}-\mathrm{m}$ & Ref 76 \\
\hline $\mathrm{CrMnFeCoNi}$ & APS & WC-Co & $20 \mathrm{~N}$ & $\ldots$ & $100 \mathrm{~m}$ & $2.7 \times 10^{-4} \mathrm{~mm}^{3} / \mathrm{N}-\mathrm{m}$ & Ref 82 \\
\hline
\end{tabular}


wear with minor abrasive wear were indicated as the prevalent mechanisms from the wear surface morphology. Also, the wear surface was observed to have oxidized slightly at $500{ }^{\circ} \mathrm{C}$ compared to that at $25{ }^{\circ} \mathrm{C}$. Wear volume rate at $700{ }^{\circ} \mathrm{C}$ was measured as $0.23 \pm 0.02 \times 10^{-4} \mathrm{~mm}^{3} /$ $\mathrm{N}-\mathrm{m}$, which increased further at $900{ }^{\circ} \mathrm{C}$. The wear mechanisms at both temperatures were tribo-oxidation wear and abrasion wear. In summary, APS AlTiCrFeCoNi HEA coating exhibited excellent wear resistance at $700{ }^{\circ} \mathrm{C}$ compared to stainless steel due to the development of tribofilms and the formation of a hard and brittle $\sigma-\mathrm{CrFe}$ precipitate phase during high-temperature wear testing.

Lobel et al. (Ref 37) sprayed blended, MA- and GAbased equi-atomic AlTiCrFeCoNi feedstock onto steel substrates via APS, and analyzed the wear performance of the coatings using three methods: ball-on-disk test, oscillating wear test, and scratch test. Coatings obtained using atomized feedstock exhibited the highest wear resistance in both the ball-on-disk and oscillating wear tests owing to the homogenous microstructure and higher hardness of GAAPS coatings. In contrast, the coating deposited using MA powder performed better in scratch testing compared to blended and atomized powder. Lobel et al. (Ref 72) also generated HVOF AlTiCrFeCoNi coatings and conducted wear tests as stated above and compared them against hard chrome-plated samples. The HVOF coating outperformed the hard chrome-plated sample as well the previously coated GA-APS AlCrFeCoNi coatings (Ref 37). Additionally, the HVOF coating did not show any brittle failure during scratch testing, unlike the APS coating of the same alloy (Ref 37).

Chen et al. (Ref 73) studied fracture toughness and wear performance of GA-HVOF $\mathrm{Al}_{0.6} \mathrm{TiCrFeCoNi}$. The wear behavior of the coating was examined using a pin-on-disk tribometer at room temperature (RT), 300 and $500{ }^{\circ} \mathrm{C}$. The measured wear rates were $1.044 \times 10^{-4}, 2.757 \times 10^{-4}$, and $2.674 \times 10^{-4} \mathrm{~mm}^{3} / \mathrm{N}-\mathrm{m}$ at RT, 300 , and $500{ }^{\circ} \mathrm{C}$, respectively. Morphological analysis of wear tracks depicted that both abrasion and fatigue wear contributed to coating wear. However, severity of both wear mechanisms increased with an increase in test temperature. Moreover, the difference between wear rates at 300 and $500{ }^{\circ} \mathrm{C}$ was not significantly high due to the formation of an oxide layer on the wear track at $500{ }^{\circ} \mathrm{C}$. XRD analysis revealed that no phase changes occurred after friction testing at different temperatures, and the coating exhibits the BCC phase, i.e., the same as in the as-sprayed state. The fracture toughness of the as-sprayed coating obtained was $8.4 \mathrm{MPa} \mathrm{m}^{1 / 2}$, which further decreased to $5 \mathrm{MPa} \mathrm{m}^{1 / 2}$ post-heat treatment at $800{ }^{\circ} \mathrm{C}$ due to the precipitation of $\sigma-\mathrm{CrFe}$ phase, signifying increased coating brittleness due to heat treatment.

Tian et al. (Ref 74) fabricated MA-APS AlSiCrFeCoNi HEA coatings and analyzed the wear performance of coating against $\mathrm{Si}_{3} \mathrm{~N}_{4}$ abrasion media. The coating exhibited a wear rate of $0.38 \pm 0.08 \times 10^{-4} \mathrm{~mm}^{3} / \mathrm{N}-\mathrm{m}$, which was better in comparison with previously analyzed APS AlTiCrFeCoNi coating $\left(0.77 \pm 0.01 \times 10^{-4} \mathrm{~mm}^{3} / \mathrm{N}-\mathrm{m}\right)$ (Ref 70) and conventional flame-sprayed NiCrBSi coating $\left(1.7 \times 10^{-4} \mathrm{~mm}^{3} / \mathrm{N}-\mathrm{m}\right)($ Ref 100$)$. Further analysis of wear tracks revealed that adhesive wear and tribo-oxidation wear as well as slight abrasion wear were active mechanisms. The superior wear performance of the AlSiCrFeCoNi coating may be attributed to the dense microstructure and the formation of hard tribofilms during the wear test.

Xiao et al. (Ref 76) investigated the tribological performance of $\mathrm{Al}_{x} \mathrm{SiCrFeCoNi}$ (where $x$ is $0.5,1.0$, and 1.5 as molar ratios) under both dry and water sliding conditions to simulate the operating environment of compressed air and water pipelines. The volume wear rate of as-sprayed coatings had a decreasing trend with an increase in aluminum content from 0.5 to 1.5 under dry sliding conditions. The wear rates obtained were $5.5 \times 10^{-5}$, $4.3 \times 10^{-5}$, and $3 \times 10^{-5} \mathrm{~mm}^{3} / \mathrm{N}-\mathrm{m}$ for $\mathrm{Al}_{0.5-}$, $\mathrm{SiCrFeCoNi}, \quad \mathrm{Al}_{1.0} \mathrm{SiCrFeCoNi}$, and $\mathrm{Al}_{1.5} \mathrm{SiCrFeCoNi}$, respectively, which were slightly higher than previously attained by Tian et al. (Ref 74). The wear rate decreases significantly to $6.7 \times 10^{-6} \mathrm{~mm}^{3} / \mathrm{N}-\mathrm{m}$ for the $\mathrm{Al}_{1.0}$ $\mathrm{SiCrFeCoNi}$ coating after heat treatment due to the formation of BCC and $\mathrm{Cr}_{3} \mathrm{Ni}_{5} \mathrm{Si}_{2}$ phases. SEM analysis of the wear surface displayed the formation of grooves, micropits due to spalling of splats, and micro-cracks at the interface of splats, which all suggest abrasive wear as the main wear mechanism. In contrast, the wear rate under water sliding conditions was lower than under dry sliding conditions due to lubricating as well as cooling effects promoted by the water media. However, the addition of aluminum to HEA and heat treatment had little influence on wear rate under these conditions as opposed to dry sliding conditions.

Tian et al. (Ref 38) studied the wear behavior of APS AlTiCrFeCoNi HEA coating reinforced with Ni60 (0.63 C, 2.97 B, 4.50 Si, 5.31 Fe, $16.20 \mathrm{Cr}$, Bal. Ni; all in wt.\%). The reinforced coating exhibited a lower volume wear rate in comparison with the AlTiCrFeCoNi coating ( $\mathrm{Ref} 70$ ), at both 25 and $500{ }^{\circ} \mathrm{C}$ testing conditions. Solution hardening in $\gamma-\mathrm{Ni}$ and dispersion strengthening of hard interstitial compounds were attributed to better wear behavior of this coating. The volume wear rates at 25 and $500{ }^{\circ} \mathrm{C}$ were $0.55 \pm 0.06 \times 10^{-4}$ and $0.66 \pm 0.02 \times 10^{-4} \mathrm{~mm}^{3} / \mathrm{N}-\mathrm{m}$, respectively. There was no indication whether there was any statistical difference in these measurements.

Li et al. (Ref 98) evaluated the tribological performance of an $\mathrm{Al}_{0.2} \mathrm{TiCrFeCo}_{1.5} \mathrm{Ni}_{1.5}-5$ wt.\%Ag-based HEA composite coating at temperatures ranging from 25 to $750{ }^{\circ} \mathrm{C}$ against $\mathrm{Si}_{3} \mathrm{~N}_{4}$ ball at a load of $5 \mathrm{~N}$. The HEA-Ag composite coating exhibited a lower friction coefficient than the HEA 
coating at $25-400{ }^{\circ} \mathrm{C}$ due to the lubrication effect of silver. However, at high temperature $\left(600\right.$ and $\left.750{ }^{\circ} \mathrm{C}\right)$, the silver lubrication effect seems negligible since the wear mechanism changes to adhesion and oxidative wear, leading to a further decrease in the friction coefficient for both coatings. The wear rates obtained for HEA-Ag and HEA coatings at $25^{\circ} \mathrm{C}$ were $0.8 \times 10^{-5}$ and $4 \times 10^{-5} \mathrm{~mm}^{3} / \mathrm{N}-\mathrm{m}$, and at $750{ }^{\circ} \mathrm{C}$ were $8.9 \times 10^{-6}$ and $3.3 \times 10^{-5} \mathrm{~mm}^{3} / \mathrm{N}-\mathrm{m}$, respectively, which were much lower than for both SKH51 $(\mathrm{C}=0.80-0.88, \quad \mathrm{Cr}=3.80-4.50, \quad \mathrm{~V}=1.70-2.10$, $\mathrm{Mo}=4.70-5.20, \quad \mathrm{~W}=5.90-6.70, \quad \mathrm{Si}=0.45 \quad \max$, $\mathrm{Mn}=0.40 \max , \mathrm{P} \leq 0.030, \mathrm{~S} \leq 0.030$, and $\mathrm{Fe}=$ bal; all in wt.\%) and Q125 $(\mathrm{C}=0.350, \mathrm{Cr}=1.50, \mathrm{Ni}=0.990$, $\mathrm{Mo}=0.850, \mathrm{Mn}=1.350, \mathrm{P} \leq 0.020, \mathrm{~S} \leq 0.010, \mathrm{Fe}=$ bal.; all in wt.\%) steels, predominantly at high temperature. The combinatorial effect of silver lubrication and oxide formation on the surface led to excellent tribological properties of these HEA coatings.

Hsu et al. (Ref 39) also studied the wear resistance of APS and HVOF $\mathrm{AlSi}_{0.2} \mathrm{Ti}_{0.2} \mathrm{CrFe}_{0.2} \mathrm{Co}_{0.6} \mathrm{Ni}_{0.2}$-based HEA coatings. Pin-on-disk wear tests were performed at a load of $1 \mathrm{~kg}$ for $20 \mathrm{~m}$. Wear resistance values obtained were $21 \pm 3$ and $20 \pm 2 \mathrm{~m} / \mathrm{mm}^{3}$ for APS and HVOF coatings, respectively, which were better than conventional bearing steel SUJ2 $\left(12 \mathrm{~m} / \mathrm{mm}^{3}\right)$. Precipitation of a hard and stable $\mathrm{Cr}_{3} \mathrm{Si}$ phase within the coating contributed to this enhanced wear resistance. Hsu et al. (Ref 40) also tested the wear resistance of APS $\mathrm{AlSiTi}_{0.2} \mathrm{Cr}_{1.5} \mathrm{Fe}_{0.2} \mathrm{Co}_{0.6} \mathrm{Ni}$ HEA under similar test conditions (Ref 39 ). The as-sprayed coating exhibited wear resistance of around $8.5 \mathrm{~mm} / \mathrm{mm}^{3}$, which increased to approximately $18 \mathrm{~mm} / \mathrm{mm}^{3}$ after annealing at $800{ }^{\circ} \mathrm{C}$. As in the previous study, precipitation of $\mathrm{Cr}_{3} \mathrm{Si}$ post-heat treatment was responsible for the increase in wear resistance.

The wear behavior of APS, HVOF, and WS AlSiTi $i_{0.2-}$ $\mathrm{Cr}_{1.5} \mathrm{Fe}_{0.2} \mathrm{Co}_{0.6} \mathrm{Ni}$ and $\mathrm{AlSiCr}{ }_{1.3} \mathrm{Fe}_{0.2} \mathrm{Co}_{0.6} \mathrm{Ni}$ HEA coatings synthesized by Hsu et al. (Ref 77) mirrored their hardness trends. In the as-sprayed condition, warm-sprayed AlSiTi ${ }_{0.2} \mathrm{Cr}_{1.5} \mathrm{Fe}_{0.2} \mathrm{Co}_{0.6} \mathrm{Ni}$ coatings outperformed both APS and HVOF coatings. Furthermore, the wear resistance of all the coatings increased significantly after aging due to the precipitation of $\mathrm{Cr}_{3} \mathrm{Si}$ phase within the coating.

As reported by Liu et al. (Ref 101), as-cast CrFeCoNiMo exhibited high strength without any embrittlement. $\mathrm{Li}$ et al. (Ref 79) explored this alloy system as $\mathrm{CrFeCoNiMo}_{0.2}$ APS and HVOF coatings. Tribological trials were executed with a reciprocating friction and wear tester against $\mathrm{GCr} 15$ balls $(\mathrm{C}=0.95-1.05, \mathrm{Si}=0.15-0.35$, $\mathrm{Mn}=0.25-0.45, \mathrm{Cr}=1.40-1.65, \mathrm{P} \leq 0.025, \mathrm{~S} \leq 0.025$, $\mathrm{Fe}=$ bal.; all in wt.\%) at a load of $10 \mathrm{~N}$. The average friction coefficient and volume wear rate were measured to be 0.75 and $3.9 \times 10^{-5} \mathrm{~mm}^{3} / \mathrm{N}-\mathrm{m}$ for APS coating and 0.84 and $4.8 \times 10^{-4} \mathrm{~mm}^{3} / \mathrm{N}-\mathrm{m}$ for HVOF coating. The superior wear resistance of APS coating was due to the lubrication effect created by the formation of an oxide layer during wear. The dominant wear mechanism for the HVOF coating was abrasive wear, and lower degree of oxide inclusions apparently reduced the self-lubrication effect, thereby lowering the wear resistance compared to the APS coating.

Xiao et al. (Ref 82) also studied the wear behavior of APS CrMnFeCoNi HEA coatings prepared with varying $\mathrm{H}_{2}$ flow rates. The wear rate was reported to be halved when the $\mathrm{H}_{2}$ flow rate was doubled during plasma spraying. The wear rates obtained were $5.3 \times 10^{-4}$ and $2.7 \times 10^{-4} \mathrm{~mm}^{3} / \mathrm{N}-\mathrm{m}$ for coatings developed using $\mathrm{H}_{2}$ flow rate 3 and $6 \mathrm{~L} / \mathrm{min}$, respectively. It was explained that an increase in secondary gas flow rate enhances the cohesive strength of splats, thus leading to a reduction in splats spalling during wear testing. The cross-sectional SEM analysis of the as-sprayed coating after wear testing revealed the formation of micro-cracks along the splat interfaces as well as spalling pits just below the surface.

Lin et al. (Ref 63) prepared an $\mathrm{AlCrFeCoNi}$ coating by a supersonic APS process. The coated samples were further vacuum-heat-treated and laser-remelted to enhance the coating quality. Wear analysis was carried out using a universal wear tester on abrasive media (D2 tool steel, also termed as 'Cr12MoV,' of composition $\mathrm{Fe}$ (bal.), $\mathrm{C}=1.4-$ $1.6, \mathrm{P} \leq 0.030, \mathrm{Si}=0.10-0.60, \mathrm{~S} \leq 0.030, \mathrm{Mn}=0.20$ $0.60, \mathrm{Cr}=11.0-13.0, \mathrm{~V}=0.50-1.1$; all in wt.\%) at a load of $100 \mathrm{~N}$. Mass loss statistics after wear testing

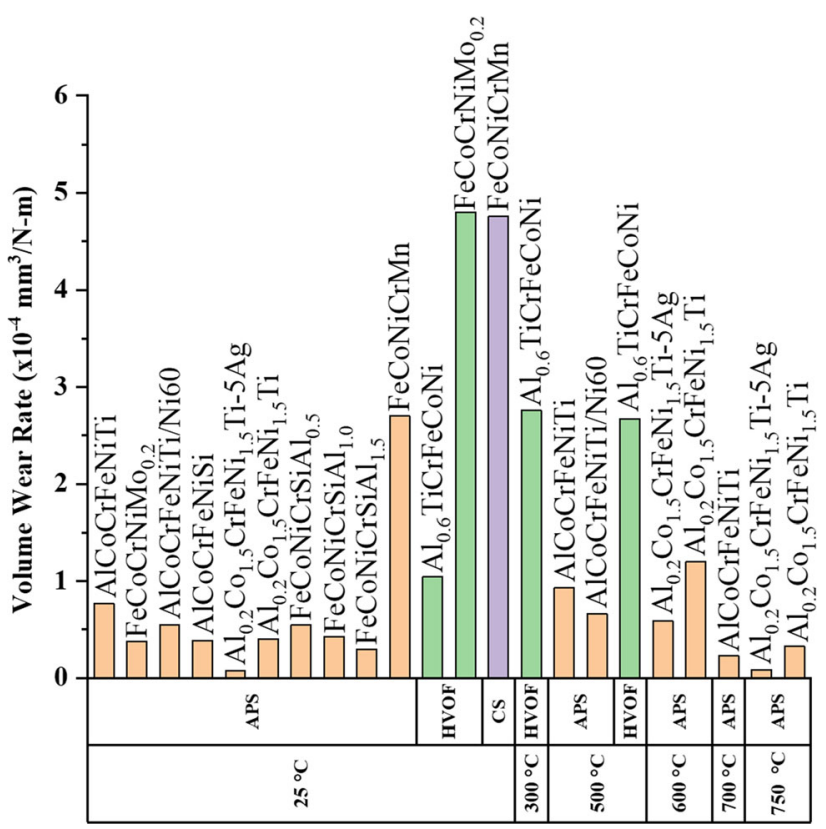

Fig. 16 Graphical analysis of volume wear rate for thermal sprayed high-entropy alloy coatings with respect to wear evaluation temperature 
demonstrated that the as-sprayed coating was the least wear resistant compared to vacuum-heat-treated and laserremelted coatings. Laser-remelted coatings performed better due to the formation of intermetallic compounds, which increased the coatings hardness considerably, thus decreasing the effect of abrasive wear. On the other hand, the as-sprayed coating consisted of supersaturated alloy phases with lower hardness.

$\mathrm{Mu}$ et al. (Ref 65) reinforced $\mathrm{AlCrFeCoNi}$ and $\mathrm{CrFe}-$ CoNiMo coatings in situ with nano-multicomponent oxides during APS, and studied their wear behavior. The coefficient of friction (COF) value of APS CrFeCoNiMo HEA coating measured was similar to Li et al. (Ref 79), i.e., $0.75 \pm 0.02$, but that for $\mathrm{AlCrFeCoNi}$ was much lower at $0.49 \pm 0.04$. Morphological analysis suggested that wear mechanisms involving both adhesive and abrasive wear were more severe in the case of the $\mathrm{CrFeCoNiMo}$ HEA coating. Reinforcement of nano-oxides and lubrication effects caused by the creation of micrometer-sized debris during wear were collectively responsible for enhancing the wear resistance of the $\mathrm{AlCrFeCoNi} \mathrm{HEA}$ coating.

Yin et al. (Ref 49) reported on the fabrication and tribological properties of cold-sprayed $\mathrm{CrMnFeCoNi}$. The volume wear rate of the CS coating was $4.76 \pm 0.22 \times 10^{-4} \mathrm{~mm}^{3} / \mathrm{N}-\mathrm{m}$, with abrasive wear operating as the dominant mechanism. The measured volume wear rate was lower than that for laser-clad $\mathrm{SiCrFeCoNi(B)} \mathrm{(Ref} \mathrm{102,} \mathrm{103)} \mathrm{coatings.} \mathrm{This} \mathrm{value} \mathrm{was}$ considerably higher than those for APS AlTiCrFeCoNi (Ref 70), HVOF $\mathrm{Al}_{0.6} \mathrm{TiCrFeCoNi}$ (Ref 73), and APS AlSiCrFeCoNi HEA coatings (Ref 74).

Contrary to TS HEA coatings, laser clad (LC) HEA coatings are characterized by a dense, dendritic microstructure, with a concurrent improvement in tribological behavior (Ref 28). For example, Liu et al. (Ref 95) assessed the wear behavior of $\mathrm{AlTi}_{x} \mathrm{CrFeCoNi}$-based $\mathrm{LC}$ coatings at room and high temperatures. The addition of $\mathrm{Ti}$ to the $\mathrm{AlCrFeCoNi}$ enhanced the wear resistance at both temperatures. The wear volume rates were $1.3 \times 10^{-8}$ and $5.8 \times 10^{-8} \mathrm{~mm}^{3} / \mathrm{N}-\mathrm{m}$ at room temperature and $600{ }^{\circ} \mathrm{C}$, respectively, which were significantly lower than the measurements for APS AlTiCrFeCoNi HEA coatings (Ref 70). Oxidative wear was the major wear mechanism for both coatings.

In summary: analysis of the wear results shown in Table 3 and Fig. 16 concludes that APS HEA coatings performed better than both HVOF and CS HEA coatings. However, the commercial opportunity for TS HEA coatings in wear applications needs to be validated further due to the limited open-source literature and lack of hightemperature wear data.

\section{Oxidation Behavior}

Oxidation resistance at elevated temperatures is a critical requirement for extreme environment materials. Several TS HEA coatings have been studied with regard to their oxidation behavior, as elucidated below.

Huang et al. (Ref 32) oxidized APS $\mathrm{AlSiTiCrFeCoNiMo}_{0.5}$ and $\mathrm{AlSiTiCrFeNiMo}_{0.5}$ at 900, 1000 , and $1100{ }^{\circ} \mathrm{C}$ for equal durations. The coatings exhibited good oxidation resistance up to $1000^{\circ} \mathrm{C}$ over $100 \mathrm{~h}$, which was attributed to the formation of protective $\mathrm{TiO}_{2}$ and $\mathrm{Cr}_{2} \mathrm{O}_{3}$ layers.

Bhattacharya et al. (Ref 43) studied the oxidation of HVOF $\mathrm{Al}_{30} \mathrm{Si}_{2} \mathrm{Cr}_{23} \mathrm{Co}_{22} \mathrm{Ni}_{23}$ (at.\%) HEA coatings at $1050{ }^{\circ} \mathrm{C}$ for 50,100 , and $200 \mathrm{~h}$ for applications intended as bond coat materials for TBCs. The oxidized microstructure was composed of $\mathrm{BCC} / \mathrm{B} 2+\mathrm{FCC}+\mathrm{Al}_{2} \mathrm{O}_{3}$, with alumina providing the oxidation resistance. The initial weight gain after 100 cycles was $0.2 \mathrm{mg} / \mathrm{cm}^{2}$, which was much less than MCrAlX bond coats at $1 \mathrm{mg} / \mathrm{cm}^{2}$. Thus, $\mathrm{HVOF}$ $\mathrm{Al}_{30} \mathrm{Si}_{2} \mathrm{Cr}_{23} \mathrm{Co}_{22} \mathrm{Ni}_{23}$ coatings demonstrated excellent oxidation resistance as required for aerospace applications.

Hsu et al. (Ref 39, 40, 77) examined the oxidation behavior of AlSiTiCrFeCoNi-based HEA coatings sprayed by several TS processes. APS and HVOF $\mathrm{AlSi}_{0.2} \mathrm{Ti}_{0.2-}$ $\mathrm{CrFe}_{0.2} \mathrm{Co}_{0.6} \mathrm{Ni}_{0.2}$ HEA coatings were synthesized on alumina substrates, and oxidation at $1100{ }^{\circ} \mathrm{C}$ was conducted for comparison against conventional MCrAlY coatings. Weight gain analysis indicated that HEA coatings possessed oxidation resistance similar to MCrAlY coatings at $1100{ }^{\circ} \mathrm{C}$. The weight gain was observed to plateau for HEA coatings after $50 \mathrm{~h}$, whereas it continued to increase until $168 \mathrm{~h}$ for MCrAlY coatings. Cross-sectional SEM of HEA coatings indicated that the oxide scale consisted of two distinct layers. The first layer consisted of Ti-Cr-Al mixed oxides and gave rise to the initial weight gain. The second layer was $\alpha-\mathrm{Al}_{2} \mathrm{O}_{3}$ and deterred further oxidation at high temperature. Comparison between APS and HVOF HEAs coatings illustrated that the oxide scale was thicker in the case of APS due to the formation of more oxide stringers (Ref 39).

Hsu et al. (Ref 40) also fabricated APS AlSiTi ${ }_{0.2} \mathrm{Cr}_{1.5}$ $\mathrm{Fe}_{0.2} \mathrm{Co}_{0.6} \mathrm{Ni}$ HEA coatings and evaluated their oxidation behavior at $1100{ }^{\circ} \mathrm{C}$. The weight change statistics revealed a rapid increase at the initial stage that became steady state after $100 \mathrm{~h}$. The weight gain was less than that for NiCrAlY coatings, but higher than that for as-cast bulk AlSiTi ${ }_{0.2} \mathrm{Cr}_{1.5} \mathrm{Fe}_{0.2} \mathrm{Co}_{0.6} \mathrm{Ni}$ HEA. The formation of thermally grown oxides (TGOs) consisting of Ti-Cr-Al mixed oxides was observed. $\mathrm{A} \mathrm{Cr}_{2} \mathrm{O}_{3} / \mathrm{Al}_{2} \mathrm{O}_{3}$ and an $\alpha-\mathrm{Al}_{2} \mathrm{O}_{3}$ sublayer were responsible for the good oxidation resistance of this $\mathrm{AlSiTi}_{0.2} \mathrm{Cr}_{1.5} \mathrm{Fe}_{0.2} \mathrm{Co}_{0.6} \mathrm{Ni}$ HEA coating. 
Hsu et al. (Ref 77) further studied the oxidation characteristics of $\mathrm{AlSiTi}_{0.2} \mathrm{Cr}_{1.5} \mathrm{Fe}_{0.2} \mathrm{Co}_{0.6} \mathrm{Ni}$ and $\mathrm{AlSiCr}_{1.3-}$ $\mathrm{Fe}_{0.2} \mathrm{Co}_{0.6} \mathrm{Ni}$ HEAs sprayed by APS, HVOF, and WS. Oxidation tests were conducted at $1100{ }^{\circ} \mathrm{C}$, and weight change was measured after 5, 50, 100, 150, 240, and $336 \mathrm{~h}$. WS HEA coatings exhibited better oxidation resistance compared to APS and HVOF ones and were comparable to conventional MCrAlY bond coats. As reported in an earlier study (Ref 40), oxidized $\mathrm{AlSiTi}_{0.2} \mathrm{Cr}_{1.5} \mathrm{Fe}_{0.2} \mathrm{Co}_{0.6} \mathrm{Ni} \mathrm{HEA}$ coatings also consisted of dual oxide layers. On the other hand, the absence of $\mathrm{Ti}$ in $\mathrm{AlSiCr}_{1.3} \mathrm{Fe}_{0.2} \mathrm{Co}_{0.6} \mathrm{Ni}$ resulted in a solitary protective $\alpha-\mathrm{Al}_{2} \mathrm{O}_{3}$ layer. As a result, weight change characteristics of $\mathrm{AlSiCr}_{1.3} \mathrm{Fe}_{0.2} \mathrm{Co}_{0.6} \mathrm{Ni} \mathrm{HEA}$ coatings were better in comparison with $\mathrm{AlSiTi}_{0.2} \mathrm{Cr}_{1.5}$ $\mathrm{Fe}_{0.2} \mathrm{Co}_{0.6} \mathrm{Ni}$ coatings.

Hsu et al. (Ref 77) subsequently used WS AlSiTi ${ }_{0.2-}$ $\mathrm{Cr}_{1.5} \mathrm{Fe}_{0.2} \mathrm{Co}_{0.6} \mathrm{Ni}$ and $\mathrm{AlSiCr}{ }_{1.3} \mathrm{Fe}_{0.2} \mathrm{Co}_{0.6} \mathrm{Ni} \mathrm{HEAs}$ as bond coats in a thermal barrier coating (TBC) system that incorporated a YSZ topcoat. These HEA-based TBC systems were then exposed to oxidation at $1100{ }^{\circ} \mathrm{C}$, and the results were compared with a conventional MCrAlY-YSZbased TBC system. It was concluded that the $\mathrm{AlSiCr}_{1.3-}$ $\mathrm{Fe}_{0.2} \mathrm{Co}_{0.6} \mathrm{Ni}$-based TBC demonstrated longer life (adhesion failed after the 168th cycle) than $\mathrm{AlSiTi}_{0.2} \mathrm{Cr}_{1.5} \mathrm{Fe}_{0.2} \mathrm{Co}_{0.6} \mathrm{Ni}$-based $\mathrm{TBC}$ (adhesion failed after the 100th cycle), while the MCrAlY-based TBC did not fail until the 240th cycle.

Anupam et al. (Ref 46) also studied the oxidation of cold-sprayed AlCrFeCoNi HEAs, isothermally treated at $1100{ }^{\circ} \mathrm{C}$ for $25 \mathrm{~h}$. Cross-sectional SEM in back-scattered electron (BSE) mode and XRD analysis revealed that the top of the coating oxidized to form a protective $\mathrm{Al}_{2} \mathrm{O}_{3}$ layer that was responsible for preventing substrate oxidation. The interface of the coating and substrate also remained stable after the oxidation treatment.

Laser clad $\mathrm{Al}_{x} \mathrm{CrFeCoNi} \mathrm{HEA}$ coatings have been analyzed by Cai et al. (Ref 104) for their oxidation behavior. Oxidation rates decreased with an increase in $\mathrm{Al}$ content and the concurrent formation of $(\mathrm{Al}, \mathrm{Cr})_{2} \mathrm{O}_{3}$ and $\mathrm{Al}_{2} \mathrm{O}_{3}$. The formation of a $\mathrm{TGO} \mathrm{Al}_{2} \mathrm{O}_{3}$ layer was the major reason for enhancement of the high-temperature oxidation resistance.

\section{Electrochemical Properties}

Corrosion protection to the advanced engineering materials, especially under highly aggressive environments, such as marine applications and chemical processing industries, is generally furnished by a coating system with superior electrochemical performance. Coatings with high corrosion resistance under different environments act as a barrier to the engineering component, and enhance the component lifetime. Thermal sprayed HEA coatings are not yet widely investigated with respect to their corrosive behavior in comparison with their laser clad and cast counterparts (Ref 105-109). Two reports have been published concerning of the corrosion behavior of HEA coatings formed by a thermal spray process (Ref 68, 80).

Wang et al. (Ref 80) examined the corrosive behavior of vacuum-plasma-sprayed $(\mathrm{CrFeCoNi})_{95} \mathrm{Nb}_{5} \mathrm{HEA}$ coatings in a 3.5 wt.\% NaCl solution. Polarization curve analysis showed that $(\mathrm{CrFeCoNi})_{95} \mathrm{Nb}_{5}$ HEA coatings possessed a higher corrosion potential $(-0.37 \mathrm{~V})$ and lower current density $\left(7.23 \times 10^{-6} \mathrm{~A} / \mathrm{cm}^{2}\right)$ compared to other similar HEA systems, thus representing better corrosion resistance. SEM analysis of coating after electrochemical treatment indicated that selective corrosion occurred, with the formation of tiny dish-shaped pits and large pits on the coating surface. The interdendritic phases rich in $\mathrm{Nb}$ and $\mathrm{Cr}$ were more susceptible to corrosion compared to the $\mathrm{Co}-$, Ni-, and Fe-rich dendritic phase. Formation of stable oxides such as $\mathrm{Cr}_{2} \mathrm{O}_{3}$ and $\mathrm{Nb}_{2} \mathrm{O}_{5}$ in the passivation film promoted the corrosion resistance of the coating, as detected by XPS analysis.

The second report by Vallimanalan et al. (Ref 68) analyzed the corrosion behavior of $\mathrm{HVOF}$-sprayed AlCrCoNiMo HEA coatings and compared it with a conventional NiCrSiB-based HVOF coating. Corrosion rate calculation using a Tafel plot suggested that the HEA coating demonstrated a lower corrosion rate $(0.00276 \mathrm{~mm} / \mathrm{year})$ compared to $\mathrm{NiCrSiB}$ coating $(0.018 \mathrm{~mm} / \mathrm{year})$, thus concluding higher corrosion resistance for this particular HEA coating.

\section{Applications}

A coating provides improved properties in the working environment without compromising the properties of the engineering component, thereby increasing the lifetime of the part and providing economic and efficiency gains over the lifetime of the engineering assembly.

A prime example is thermal barrier coatings (TBCs) on superalloy blades in turbines. Superalloys have evolved through several generations and exhibit excellent creep properties and oxidation resistance under extreme harsh environments. However, oxidation resistance comes at the expense of creep performance. Thus, rather than compromising the superalloy creep resistance by adjusting compositions to benefit thermal stability, a suitable TBC can be designed to mitigate the oxidation and thermal resistance. The outcome is that the turbine blade lasts longer with lower maintenance. The coating is sacrificial in nature and can be stripped and replaced periodically, which is much more economical than replacing the superalloy blade.

The potential of high-entropy alloys lies in the unexplored materials hyperspace, as summarized by Miracle 
et al. in their review (Ref 110). New HEA compositions are being discovered that exhibit exceptional properties. This knowledge may be used to design HEAs for specific applications, which can be translated into coatings using the versatile thermal spray processes.

TS coatings are primarily developed for (a) wear, (b) oxidation, (c) corrosion, (d) biomedical, and (e) electronic applications, each of which is open for TS-HEAs.

\section{Wear and Abrasion Resistance}

The sheer number of industries requiring wear- and abrasion-resistant coatings is staggering. From earth-moving and mining equipment to agricultural machinery such as harvester blades, and from transmission, steering, and suspension components in automobiles to wear plates in bottling and canning industries, there are ample opportunities for developing HEA TS coating solutions for each case-specific scenario.

In addition to traditional industries, there is also scope in the renewable energy sector, for example in wind energy where turbine blades need abrasion resistance from dust and hail, as well as being lightweight yet strong-an ideal case for coatings. Wear resistance HEA coatings have been a focus of the TS HEA community, as is detailed in "Tribological Assessment" section. The AlCrFeCoNiX family exhibits good wear resistance at room and elevated temperatures, relying on solid solution strengthening and, in some cases, precipitation hardening and operating via oxidative wear mechanisms. On the other end of the HEA spectrum, refractory HEAs (RHEAs) have excellent wear and abrasion resistance in cast and laser clad forms (Ref $111,112)$, though they have not been fully exploited by TS manufacturing methods.

There is also scope for generating metal matrix composites as illustrated by Mu et al. (Ref 65), where ceramic particles are incorporated into a metallic binder. Other variants, such as replacing metallic binders with ductile FCC HEAs (i.e., the $\mathrm{CrFeCoNi}$ alloy family), and the ceramic with $\mathrm{B} 2$ phase or refractory HEAs, may be viable. Precedent exists from Zhu et al. (Ref 113) in the form of $\mathrm{Ti}(\mathrm{C}, \mathrm{N})$ cermets using $\mathrm{FCC} \mathrm{AlCrFeCoNi}$ alloy as binders, which exhibited better oxidation resistance than conventional materials. It is also possible to adjust spray parameters to generate highentropy ceramics in situ for wear resistance applications. Extensive literature on thin-film HEA-C/N/B/O compositions exists (Ref 31 ); therefore, there is similar potential to develop thick coatings via TS processes.

\section{Oxidation Resistance}

As detailed in "Oxidation Behavior" section, there has been a focus on exploring HEAs as alternatives to MCrAlY bond coat materials (Ref 10). Compositions with varying quantities of $\mathrm{Al}, \mathrm{Cr}, \mathrm{Si}, \mathrm{Ti}$, and $\mathrm{Ni}$ have shown promising results. Besides bond coats, oxidation resistance is required at lower temperatures $\left(<700{ }^{\circ} \mathrm{C}\right)$ in power generation industries, where $\mathrm{Fe}$ and $\mathrm{Cr}$ would be the primary oxidation-resistant elements. Furthermore, RHEAs, which are known to be limited by poor oxidation resistance at elevated temperatures, can be tuned with the addition of $\mathrm{Al}$, $\mathrm{Ti}$, etc., as evidenced by reports on cast RHEAs (Ref $114,115)$. Processing these coatings by vacuum plasma spray (VPS) or controlled atmospheric plasma spray (CAPS) is recommended to avoid IFO while promoting particle melting and splat formation.

\section{Corrosion Resistance}

Protection from corrosion is an important and viable area for application of TS HEA coatings. Practically, all areas of industry operating in non-ambient conditions require some form of corrosion resistance. The market for thermal sprayed corrosion-resistant coatings is extremely large: from oil and gas/petroleum industries, chemical and metal processing industries, to marine environments-offshore oil rigs, naval applications in ships and submarines; and from food processing industries to powder generationhydro, thermal, geothermal, and land-based turbines. Each industry has specific stringent working environments for which TS HEA coatings can be tailored. Whereas there is a growing body of work on the corrosion behavior of TS HEA coatings, there is a rich body of literature exploring and proving the promise of corrosion-resistant HEAs in the cast or laser clad form (Ref 22, 91). These compositions can be adopted by appropriate TS methods where it will be necessary to optimize the coating thickness and density for optimum performance.

\section{Biomedical Applications}

Thermal spray is also a popular method for developing titanium and hydroxyapatite coatings for orthopedic applications (Ref 116). TS processing provides the right balance between coating density and defect (pores, cracks) distribution required for osteointegration. APS is the favored method for spraying biomaterials.

Developing biocompatible HEAs for drug delivery and other related applications is a major focus of the HEA research community. For example, Alagarsamy et al. (Ref 117) have investigated $\mathrm{Al}_{0.1} \mathrm{CrFeCoNi}$ for application in peripheral vascular stent implants. Popescu et al. (Ref 118) have explored the TiFeZrNbTa system for biomedical applications as dental or orthopedic implants. It is imperative to mention that currently the metallic implants are formed or machined, and the TS coating on them is 
polymer or composite in nature. However, there is scope for biocompatible wear-resistant TS HEA composite coatings. Sputtered HEA carbide coatings have been under investigation by Vladescu et al. (Ref 119) due to their biocompatibility and mechanical properties, and such materials processing data can spearhead applications for in situ HEA ceramics generated by TS.

\section{Electronics}

Thermal spray coatings are applied in the electronics industry for EMI/RFI (electromagnetic interference/radio frequency interference) shielding. These coatings prevent noise and interference associated with the operation of electronic equipment. Typically, materials with high electrical conductivity and/or high values of magnetic constant and dielectric constant are preferred for EMF shielding via reflection and absorption, respectively.

Nanocrystalline ferromagnetic alloys containing $\mathrm{Fe}, \mathrm{Co}$, and $\mathrm{Ni}$ have been suggested as promising candidates for EMF shielding. Yang et al. (Ref 120) were the first to explore the EM wave absorption properties of $\mathrm{AlCrFeCoNi}$ (70 wt.\% powder dispersed with paraffin matrix) synthesized by mechanical alloying. They report an effective absorption bandwidth of $2.7 \mathrm{GHz}$, indicating the powders' excellent EM wave absorption properties. Zhang et al. (Ref 121) also studied the $\mathrm{AlCrFeCoNi/epoxy} \mathrm{system,} \mathrm{focusing}$ on the effect of different powder morphologies and sizes on the EM absorption properties. They conclude that finer $(0.2-7 \mu \mathrm{m})$ wet milled HEA exhibited higher total shielding due to enhancement of absorption, vis à vis larger flaky alloy particles, and are excellent candidates for microwave shielding applications. This nature of HEA particles can be translated to TS coatings by low-temperature cold spray processes.

\section{Future Trends: An Optimistic Future for HEAs}

'The 2016 Thermal Spray Roadmap' by Vardelle et al. (Ref 122) does not mention the evolving technical area of HEAs, but presents an overview of thermal spray technology. In an alike fashion, editorials on 'We Never have Enough Energy' (Ref 123) and 'Finding the 'Magic Pudding' in the Thermal Spray Industry' (Ref 124) state the pervasive need for materials technology, specifically thermal spray, to master critical current and emerging societal needs. High-entropy alloys present technical and commercial opportunities that address these needs. High-entropy alloys in the form of bulk alloys, thin films, and coatings have already been exploited throughout the recent timeline of discovery, especially in traditional technologies such as casting, laser cladding, and sputtering.
High-entropy alloys are still an emerging class of materials where fundamental science is not keeping pace with their practical engineering application. This deficiency is magnified in the area of using HEAs as functional coatings, wherein traditional thermal spray technology can play a major role. Alternative thermal spray and other processing techniques, such as cold spray and high-speed laser cladding, have gained importance. Herein lie opportunities for scientific discoveries that will enable databases of physical properties that can further be exploited for high functional performance.

The near-future developments of TS-HEAs lie in the sub-topics of (1) feedstock preparation, (2) TS process optimization, (3) mechanical, chemical, and thermal testing of HEA coatings, (4) initiation and normalization of HEA databases, and (5) qualification and industrial adoption of bespoke HEA coatings for specific extreme environments.

Feedstock preparation: "HEA Feedstock: Synthesis and Properties" section reviewed the existing TS-HEA alloys that have been documented. Future TS-HEA feedstocks that mimic the traditional materials growth process are (1) high-entropy ceramics (Ref 125), (2) refractory high-entropy alloys (Ref 126, 127), (3) high-entropy amorphous alloys (Ref 128, 129), and (4) HEAs as binder materials for composite coatings (Ref 130-133). The process technologies for these sub-categories of potential feedstocks have been described in "HEA Feedstock: Synthesis and Properties" section. However, other preparation methods such as aerosol technology and solgel methods are also viable. There has been no TS-related work on high-entropy polymers presumably because the excessive TS thermal environment causes adverse material damage.

TS process optimization: Atmospheric plasma spraying is the current method of choice in forming TS-HEAs since it is economical and relatively simple. Cold spray (Ref $46,49,83$ ) has been used with success for HEAs but will be limited to ductile materials. Other TS methods of specific relevance include (1) solution thermal spray (STS) such as suspension plasma spray (SPS) and solution precursor plasma spray (SPPS) (Ref 134, 135), (2) controlled atmosphere plasma spray (CAPS) (Ref 136, 137), and (3) vacuum plasma spray (VPS) (Ref 138). These three classes of TS processing will come on line when HEAs are proven and qualified by APS, since they enable the creation of more precise chemistries and refined microstructures that mimic traditional HEA routes.

The process optimization will be guided by the implementation of advanced diagnostic systems that allow realtime monitoring of the particle flux conditions (Ref 139) during the spray process.

Mechanical, chemical, and thermal testing of HEA coatings: This review compiles and summarizes the known literature on HEAs. It is critical to indicate that there are 
deficiencies in some reports. For example: (1) testing conditions are not fully documented, and (2) replication of test results has not been universally implemented within individual studies. It is recommended that future studies will follow documented metallographic practice (Ref 140), mechanical testing procedures (Ref 4$)$, and thermal tests (Ref 141-143).

Initiation and normalization of HEA databases and modeling studies: The results from the previous section can be formalized into an intelligent database (Ref 144) that will enable quick determinations of HEA coating solutions. As well, the work by Senkov et al. (Ref 36) is important since it provides a pathway to identifying promising compositions for more time-intensive experimental studies.' These conjoint approaches, i.e., database approach with alloy selection, are mutually validating since they accelerate the development of HEA exploration. This approach can be extended to novel materials that are suggested in the 'Feedstock preparation' paragraph above.

Qualification and industrial adoption of HEA coatings: HEAs are on the verge of adoption in industries that address extreme environments that need to address wear and thermal environments (Ref 145). Market expansion will arise where other functional properties are desirable, e.g., high-entropy alloy-based solar absorber coatings (Ref 146, 147). Therefore, the unrealized potential of HEA applications will be more openly revealed as the unique materials properties of HEAs are discovered.

A final comment concerning 'Future Trends' relates to the changing environment concerning the research method as it progresses from Technological Readiness Level 1 through to 9 (TRL1-9). HEA technology, overall, is approaching TRL7-8. TS-HEA technology is at TRL4-5, hence implying their optimistic future (Ref 148). The mechanism that will support this growth is found on interdisciplinary cooperation since there are many unknowns that need to be uncovered.

\section{Summary and Conclusions}

Thermal sprayed HEA coatings exhibit unique and outstanding properties in comparison with traditional materials and have established a positive commercial outlook in surface engineering within a short time span.

This early-stage review on thermal sprayed HEA coatings focuses on HEA as feedstock and its synthesis routes with their properties, coating phase compositions along with microstructural development, and mechanical and oxidation behavior of HEA coatings. In addition, this paper (1) suggests applications targeted for these coatings, and (2) other HEA compositions that have not been reported in the thermal spray domain.
The concluding remarks of this early-stage review paper are:

1. Most HEAs in the surface engineering field are processed through cladding and vapor deposition techniques. However, there is a growing market for thick HEA coatings. APS and HVOF are the major thermal spray techniques used for generating HEA coatings, with fewer reports on WS and CS.

2. HEA feedstock containing $\mathrm{Al}, \mathrm{Si}$, and/or Ti with a base of $\mathrm{CrFeCoNi}$ has been the major research interest since the focused application area is for performance at high temperatures.

3. Development of HEA feedstocks has unique implications on the TS coating microstructure and properties. Gas atomization (GA) is the leading processing route for HEA feedstocks. Blending, mechanical alloying (MA), arc melting followed by mechanical milling (AM-MM) are the other major HEA feedstock synthesis routes. While gas atomization delivers the widest particle size range, mechanical alloying results in a finer particle size of nanocrystalline character.

4. The microstructural advancement of the APS, HVOF, WS, and CS HEA coatings is described in conjunction with their phase composition development. As reported, thermal sprayed HEA coating microstructures are composed of one or more solid solution phases. In some cases, mainly APS, oxides are also reported. The prime feature of the TSC is a lamellar microstructure with development of complementary phases that are revealed by atomic number contrasts.

5. Mechanical behavior of the thermal sprayed coatings in terms of porosity, hardness and wear, along with oxidation resistance, is discussed. HVOF HEA coatings, with their dense microstructure, achieved the highest hardness. However, in most cases the hardness and wear resistance were superior to conventional materials due to the development of supersaturated multicomponent phases and different strengthening mechanisms. Excellent oxidation resistance of the thermal sprayed HEA coatings has displayed potential in replacing conventional bond coat materials.

6. The major focus of the thermal sprayed HEA coatings has been to develop wear- and oxidation-resistant coatings, especially for high-temperature applications. In contrast, there are only two reports available on analyzing the corrosion behavior of TS-HEA coatings. Therefore, the corrosion-resistant applications for TSHEAs have not been fully exploited. Also, fracture toughness, being an important mechanical property, to evaluate the flaw behavior within coating during deformation, has only been reported in one article. Thus, future studies that discover vital properties 
including not only fracture toughness but also creep, fatigue, and tensile strength are required for the formal establishment of thermal sprayed HEA coatings for different applications.

7. Thermal sprayed HEA coatings have shown immense potential of being next-generation coatings within their relatively brief time span under development. TSHEAs have demonstrated promise, especially for applications in extreme engineering environments. There is further scope to study their properties in situ by methods such as higher temperature nanoindentation.

One of the major proponents of surface engineering is its ability to elevate the lifetime of an inferior part using a high-performance surface coating. High-entropy alloys are a recent addition to this field, with the potential to replace several traditional coating materials on the basis of their excellent properties. To this end, selection of elements and the proportion in which to alloy them is of great importance. Although HEAs were initially defined as equiatomic alloys exhibiting single solid solution phases, recent literature has evidenced superior strength-ductility properties derived from multi-phase non-equiatomic compositions. TS-HEAs have followed a similar developmental path, for example, incorporating post-processing treatment to enhance wear properties of the coating.

The most commonly used base elements that confer high operational performance and phase stability consist of $\mathrm{Al}$, $\mathrm{Co}, \mathrm{Cr}, \mathrm{Fe}, \mathrm{Mo}$ and $\mathrm{Ni}$, of which $\mathrm{Co}$, Mo, and $\mathrm{Ni}$ are considered as strategic materials that are not only regulated by government policies but are expensive raw materials. The advantage of the thermal spray manufacturing route is that only a coating of 50-300 $\mu \mathrm{m}$ thickness is required, thus saving the need for expensive feedstocks. Likewise, experimenting with additional principal or trace elements, for example $\mathrm{Ti}$ and $\mathrm{W}$, reduces quantities of these costly elements to achieve performance.

The advantage of TS manufacturing revolves around their ability to have rapid buildup of an engineered surface in comparison with vacuum-based film technology such as physical vapor deposition (PVD). The costlier alternatives of vacuum or low-pressure plasma spray are currently adopted for spraying oxygen-sensitive alloys.

The cost of an APS TS installation is moderate and either factory or field operations have been established globally for local niche markets. TS-HEA research is thus focused on employing APS while controlling the extent of IFO by optimizing composition and coating process parameters, to engineer desirable coatings economically. Additive manufacturing by cold spray is another venture for exploiting the advantages offered by HEAs without being uneconomical.
Therefore, the feasibility of producing a HEA coating by TS within a production environment has been proven to be economically viable with many case histories documented (Ref 149) for specific industries that use non-HEA feedstocks.

Thermal sprayed high-entropy alloy coatings are in the initial stage of exploration. This early-stage review highlights and summarizes knowledge and understanding from a diverse array of original sources. The future for TS-HEAs is positive in terms of interesting science and potential commercial outcomes for engineering applications.

Acknowledgments This study was supported by the Australian Research Council under the Industrial Transformation Training Centre project IC180100005 that is titled 'Surface Engineering for Advanced Materials,' SEAM. Ms. Ameey Anupam acknowledges the Joint Doctoral Degree Program between Swinburne University and IIT Madras for facilitating this collaboration. The authors are grateful for seed funding provided by Prof. A. Kapoor (Swinburne University) that initiated this international collaboration. A. Anupam, B.S. Murty, and R.S. Kottada acknowledge discussions with project review committee members (Profs. V. Jayaram, D. Banerjee, and S. Raghavan of IISc Bengaluru; and Dr. D. Das of DMRL, Hyderabad, India) under funding from Aeronautics Research and Development Board, India; sanction \# ARDB/GTMAP/01/2031783/M/1/285/ $\mathrm{D}(\mathrm{R} \& \mathrm{D})$.

Historical Perspective and Dedication This manuscript has been finalized over a critical point in our history as we recover from a global pandemic. This manuscript is testament to scientific cooperation between high-entropy alloy research groups in Australia and India over this challenging period. It is timely and appropriate to recognize Professor S. Ranganathan (Emeritus Professor \& Senior Homi Bhabha Fellow, Indian Institute of Science, Bangalore, India) whose article titled 'Alloyed pleasure: Multimetallic cocktails' (Current Science, 2003, 85(10), 1404-1407, 267 citations) has been inspiring. The authors are grateful for his leadership and mentoring in physical metallurgy that has spanned five decades. We dedicate this review to Prof. S. Ranganathan.

Open Access This article is licensed under a Creative Commons Attribution 4.0 International License, which permits use, sharing, adaptation, distribution and reproduction in any medium or format, as long as you give appropriate credit to the original author(s) and the source, provide a link to the Creative Commons licence, and indicate if changes were made. The images or other third party material in this article are included in the article's Creative Commons licence, unless indicated otherwise in a credit line to the material. If material is not included in the article's Creative Commons licence and your intended use is not permitted by statutory regulation or exceeds the permitted use, you will need to obtain permission directly from the copyright holder. To view a copy of this licence, visit http://creativecommons. org/licenses/by/4.0/.

\section{References}

1. J.R. Davis, Handbook of Thermal Spray Technology, 1st ed., ASM International, Materials Park, 2004

2. M. Renner, Thermal Spray Coating Applications in the Chemical Process Industries. MTI Publication No. 42. Von R. P. Krepski, The Materials Technology Institute of the Chemical 
Industry Inc., 1993, St. Louis, USA, Materials and Corrosion, 1995, 46(11), p 657-657.

3. L. Pawlowski, The Science and Engineering of Thermal Spray Coatings, 2nd ed., Wiley, New York, 2008, p 656

4. A.S.M. Ang and C.C. Berndt, A Review of Testing Methods for Thermal Spray Coatings, Int. Mater. Rev., 2014, 59(4), p 179223

5. P.L. Fauchais, J.V.R. Heberlein, and M.I. Boulos, Thermal Spray Fundamentals: From Powder to Part, 1st ed., Springer, New York, 2014, p 1566

6. A.P. Alkhimov, A.N. Papyrin, V.F. Kosarev, N.I. Nesterovich, and M.M. Shushpanov, Gas-Dynamic Spraying Method for Applying a Coating, A.N. Papyrin, Ed., U.S. Patent, 1992.

7. A. Papyrin, V. Kosarev, S. Klinkov, A. Alkhimov, and V.M. Fomin, Cold Spray Technology, 1st ed., Elsevier Science, New York, 2006, p 336

8. L.M. Berger, Application of Hardmetals as Thermal Spray Coatings, Int. J. Refract. Met. Hard Mater., 2015, 49, p 350-364

9. B. Cantor, I.T.H. Chang, P. Knight, and A.J.B. Vincent, Microstructural Development in Equiatomic Multicomponent Alloys, Mater. Sci. Eng. A, 2004, 375-377(1-2), p 213-218

10. J.-W. Yeh, S.-K. Chen, S.-J. Lin, J.-Y. Gan, T.-S. Chin, T.-T. Shun, C.-H. Tsau, and S.-Y. Chang, Nanostructured High-Entropy Alloys with Multiple Principal Elements: Novel Alloy Design Concepts and Outcomes, Adv. Eng. Mater., 2004, 6(5), p 299-303+274

11. B.S. Murty, J.W. Yeh, S. Ranganathan, and P.P. Bhattacharjee, High-Entropy Alloys, 2nd ed., Elsevier, New York, 2019, p 388

12. B. Gludovatz, A. Hohenwarter, D. Catoor, E.H. Chang, E.P. George, and R.O. Ritchie, A Fracture-Resistant High-Entropy Alloy for Cryogenic Applications, Science, 2014, 345(6201), p 1153-1158

13. Z. Li, K.G. Pradeep, Y. Deng, D. Raabe, and C.C. Tasan, Metastable High-Entropy Dual-Phase Alloys Overcome the Strength-Ductility Trade-Off, Nature, 2016, 534, p 227-230

14. S. Haas, M. Mosbacher, O.N. Senkov, M. Feuerbacher, J. Freudenberger, S. Gezgin, R. Völkl, and U. Glatzel, Entropy Determination of Single-Phase High Entropy Alloys with Different Crystal Structures Over a Wide Temperature Range, Entropy, 2018, 20(9), p 654

15. Y. Zhang, T.T. Zuo, Z. Tang, M.C. Gao, K.A. Dahmen, P.K. Liaw, and Z.P. Lu, Microstructures and Properties of High-Entropy Alloys, Prog. Mater Sci., 2014, 61, p 1-93

16. D.B. Miracle, High-Entropy Alloys: A Current Evaluation of Founding Ideas and Core Effects and Exploring "Nonlinear Alloys", JOM, 2017, 69(11), p 2130-2136

17. S. Ranganathan, Alloyed Pleasures: Multimetallic Cocktails, Curr. Sci., 2003, 85(10), p 1404-1406

18. M.H. Chuang, M.H. Tsai, W.R. Wang, S.J. Lin, and J.W. Yeh, Microstructure and Wear Behavior of $\mathrm{Al}_{x} \mathrm{Co}_{1.5} \mathrm{CrFeNi}_{1.5} \mathrm{Ti}_{y}$ High-Entropy Alloys, Acta Mater., 2011, 59(16), p 6308-6317

19. A. Verma, P. Tarate, A.C. Abhyankar, M.R. Mohape, D.S. Gowtam, V.P. Deshmukh, and T. Shanmugasundaram, High Temperature Wear in $\mathrm{CoCrFeNiCu}$ High Entropy Alloys: The Role of Cu, Scr. Mater., 2019, 161, p 28-31

20. T.M. Butler, Phase Stability and Oxidation Behavior of Al-NiCo-Cr-Fe Based High-Entropy Alloys, Ph.D. Thesis, The University of Alabama, 2016.

21. K.-C. Lo, Y.-J. Chang, H. Murakami, J.-W. Yeh, and A.-C. Yeh, An Oxidation Resistant Refractory High Entropy Alloy Protected by $\mathrm{CrTaO}_{4}$-Based Oxide, Sci. Rep., 2019, 9, p 7266

22. Y. Shi, B. Yang, and P.K. Liaw, Corrosion-Resistant High-Entropy Alloys: A Review, Metals, 2017, 7(2), p 43

23. Y.P. Wang, B.S. Li, M.X. Ren, C. Yang, and H.Z. Fu, Microstructure and Compressive Properties of $\mathrm{AlCrFeCoNi}$
High Entropy Alloy, Mater. Sci. Eng. A, 2008, 491(1), p 154158

24. Y.D. Wu, Y.H. Cai, T. Wang, J.J. Si, J. Zhu, Y.D. Wang, and X.D. Hui, A Refractory $\mathrm{Hf}_{25} \mathrm{Nb}_{25} \mathrm{Ti}_{25} \mathrm{Zr}_{25}$ High-Entropy Alloy with Excellent Structural Stability and Tensile Properties, Mater. Lett., 2014, 130, p 277-280

25. F. He, Z. Wang, S. Niu, Q. Wu, J. Li, J. Wang, C.T. Liu, and Y. Dang, Strengthening the $\mathrm{CoCrFeNiNb}_{0.25}$ High Entropy Alloy by FCC Precipitate, J. Alloys Compd., 2016, 667, p 53-57

26. J.Y. He, H. Wang, H.L. Huang, X.D. Xu, M.W. Chen, Y. Wu, X.J. Liu, T.G. Nieh, K. An, and Z.P. Lu, A Precipitation-Hardened High-Entropy Alloy with Outstanding Tensile Properties, Acta Mater., 2016, 102, p 187-196

27. L. Pawlowski, Thick Laser Coatings: A Review, J. Therm. Spray Technol., 1999, 8(2), p 279-295

28. H. Zhang, Y. Pan, Y.-Z. He, J.-L. Wu, T.M. Yue, and S. Guo, Application Prospects and Microstructural Features in LaserInduced Rapidly Solidified High-Entropy Alloys, JOM, 2014, 66(10), p 2057-2066

29. X.H. Yan, J.S. Li, W.R. Zhang, and Y. Zhang, A Brief Review of High-Entropy Films, Mater. Chem. Phys., 2018, 210, p 12-19

30. A.D. Pogrebnjak, A.A. Bagdasaryan, I.V. Yakushchenko, and V.M. Beresnev, The Structure and Properties of High-Entropy Alloys and Nitride Coatings Based on Them, Russ. Chem. Rev., 2014, 83(11), p 1027-1061

31. W. Li, P. Liu, and P.K. Liaw, Microstructures and Properties of High-Entropy Alloy Films and Coatings: A Review, Mater. Res. Lett., 2018, 6(4), p 199-229

32. P.K. Huang, J.W. Yeh, T.T. Shun, and S.K. Chen, Multi-principal-element Alloys with Improved Oxidation and Wear Resistance for Thermal Spray Coating, Adv. Eng. Mater., 2004, 6(1-2), p 74-78

33. L.M. Wang, C.C. Chen, J.W. Yeh, and S.T. Ke, The Microstructure and Strengthening Mechanism of Thermal Spray Coating $\mathrm{Ni}_{x} \mathrm{Co}_{0.6} \mathrm{Fe}_{0.2} \mathrm{Cr}_{y} \mathrm{Si}_{z} \mathrm{AlTi}_{0.2}$ High-Entropy Alloys, Mater. Chem. Phys., 2011, 126(3), p 880-885

34. A.S.M. Ang, C.C. Berndt, M.L. Sesso, A. Anupam, S. Praveen, R.S. Kottada, and B.S. Murty, Plasma-Sprayed High Entropy Alloys: Microstructure and Properties of $\mathrm{AlCoCrFeNi}$ and MnCoCrFeNi, Metall. Mater. Trans. A, 2015, 46A(2), p 791-800

35. E.J. Pickering and N.G. Jones, High-Entropy Alloys: A Critical Assessment of Their Founding Principles and Future Prospects, Int. Mater. Rev., 2016, 61(3), p 183-202

36. O.N. Senkov, J.D. Miller, D.B. Miracle, and C. Woodward, Accelerated Exploration of Multi-principal Element Alloys with Solid Solution Phases, Nat. Commun., 2015, 6, p 6529

37. M. Lobel, T. Lindner, C. Kohrt, and T. Lampke, Processing of AlCoCrFeNiTi High Entropy Alloy by Atmospheric Plasma Spraying, IOP Conf. Ser.: Mater. Sci. Eng., 2017, 181, p 012015

38. L.H. Tian, Z.K. Feng, and W. Xiong, Microstructure, Microhardness, and Wear Resistance of AlCoCrFeNiTi/Ni60 Coating by Plasma Spraying, Coatings, 2018, 8(3), p 112

39. W.L. Hsu, H. Murakami, J.W. Yeh, A.C. Yeh, and K. Shimoda, On the Study of Thermal-Sprayed $\mathrm{Ni}_{0.2} \mathrm{Co}_{0.6} \mathrm{Fe}_{0.2} \mathrm{CrSi}_{0.2} \mathrm{AlTi}_{0.2}$ HEA Overlay Coating, Surf. Coat. Technol., 2017, 316, p 71-74

40. W.L. Hsu, Y.C. Yang, C.Y. Chen, and J.W. Yeh, Thermal Sprayed High-Entropy $\mathrm{NiCo}_{0.6} \mathrm{Fe}_{0.2} \mathrm{Cr}_{1.5} \mathrm{SiAlTi}_{0.2}$ Coating with Improved Mechanical Properties and Oxidation Resistance, Intermetallics, 2017, 89, p 105-110

41. C. Suryanarayana, Mechanical Alloying And Milling, 1st ed., CRC Press, Boca Raton, 2004, p 488

42. M. Vaidya, G.M. Muralikrishna, and B.S. Murty, High-Entropy Alloys by Mechanical Alloying: A Review, J. Mater. Res., 2019, 34(5), p 664-686

43. R. Bhattacharya, O.N. Senkov, A.K. Rai, X. Ma, and P. Ruggiero, High Entropy Alloy Coatings for Application as Bond 
Coating for Thermal Barrier Coating Systems, Thermal Spray: Fostering a Sustainable World for a Better Life, 10-12 May 2016 (Shanghai, China), ASM International, 2016, p 279-285

44. J. Amouroux, A. Gicquel, S. Cavvadias, D. Morvan, and F. Arefi, Progress in the Applications of Plasma Surface Modifications and Correlations with the Chemical Properties of the Plasma Phase, Pure Appl. Chem., 1985, 57(9), p 1207-1222

45. S. Praveen, A. Anupam, R. Tilak, and R.S. Kottada, Phase Evolution and Thermal Stability of AlCoCrFe High Entropy Alloy with Carbon as Unsolicited Addition from Milling Media, Mater. Chem. Phys., 2018, 210, p 57-61

46. A. Anupam, S. Kumar, N.M. Chavan, B.S. Murty, and R.S. Kottada, First Report on Cold-Sprayed AlCoCrFeNi High-Entropy Alloy and Its Isothermal Oxidation, J. Mater. Res., 2019, 34(5), p 796-806

47. M. Srivastava, M. Jadhav, R.P.S. Chakradhar, M. Muniprakash, and S. Singh, Synthesis and Properties of High Velocity OxyFuel Sprayed $\mathrm{FeCoCrNi} 2 \mathrm{Al}$ High Entropy Alloy Coating, Surf. Coat. Technol., 2019, 378, p 124950

48. N. Ashgriz, Handbook of Atomization and Sprays: Theory and Applications, 1st ed., Springer, New York, 2011, p 935

49. S. Yin, W. Li, B. Song, X. Yan, M. Kuang, Y. Xu, K. Wen, and R. Lupoi, Deposition of FeCoNiCrMn High Entropy Alloy (HEA) Coating Via Cold Spraying, J. Mater. Sci. Technol., 2019, 35(6), p 1003-1007

50. B. He, N. Zhang, D. Lin, Y. Zhang, F. Dong, and D. Li, The Phase Evolution and Property of FeCoCrNiAlTi ${ }_{x}$ High-Entropy Alloying Coatings on Q253 Via Laser Cladding, Coatings, 2017, 7(10), p 157

51. K.J. Huang, X. Lin, Y.Y. Wang, C.S. Xie, and T.M. Yue, Microstructure and Corrosion Resistance of $\mathrm{Cu}_{0}{ }_{9} \mathrm{NiAlCoCrFe}$ High Entropy Alloy Coating on AZ91D Magnesium Alloys by Laser Cladding, Mater. Res. Innov., 2014, 18, p S21008-S21011

52. Z. Cai, G. Jin, X. Cui, Z. Liu, W. Zheng, Y. Li, and L. Wang, Synthesis and Microstructure Characterization of Ni-Cr-Co-TiV-Al High Entropy Alloy Coating on Ti-6Al-4V Substrate by Laser Surface Alloying, Mater. Charact., 2016, 120, p 229-233

53. M.P. Planche, H. Liao, and C. Coddet, Oxidation Control in Atmospheric Plasma Spraying Coating, Surf. Coat. Technol., 2007, 202(1), p 69-76

54. Q. Wei, Z. Yin, and H. Li, Oxidation Control in Plasma Spraying NiCrCoAlY Coating, Appl. Surf. Sci., 2012, 258(12), p 5094-5099

55. F. Azarmi, T.W. Coyle, and J. Mostaghimi, Optimization of Atmospheric Plasma Spray Process Parameters Using a Design of Experiment for Alloy 625 Coatings, J. Therm. Spray Technol., 2008, 17(1), p 144-155

56. X.B. Liang, W. Guo, Y.X. Chen, and L.L. Wang, Microstructure and Mechanical Properties of $\mathrm{FeCrNiCoCu}(\mathrm{B})$ High-Entropy Alloy Coatings, Frontier of Nanoscience and Technology, Vol 694, R. Chen, Ed., Materials Science Forum, 2011, p 502-507.

57. W.R. Wang, W.-L. Wang, and J.-W. Yeh, Phases, Microstructure and Mechanical Properties of $\mathrm{Al}_{x} \mathrm{CoCrFeNi}$ High-Entropy Alloys at Elevated Temperatures, J. Alloys Compd., 2014, 589, p 143-152

58. Y.-F. Kao, T.-D. Lee, S.-K. Chen, and Y.-S. Chang, Electrochemical Passive Properties of $\mathrm{Al}_{x} \mathrm{CoCrFeNi}(x=0,0.25,0.50$, 1.00) Alloys in Sulfuric Acids, Corros. Sci., 2010, 52(3), p 1026-1034

59. T.M. Butler and M.L. Weaver, Oxidation Behavior of Arc Melted AlCoCrFeNi Multi-component High-Entropy Alloys, $J$. Alloys Compd., 2016, 674, p 229-244

60. K.S. Lee, J.-H. Kang, K.R. Lim, and Y.S. Na, Influence of Compressive Strain on the Microstructural Evolution of an AlCoCrFeNi High Entropy Alloy, Mater. Charact., 2017, 132, p 162-168
61. T.M. Yue, H. Xie, X. Lin, H. Yang, and G. Meng, Microstructure of Laser Re-melted AlCoCrCuFeNi High Entropy Alloy Coatings Produced by Plasma Spraying, Entropy, 2013, 15(7), p 2833-2845

62. C.C. Tung, J.W. Yeh, T.T. Shun, S.K. Chen, Y.S. Huang, and H.C. Chen, On the Elemental Effect of AlCoCrCuFeNi HighEntropy Alloy System, Mater. Lett., 2007, 61(1), p 1-5

63. D.Y. Lin, N.N. Zhang, B. He, B.Q. Jin, Y. Zhang, D.Y. Li, and F.Y. Dong, Influence of Laser Re-melting and Vacuum Heat Treatment on Plasma-Sprayed FeCoCrNiAl Alloy Coatings, $J$. Iron Steel Res. Int., 2017, 24(12), p 1199-1205

64. K.C. Cheng, J.H. Chen, S. Stadler, and S.H. Chen, Properties of Atomized AlCoCrFeNi High-Entropy Alloy Powders and Their Phase-Adjustable Coatings Prepared via Plasma Spray Process, Appl. Surf. Sci., 2019, 478, p 478-486

65. Y.K. Mu, Y.D. Jia, L. Xu, Y.F. Jia, X.H. Tan, J. Yi, G. Wang, and P.K. Liaw, Nano Oxides Reinforced High-Entropy Alloy Coatings Synthesized by Atmospheric Plasma Spraying, Mater. Res. Lett., 2019, 7(8), p 312-319

66. A. Anupam, R.S. Kottada, S. Kashyap, A. Meghwal, B.S. Murty, C.C. Berndt, and A.S.M. Ang, Understanding the Microstructural Evolution of High Entropy Alloy Coatings Manufactured by Atmospheric Plasma Spray Processing, Appl. Surf. Sci., 2020, 505, p 144117

67. A. Vallimanalan, S.P.K. Babu, S. Muthukumaran, M. Murali, R. Mahendran, V. Gaurav, and S. Manivannan, Synthesis, Characterisation and Erosion Behaviour of $\mathrm{AlCoCrMoNi} \mathrm{High}$ Entropy Alloy Coating, Mater. Res. Express, 2019, 6(11), p 116543

68. A. Vallimanalan, S.P. Kumaresh Babu, S. Muthukumaran, M. Murali, V. Gaurav, and R. Mahendran, Corrosion Behaviour of Thermally Sprayed MoAdded AlCoCrNi High Entropy Alloy Coating, Mater. Today: Proc., 2019. https://doi.org/10.1016/j. matpr.2019.09.149

69. Y. Wang, S. Ma, X. Chen, J. Shi, Y. Zhang, and J. Qiao, Optimizing Mechanical Properties of $\mathrm{AlCoCrFeNiTi}_{x}$ HighEntropy Alloys by Tailoring Microstructures, Acta Metall. Sin. (Engl. Lett.), 2013, 26(3), p 277-284

70. L.H. Tian, W. Xiong, C. Liu, S. Lu, and M. Fu, Microstructure and Wear Behavior of Atmospheric Plasma-Sprayed AlCoCrFeNiTi High-Entropy Alloy Coating, J. Mater. Eng. Perform., 2016, 25(12), p 5513-5521

71. L. Tian, J. Wang, Q. Zhang, R. Li, and C. Liu, Microstructure Characterization of AlCoCrFeNiTi High-Entropy Alloy Coating Produced by Atmospheric Plasma Spraying, Mater. Res. Express, 2019, 6(11), p 116416

72. M. Lobel, T. Lindner, T. Mehner, and T. Lampke, Microstructure and Wear Resistance of AlCoCrFeNiTi High-Entropy Alloy Coatings Produced by HVOF, Coatings, 2017, 7(9), p 144-152, 144

73. L. Chen, K. Bobzin, Z. Zhou, L. Zhao, M. Öte, T. Königstein, Z. Tan, and $\mathrm{D}$. He, Wear Behavior of HVOF-Sprayed $\mathrm{Al}_{0.6-}$ TiCrFeCoNi High Entropy Alloy Coatings at Different Temperatures, Surf. Coat. Technol., 2019, 358, p 215-222

74. L. Tian, M. Fu, and W. Xiong, Microstructural Evolution of AlCoCrFeNiSi High-Entropy Alloy Powder During Mechanical Alloying and Its Coating Performance, Materials, 2018, 11(2), p 320

75. B. Jin, N. Zhang, S. Guan, Y. Zhang, and D. Li, Microstructure and Properties of Laser Re-melting $\mathrm{FeCoCrNiAl}_{0.5} \mathrm{Si}_{x}$ HighEntropy Alloy Coatings, Surf. Coat. Technol., 2018, 349, p $867-$ 873

76. J.K. Xiao, Y.Q. Wu, J. Chen, and C. Zhang, Microstructure and Tribological Properties of Plasma Sprayed $\mathrm{FeCoNiCrSiAl}_{x}$ High Entropy Alloy Coatings, Wear, 2020, 448-449, p 203209 
77. W.L. Hsu, H. Murakami, H. Araki, M. Watanabe, S. Kuroda, A.C. Yeh, and J.W. Yeh, A Study of $\mathrm{NiCo}_{0.6} \mathrm{Fe}_{0.2} \mathrm{Cr}_{x} \mathrm{SiAlTi}_{y}$ High-Entropy Alloys for Applications as a High-Temperature Protective Coating and a Bond Coat in Thermal Barrier Coating Systems, J. Electrochem. Soc., 2018, 165(9), p C524-C531

78. S. Kuroda, J. Kawakita, M. Watanabe, and H. Katanoda, Warm Spraying-A Novel Coating Process Based on High-Velocity Impact of Solid Particles, Sci. Technol. Adv. Mater., 2008, 9(3), p 033002

79. T.C. Li, Y. Liu, B. Liu, W.M. Guo, and L.Y. Xu, Microstructure and Wear Behavior of $\mathrm{FeCoCrNiMo}{ }_{0.2}$ High Entropy Coatings Prepared by Air Plasma Spray and the High Velocity Oxy-Fuel Spray Processes, Coatings, 2017, 7(9), p 151

80. W. Wang, W. Qi, L. Xie, X. Yang, J. Li, and Y. Zhang, Microstructure and Corrosion Behavior of $(\mathrm{CoCrFeNi})_{95} \mathrm{Nb}_{5}$ High-Entropy Alloy Coating Fabricated by Plasma Spraying, Materials, 2019, 12(5), p 694

81. C. Wang, J. Yu, Y. Zhang, and Y. Yu, Phase Evolution and Solidification Cracking Sensibility in Laser Remelting Treatment of the Plasma-Sprayed CrMnFeCoNi High Entropy Alloy Coating, Mater. Des., 2019, 182, p 108040

82. J.K. Xiao, H. Tan, Y.Q. Wu, J. Chen, and C. Zhang, Microstructure and Wear Behavior of FeCoNiCrMn High Entropy Alloy Coating Deposited by Plasma Spraying, Surf. Coat. Technol., 2020, 385, p 125430

83. J. Lehtonen, H. Koivuluoto, Y. Ge, A. Juselius, and S.P. Hannula, Cold Gas Spraying of a High-Entropy CrFeNiMn Equiatomic Alloy, Coatings, 2020, 10(1), p 53

84. Y. Yu, W.M. Liu, T.B. Zhang, J.S. Li, J. Wang, H.C. Kou, and J. $\mathrm{Li}$, Microstructure and Tribological Properties of $\mathrm{AlCoCrFeNiTi}_{0.5}$ High-Entropy Alloy in Hydrogen Peroxide Solution, Metall. Mater. Trans. A, 2014, 45(1), p 201-207

85. A.K. Sharma and R. Krishnamurthy, Microwave Processing of Sprayed Alumina Composite for Enhanced Performance, J. Eur. Ceram. Soc., 2002, 22(16), p 2849-2860

86. C.S. Yip, K.A. Khor, N.L. Loh, and P. Cheang, Thermal Spraying of Ti-6Al-4V/Hydroxyapatite Composites Coatings: Powder Processing and Post-spray Treatment, J. Mater. Process. Technol., 1997, 65(1), p 73-79

87. S. Stewart, R. Ahmed, and T. Itsukaichi, Rolling Contact Fatigue of Post-treated WC-NiCrBSi Thermal Spray Coatings, Surf. Coat. Technol., 2005, 190(2), p 171-189

88. S. Katakam, S.S. Joshi, S. Mridha, S. Mukherjee, and N.B. Dahotre, Laser Assisted High Entropy Alloy Coating on Aluminum: Microstructural Evolution, J. Appl. Phys., 2014, 116(10), p 104906

89. Q. Chao, T. Guo, T. Jarvis, X. Wu, P. Hodgson, and D. Fabijanic, Direct Laser Deposition Cladding of $\mathrm{Al}_{x} \mathrm{CoCrFeNi}$ High Entropy Alloys on a High-Temperature Stainless Steel, Surf. Coat. Technol., 2017, 332, p 440-451

90. Y.K. Shon, S.S. Joshi, S. Katakam, R.S. Rajamure, and N.B. Dahotre, Laser Additive Synthesis of High Entropy Alloy Coating on Aluminum: Corrosion Behavior, Mater. Lett., 2015, 142, p 122-125

91. S. Zhang, C.L. Wu, C.H. Zhang, M. Guan, and J.Z. Tan, Laser Surface Alloying of FeCoCrAlNi High-Entropy Alloy on 304 Stainless Steel to Enhance Corrosion and Cavitation Erosion Resistance, Opt. Laser Technol., 2016, 84, p 23-31

92. X. Li, Y. Feng, B. Liu, D. Yi, X. Yang, W. Zhang, G. Chen, Y. $\mathrm{Liu}$, and P. Bai, Influence of NbC Particles on Microstructure and Mechanical Properties of AlCoCrFeNi High-Entropy Alloy Coatings Prepared by Laser Cladding, J. Alloys Compd., 2019, 788, p 485-494

93. M.H. Sha, L. Zhang, J.W. Zhang, N. Li, T.Z. Li, and N. Wang, Effects of Annealing on the Microstructure and Wear Resistance of $\mathrm{AlCoCrFeNiTi} i_{0.5}$ High-Entropy Alloy Coating Prepared by
Laser Cladding, Rare Met. Mater. Eng., 2017, 46(5), p 1237 1240

94. J.H. Zhao, A.B. Ma, X.L. Ji, J.H. Jiang, and Y.Y. Bao, Slurry Erosion Behavior of $\mathrm{Al}_{x} \mathrm{CoCrFeNiTi}{ }_{0.5}$ High-Entropy Alloy Coatings Fabricated by Laser Cladding, Metals, 2018, 8(2), p 126

95. H. Liu, J. Liu, P. Chen, and H. Yang, Microstructure and High Temperature Wear Behaviour of In Situ TiC Reinforced AlCoCrFeNi-Based High-Entropy Alloy Composite Coatings Fabricated by Laser Cladding, Opt. Laser Technol., 2019, 118 , p 140-150

96. H. Zhang, Y. Pan, and Y. He, Laser Cladding $\mathrm{FeCoNiCrAl}_{2} \mathrm{Si}$ High-Entropy Alloy Coating, Acta Metall. Sin., 2011, 47(8), p 1075-1079

97. C.L. Wu, S. Zhang, C.H. Zhang, J. Chen, and S.Y. Dong, Phase Evolution Characteristics and Corrosion Behavior of $\mathrm{FeCo}$ $\mathrm{CrAlCu}-\mathrm{X}-0.5$ Coatings on $\mathrm{cp} \mathrm{Cu}$ by Laser High-Entropy Alloying, Opt. Laser Technol., 2017, 94, p 68-71

98. H. Li, J. Li, C. Yan, X. Zhang, and D. Xiong, Microstructure and Tribological Properties of Plasma-Sprayed Al Co CrFeNi Ti-Ag Composite Coating from 25 to $750{ }^{\circ} \mathrm{C}$, J. Mater. Eng. Perform., 2020, 29, p 1640-1649

99. T.-T. Shun, L.-Y. Chang, and M.-H. Shiu, Microstructure and Mechanical Properties of Multiprincipal Component $\mathrm{CoCrFeNiMo}_{x}$ Alloys, Mater. Charact., 2012, 70, p 63-67

100. Š. Houdková, E. Smazalová, M. Vostřák, and J. Schubert, Properties of NiCrBSi Coating, as Sprayed and Remelted by Different Technologies, Surf. Coat. Technol., 2014, 253, p 14-26

101. W.H. Liu, Z.P. Lu, J.Y. He, J.H. Luan, Z.J. Wang, B. Liu, Y. Liu, M.W. Chen, and C.T. Liu, Ductile CoCrFeNiMo ${ }_{x}$ High Entropy Alloys Strengthened by Hard Intermetallic Phases, Acta Mater., 2016, 116, p 332-342

102. F. Shu, B. Yang, S. Dong, H. Zhao, B. Xu, F. Xu, B. Liu, P. He, and J. Feng, Effects of Fe-to-Co Ratio on Microstructure and Mechanical Properties of Laser Cladded FeCoCrBNiSi HighEntropy Alloy Coatings, Appl. Surf. Sci., 2018, 450, p 538-544

103. F.Y. Shu, L. Wu, H.Y. Zhao, S.H. Sui, L. Zhou, J. Zhang, W.X. $\mathrm{He}, \mathrm{P}$. He, and B.S. Xu, Microstructure and High-Temperature Wear Mechanism of Laser Cladded CoCrBFeNiSi High-Entropy Alloy Amorphous Coating, Mater. Lett., 2018, 211, p 235-238

104. Y. Cai, L. Zhu, Y. Cui, K. Geng, S. MarwanaManladan, and Z. Luo, High-Temperature Oxidation Behavior of $\mathrm{FeCoCrNiAl}_{x}$ High-Entropy Alloy Coatings, Mater. Res. Express, 2019, 6(12), p 126552

105. Y.Y. Chen, T. Duval, U.D. Hung, J.W. Yeh, and H.C. Shih, Microstructure and Electrochemical Properties of High Entropy Alloys-A Comparison with Type-304 Stainless Steel, Corros. Sci., 2005, 47(9), p 2257-2279

106. H. Zhang, Y. Pan, and Y.Z. He, Synthesis and Characterization of $\mathrm{FeCoNiCrCu}$ High-Entropy Alloy Coating by Laser Cladding, Mater. Des., 2011, 32(4), p 1910-1915

107. Y.Q. Jiang, J. Li, Y.F. Juan, Z.J. Lu, and W.L. Jia, Evolution in Microstructure and Corrosion Behavior of $\mathrm{AlCoCr}_{x} \mathrm{FeNi}$ HighEntropy Alloy Coatings Fabricated by Laser Cladding, J. Alloys Compd., 2019, 775, p 1-14

108. J. Liu, H. Liu, P. Chen, and J. Hao, Microstructural Characterization and Corrosion Behaviour of $\mathrm{AlCoCrFeNiTi}_{x}$ High-Entropy Alloy Coatings Fabricated by Laser Cladding, Surf. Coat. Technol., 2019, 361, p 63-74

109. Y. Qiu, S. Thomas, D. Fabijanic, A.J. Barlow, H.L. Fraser, and N. Birbilis, Microstructural Evolution, Electrochemical and Corrosion Properties of $\mathrm{Al}_{x} \mathrm{CoCrFeNiTi}$. High Entropy Alloys, Mater. Des., 2019, 170, p 107698

110. D.B. Miracle and O.N. Senkov, A Critical Review of High Entropy Alloys and Related Concepts, Acta Mater., 2017, 122, p 448-511 
111. A. Poulia, E. Georgatis, A. Lekatou, and A.E. Karantzalis, Microstructure and Wear Behavior of a Refractory High Entropy Alloy, Int. J. Refract. Met. Hard Mater., 2016, 57, p 50-63

112. Y.X. Guo and Q.B. Liu, MoFeCrTiWAlNb Refractory HighEntropy Alloy Coating Fabricated by Rectangular-Spot Laser Cladding, Intermetallics, 2018, 102, p 78-87

113. G. Zhu, Y. Liu, and J. Ye, Fabrication and Properties of Ti(C, N)-Based Cermets with Multi-component AlCoCrFeNi HighEntropy Alloys Binder, Mater. Lett., 2013, 113, p 80-82

114. B. Gorr, F. Mueller, H.J. Christ, H. Chen, A. Kauffmann, R. Schweiger, D.V. Szabó, and M. Heilmaier, Development of Oxidation Resistant Refractory High Entropy Alloys for High Temperature Applications: Recent Results and Development Strategy, Metals and Materials Series, 147th Annual Meeting and Exhibition of the Minerals, Metals and Materials Society, Part F12, 2018, p 648-659

115. F. Müller, B. Gorr, H.J. Christ, J. Müller, B. Butz, H. Chen, A. Kauffmann, and M. Heilmaier, On the Oxidation Mechanism of Refractory High Entropy Alloys, Corros. Sci., 2019, 159, p 108161

116. C.C. Berndt, M.F. Hasan, U. Tietz, and K.P. Schmitz, A Review of Hydroxyapatite Coatings Manufactured by Thermal Spray, Advances in Calcium Phosphate Biomaterials, Vol 2, B. BenNissan, Ed., Springer, Berlin, 2014, p 267-329

117. K. Alagarsamy, A. Fortier, M. Komarasamy, N. Kumar, A. Mohammad, S. Banerjee, H.C. Han, and R.S. Mishra, Mechanical Properties of High Entropy Alloy $\mathrm{Al}_{0.1} \mathrm{CoCrFeNi}$ for Peripheral Vascular Stent Application, Cardiovasc. Eng. Technol., 2016, 7(4), p 448-454

118. G. Popescu, B. Ghiban, C.A. Popescu, L. Rosu, R. Trusca, I. Carcea, V. Soare, D. Dumitrescu, I. Constantin, M.T. Olaru, and B.A. Carlan, New TiZrNbTaFe High Entropy Alloy Used for Medical Applications, Modtech International ConferenceModern Technologies in Industrial Engineering VI, Iop Publishing Ltd, 2018.

119. A. Vladescu, I. Titorencu, Y. Dekhtyar, V. Jinga, V. Pruna, M. Balaceanu, M. Dinu, I. Pana, V. Vendina, and M. Braic, In Vitro Biocompatibility of Si Alloyed Multi-principal Element Carbide Coatings, PLoS ONE, 2016, 11(8), p e0161151

120. P.P. Yang, Y. Liu, X.C. Zhao, J.W. Cheng, and H. Li, Electromagnetic Wave Absorption Properties of Mechanically Alloyed FeCoNiCrAl High Entropy Alloy Powders, Adv. Powder Technol., 2016, 27(4), p 1128-1133

121. Y. Zhang, B. Zhang, K. Li, G.L. Zhao, and S.M. Guo, Electromagnetic Interference Shielding Effectiveness of High Entropy AlCoCrFeNi Alloy Powder Laden Composites, $J$. Alloys Compd., 2018, 734, p 220-228

122. A. Vardelle, C. Moreau, J. Akedo, H. Ashrafizadeh, C.C. Berndt, J.O. Berghaus, M. Boulos, J. Brogan, A.C. Bourtsalas, A. Dolatabadi, M. Dorfman, T.J. Eden, P. Fauchais, G. Fisher, F. Gaertner, M. Gindrat, R. Henne, M. Hyland, E. Irissou, E.H. Jordan, K.A. Khor, A. Killinger, Y.-C. Lau, C.-J. Li, L. Li, J. Longtin, N. Markocsan, P.J. Masset, J. Matejicek, G. Mauer, A. McDonald, J. Mostaghimi, S. Sampath, G. Schiller, K. Shinoda, M.F. Smith, A.A. Syed, N.J. Themelis, F.-L. Toma, J.P. Trelles, R. Vassen, and P. Vuoristo, The 2016 Thermal Spray Roadmap, J. Therm. Spray Technol., 2016, 25(8), p 1376-1440

123. C.C. Berndt, We Never Have Enough Energy, Adv. Mater. Process., 2017, 175(4), p 38-41

124. A.S.M. Ang, Finding the 'Magic Pudding' in the Thermal Spray Industry, Adv. Mater. Process., 2018, 176(8), p 36

125. C. Oses, C. Toher, and S. Curtarolo, High-Entropy Ceramics, Nat. Rev. Mater., 2020, 5, p 295-309

126. O.N. Senkov, G.B. Wilks, D.B. Miracle, C.P. Chuang, and P.K. Liaw, Refractory High-Entropy Alloys, Intermetallics, 2010, 18(9), p 1758-1765
127. O.N. Senkov, G.B. Wilks, J.M. Scott, and D.B. Miracle, Mechanical Properties of $\mathrm{Nb}_{25} \mathrm{Mo}_{25} \mathrm{Ta}_{25} \mathrm{~W}_{25}$ and $\mathrm{V}_{20} \mathrm{Nb}_{20}$ $\mathrm{Mo}_{20} \mathrm{Ta}_{20} \mathrm{~W}_{20}$ Refractory High Entropy Alloys, Intermetallics, 2011, 19(5), p 698-706

128. N. Li, S. Wu, D. Ouyang, J. Zhang, and L. Liu, Fe-Based Metallic Glass Reinforced FeCoCrNiMn High Entropy Alloy Through Selective Laser Melting, J. Alloys Compd., 2020, 822, p 153695

129. F. Wang, A. Inoue, F.L. Kong, C.C. Zhao, J.Y. Zhang, S.L. Zhu, W.J. Botta, C.S. Kiminami, Y.P. Ivanov, and A.L. Greer, Formation, Thermal Stability and Mechanical Properties of HighEntropy $\quad\left(\mathrm{Fe}_{0.25} \mathrm{Co}_{0.25} \mathrm{Ni}_{0.25} \mathrm{Cr}_{0.125} \mathrm{Mo}_{0.0625} \mathrm{Nb}_{0.0625}\right) 100-\mathrm{xB}_{x}$ $(x=7-14)$ Amorphous Alloys, J. Alloys Compd., 2020, 825, p 153858

130. R. de Oro Calderon, C. Edtmaier, and W.D. Schubert, Novel Binders for WC-Based Cemented Carbides with High Cr Contents, Int. J. Refract. Met. Hard Mater., 2019, 85, p 105063

131. C.-W. Li, K.-C. Chang, and A.-C. Yeh, On the Microstructure and Properties of an Advanced Cemented Carbide System Processed by Selective Laser Melting, J. Alloys Compd., 2019, 782, p 440-450

132. X. Li, D. Wei, L. Vitos, and R. Lizárraga, Micro-mechanical Properties of New Alternative Binders for Cemented Carbides: $\mathrm{CoCrFeNiW}_{x}$ High-Entropy Alloys, J. Alloys Compd., 2020, 820, p 153141

133. Y. Peng, W. Zhang, T. Li, M. Zhang, B. Liu, Y. Liu, L. Wang, and $\mathrm{S}$. Hu, Effect of WC Content on Microstructures and Mechanical Properties of FeCoCrNi High-Entropy Alloy/WC Composite Coatings by Plasma Cladding, Surf. Coat. Technol., 2020, 385, p 125326

134. J. Karthikeyan, C.C. Berndt, J. Tikkanen, S. Reddy, and H. Herman, Plasma Spray Synthesis of Nanomaterial Powders and Deposits, Mater. Sci. Eng. A, 1997, 238(2), p 275-286

135. J. Karthikeyan, C.C. Berndt, J. Tikkanen, J.Y. Wang, A.H. King, and H. Herman, Nanomaterial Powders and Deposits Prepared by Flame Spray Processing of Liquid Precursors, Nanostruct. Mater., 1997, 8(1), p 61-74

136. G. Darut, A. Niederhauser, B. Jaccoud, M. Sigrist, E. Mock, M.P. Planche, H. Liao, and G. Montavon, VLPPS: An Emerging Process to Create Well-Defined Components by Additive Manufacturing, J. Therm. Spray Technol., 2019, 28(1-2), p 255264

137. P. Fauchais, G. Montavon, and G. Bertrand, From Powders to Thermally Sprayed Coatings, J. Therm. Spray Technol., 2010, 19(1), p 56-80

138. G. Montavon, S. Sampath, C.C. Berndt, H. Herman, and C. Coddet, Effects of Vacuum Plasma Spray Processing Parameters on Splat Morphology, J. Therm. Spray Technol., 1995, 4(1), p $67-74$

139. Y.P. Wan, J.R. Fincke, S. Sampath, V. Prasad, and H. Herman, Modeling and Experimental Observation of Evaporation From Oxidizing Molybdenum Particles Entrained in a Thermal Plasma Jet, Int. J. Heat Mass Transf., 2002, 45(5), p 1007-1015

140. ASTM E1920-03, Standard Guide for Metallographic Preparation of Thermal Sprayed Coatings, ASTM International, West Conshohocken, 2014

141. R.A. Miller, Thermal Barrier Coatings for Aircraft Engines: History and Directions, J. Therm. Spray Technol., 1997, 6(1), p 35

142. R.A. Miller and M.A. Kuczmarski, Burner Rig for Small Particle Erosion Testing of Thermal Barrier Coatings, J. Test Eval., 2013, 42(3), p 648-658

143. A.J. Slifka, B.J. Filla, J.M. Phelps, G. Bancke, and C.C. Berndt, Thermal Conductivity of a Zirconia Thermal Barrier Coating, $J$. Therm. Spray Technol., 1998, 7(1), p 43-46 
144. A.S.M. Ang, N. Sanpo, M.L. Sesso, S.Y. Kim, and C.C. Berndt, Thermal Spray Maps: Material Genomics of Processing Technologies, J. Therm. Spray Technol., 2013, 22(7), p 1170-1183

145. H. Singh, A. Ang, S. Matthews, H. de Villiers-Lovelock, and B.S. Sidhu, Editorial: Thermal Spray for Extreme Environments, J. Therm. Spray Technol., 2019, 28(7), p 1339-1345

146. H.X. Guo, C.Y. He, X.L. Qiu, Y.Q. Shen, G. Liu, and X.H. Gao, A Novel Multilayer High Temperature Colored Solar Absorber Coating Based on High-Entropy Alloy MoNbHfZrTi: Optimized Preparation and Chromaticity Investigation, Sol. Energy Mater. Sol. Cells, 2020, 209, p 110444

147. S.R. Somers, Surface Engineering of Annealed High Entropy Alloys Towards Thermodynamically Stable, Anti-oxidation,
Solar Selective Absorbers, ENGS 88 Honors Thesis (AB Students).1., Thayer School of Engineering at Dartmouth, 2019

148. What are technology readiness levels (TRL)?, TWI Ltd, https:// www.twi-global.com/technical-knowledge/faqs/technologyreadiness-levels, 2020. Accessed 7 Apr 2020.

149. A. McDonald, F. Azarmi, K. Balani, J. Cizek, H. Koivuluoto, Y.-C. Lau, H. Li, and F.-L. Toma, Editorial: Special Issue Featuring Papers from the International Thermal Spray Conference (ITSC) 2019, J. Therm. Spray Technol., 2020, 29(1), p $1-2$

Publisher's Note Springer Nature remains neutral with regard to jurisdictional claims in published maps and institutional affiliations. 